\title{
Using Q-methodology to explore what is valued from child sexual exploitation services: The importance of safety.
}

\author{
Jennifer Barrow
}

Thesis submitted in partial fulfilment of the requirements of Staffordshire University for the degree of Professional Doctorate in Clinical Psychology

April 2020

Total word count: 16,625 
THESIS PORTFOLIO: CANDIDATE DECLARATION

\begin{tabular}{|l|l|}
\hline Title of degree programme & Professional Doctorate in Clinical Psychology \\
\hline Candidate name & Jennifer Barrow \\
\hline Registration number & 17024106 \\
\hline Initial date of registration & $18^{\text {th }}$ September 2017 \\
\hline
\end{tabular}

\section{Declaration and signature of candidate}

I confirm that the thesis submitted is the outcome of work that I have undertaken during my programme of study, and except where explicitly stated, it is all my own work.

I confirm that the decision to submit this thesis is my own.

I confirm that except where explicitly stated, the work has not been submitted for another academic award.

I confirm that the work has been conducted ethically and that I have maintained the anonymity of research participants at all times within the thesis.

Signed:

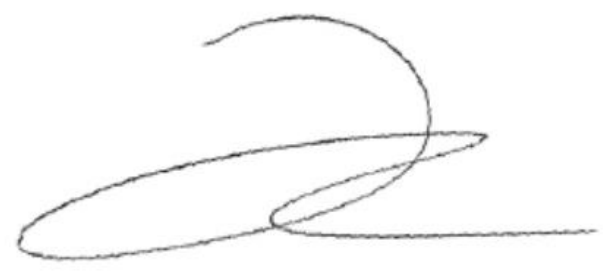

Date: 30/04/2020 


\section{Acknowledgements}

Firstly, thank you to all of the young people and staff members who gave up their time to take part in this research. I'd also like to give a huge thank you to the experts by experience that have supported me with this project. I have learned so much from all of you, your help and generosity has been invaluable to me.

I will forever be grateful to my supervisors Dr. Helen Combes and Dr. Lucy Rathbone, our 2017 cohort, my Mum and to all of my friends and family. Your unwavering compassion has been so precious to me throughout this process. I am especially thankful to my friends Laura, Sarah and Steph for the laughs, the kindness and our brunch club, and to my part-time housemate Sophie, I will miss you!

To my partner Ben, thank you for your endless patience and support.

My thesis is dedicated to the people who sadly didn't get to see me achieve this but were there right from the beginning; my grandparents and my Dad. It would all have been impossible without you. 


\section{Preface}

The literature review has been prepared in a format for submission to Child Abuse \& Neglect: The International Journal. The empirical paper has been prepared in a format for submission to The Journal of Child Sexual Abuse. Both journals require the use of an APA referencing style and the $7^{\text {th }}$ edition of the APA publication manual has been used. The guidelines for journal submission can be found in the appendices of each paper.

The terms 'child' and 'young person' are used interchangeably throughout this project to represent an individual under the age of 18.

The executive summary has been prepared in a format that is accessible to the target audience; young people aged 13 and above, and the professionals they work with. This was reviewed for readability by a young person who was involved in service development with one of the project research sites.

Chapter 1: Literature Review: 6210 words (including abstract)

Chapter 2: Empirical Paper: 7997 words (including abstract)

Chapter 3: Executive Summary: 1231 words

Thesis abstract: 304 words

Total word count: 16625 words 


\section{Contents}

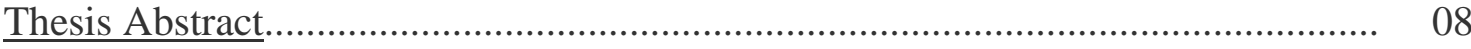

Chapter 1: Literature Review - 'What is known about the psychological and 09 trauma-based impact of being sexually exploited in childhood? A literature review'

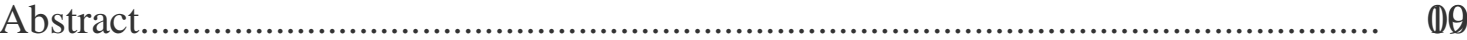

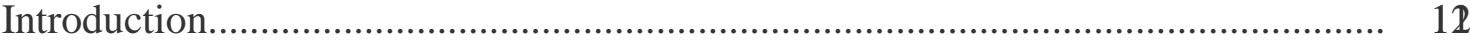

The Evolving Definition of CSE.................................................... 12

Prevalence of CSE.................................................................... 13

The Impact of CSA.............................................................. 19

Aim and Rationale of the Literature Review.................................................... 15

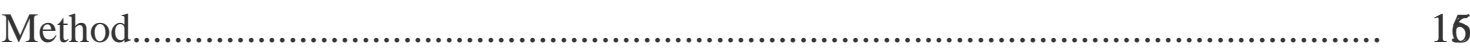

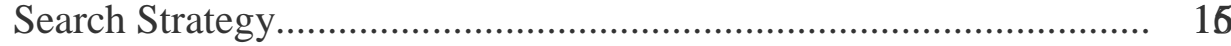

Quality Assessment.................................................................. 18

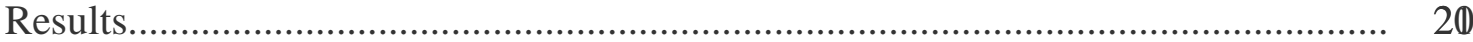

Summary of Findings.................................................................. 20

Research Quality...................................................................... $3 \mathbb{P}$

Synthesis of Findings.............................................................. 38

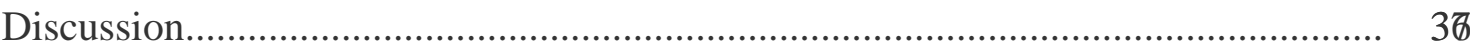

Theoretical Considerations............................................................ $3 \not \varnothing$

Clinical Implications................................................................. 38

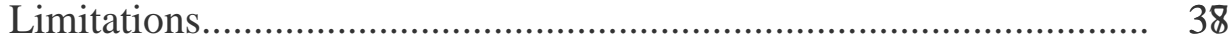

Future Research....................................................................... 38

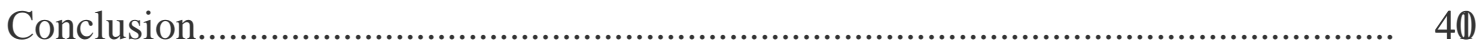

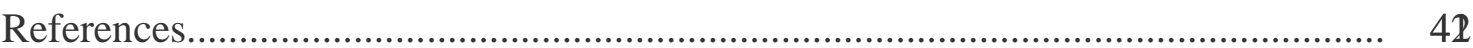

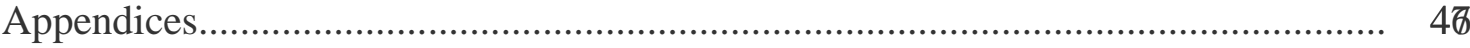

Table 1: Inclusion Criteria................................................................................. $1 \varnothing$

Table 2: Exclusion Criteria...................................................................................... 18

Table 3: Details of Included Studies..................................................................... $2 \mathbb{1}$

Figure 1: Search Strategy Flowchart.............................................................. 2 
Chapter 2: Empirical Paper - 'Using Q-methodology to explore what is valued

from child sexual exploitation services: The importance of safety'....

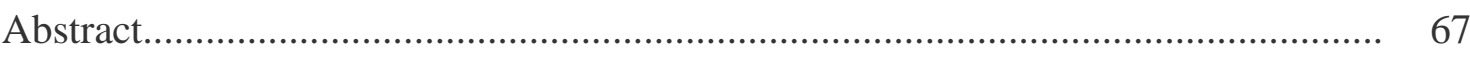

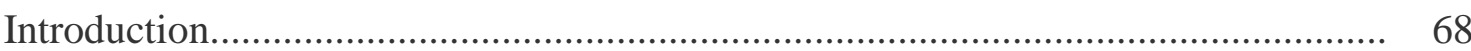

Defining Child Sexual Abuse and Child Sexual Exploitation........... 68

Support for Survivors of CSE......................................................... 69

Service Development................................................................. 71

A Role for Clinical Psychology.................................................... 72

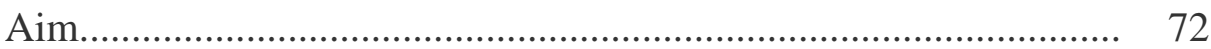

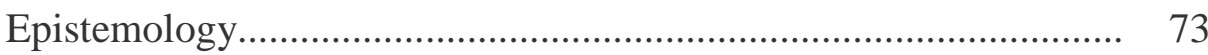

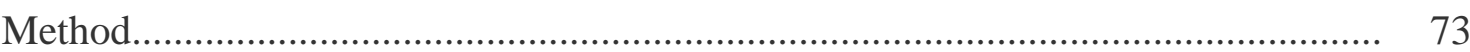

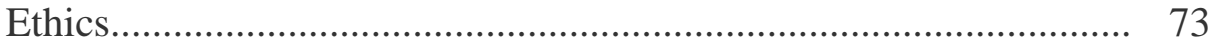

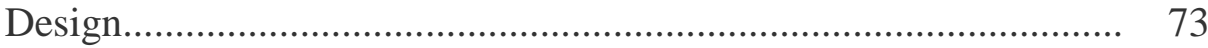

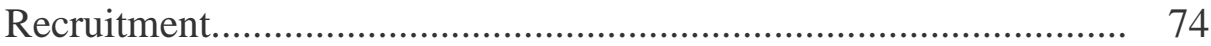

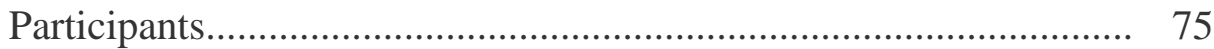

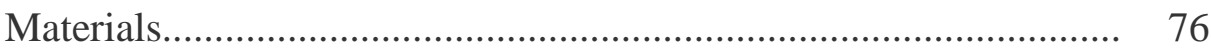

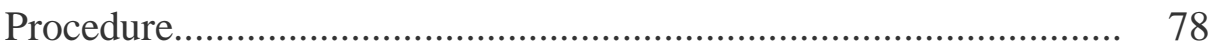

Method of Analysis...................................................................... 78

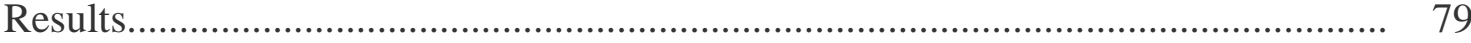

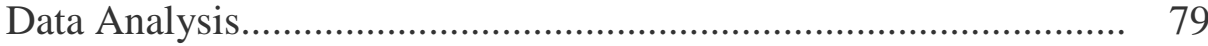

Factor Interpretation.............................................................. 83

Factor 1: The importance of safety and attunement.......... 83

Factor 2: Managing trauma and mental health difficulties 84

Factor 3: Family, normality and a relaxed approach......... 85

Comparison of Factors.............................................................. 86

Non-significant Q-sorts............................................................ 87

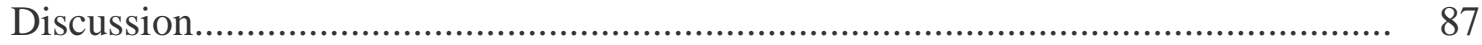

Theoretical Considerations......................................................... 87

Clinical Implications................................................................... 90

Limitations....................................................................... 91

Future Research............................................................ 93

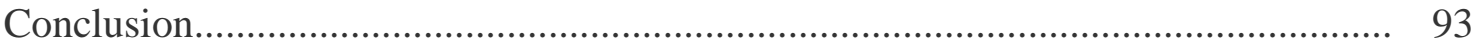

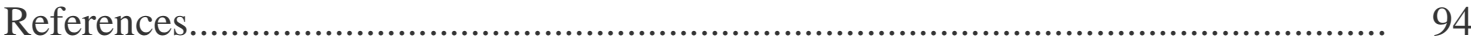


Appendices

100

Table 1: Sample Characteristics - Young People................................................. 75

Table 2: Sample Characteristics - Professionals................................................ 76

Table 3: Correlation Matrix........................................................................... 80

Table 4: Seven Factor Model............................................................................... 81

Table 5: Extracted Factor Loadings.................................................................. 82

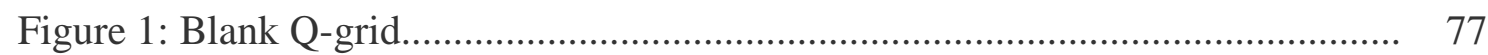

Chapter 3: Executive Summary - 'What do young people and staff members value 128 from child sexual exploitation services?' 


\section{Thesis Abstract}

This thesis was written to fulfil the requirements of the University's Doctorate in Clinical Psychology. The thesis consists of three chapters: a review of the research literature focused on the psychological and trauma-based impact of Child Sexual Exploitation (CSE), an empirical paper exploring young people and staff members' viewpoints on CSE services and interventions, and an executive summary of the empirical paper which has been designed for dissemination to young people and staff members in CSE services.

The literature review identified four important themes across the research: (1) Overall mental health difficulties, (2) Self-harm and suicide, (3) Are difficulties a precursor or consequence of CSE? (4) Strengths and resilience. The review concluded that children involved in CSE are likely to be experiencing significant mental health difficulties. It was suggested that future research could consider exploring young people's views on effective CSE interventions.

The empirical paper used Q-methodology to explore the subjective viewpoints of young people and staff members working with CSE services, regarding what is valued most from services and interventions. A total of 18 participants (nine young people and nine staff members) completed Q-sorts in which they were asked to rank 54 statements relating to different aspects of services. Three significant factors emerged: (1) The importance of safety and attunement, (2) Managing trauma and mental health difficulties, (3) Family, normality, and a relaxed approach. All three factors emphasised the importance of safety and trusting relationships between young people and professionals. These three factors identified key areas that service design would find useful to consider. It was recommended that young people are likely to benefit from specialist support from services which promote a relational approach to effectively meet the psychological needs of their service users.

The executive summary provides an overview of the findings of the empirical paper in an accessible format. 
Chapter One: Literature Review

'What is known about the psychological and trauma-based impact of being sexually exploited in childhood? A literature review'

Jennifer Barrow

Professional Doctorate in Clinical Psychology

School of Life Sciences and Education, Staffordshire University

Word Count: 6210 


\begin{abstract}
Background

Child sexual exploitation (CSE) has become prominent recently. The longer-term mental health needs of affected children requires further research in the UK, and globally, to establish the most helpful approaches to support children's recovery.

\section{Objective}

This review will explore the psychological impact of sexual exploitation on children and their experience of trauma.

\title{
$\underline{\text { Method }}$
}

The systematic search strategy yielded eight studies within the inclusion criteria, with a further four studies added following a hand-search of included articles. The studies were critically appraised using the Strengthening the Reporting of Observational Studies in Epidemiology (STROBE) - Cross-sectional and casecontrol checklists, (von Elm et al., 2008) and the Critical Appraisal Skills Programme (CASP) Qualitative Checklist (CASP, 2018).

\section{$\underline{\text { Results }}$}

The 12 studies included were geographically diverse. Nine employed an observational quantitative approach and three used qualitative methodology. Similar findings across the included studies demonstrated that children who have experienced sexual exploitation are likely to have additional experiences of trauma, related psychological difficulties, and experience suicidal ideation and engage in self-harm, but despite these experiences also display significant strengths and resilience.

\section{Conclusions}

The findings from the studies confirm that CSE survivors are likely to have similar, if not more complex, psychological difficulties to those who have experienced CSA. Clinically, this suggests that CSE services and professionals should be aware of and able to work with trauma and complex difficulties. The importance of working with 
children to explore their views on effective interventions, in order to address the psychological needs highlighted, is a suggestion for future research.

Keywords: Child sexual exploitation, child sexual abuse, mental health, psychology, trauma 


\section{Introduction}

Child sexual exploitation (CSE) has become prominent recently due to the increase in domestic and international child trafficking, technological advances and rising professional and public awareness (Frost, 2019). In May 2014, an independent inquiry by Alexis Jay was commissioned by Rotherham Metropolitan Borough Council into the prevalence of CSE in Rotherham from 1997 to 2013. The inquiry highlighted the "collective failures" of the local authority and the local Police force (Jay, 2014, p.1). This included reportedly treating survivors of CSE with contempt and downplaying the severity of the problem by not initiating the appropriate safeguarding procedures. Since the publication of the Jay report, the criminal justice and health and social care systems in the UK have become more adept at intervening to address immediate risks to children from CSE (Harris et al., 2017). However, the longer-term mental health needs of affected children require further research in order to establish the most helpful approaches to support children's recovery. Internationally, understanding the impact of CSE on the welfare of children is becoming increasingly important and acknowledged as an area that has significant public health implications (Pearce, 2017).

\section{The Evolving Definition of CSE}

It is widely recognised that the exploitation of children has existed for several centuries and was previously referred to as 'child prostitution' in the UK until 2005, when it was reframed by the English and Welsh governments as CSE (Frost, 2019). The Sexual Offences Act (2003) referred to 'child prostitution' as an offence until this was amended in 2015 to 'the sexual exploitation of children'. The connotations of the term 'child prostitution' is believed to have influenced attitudes of service providers and professionals, with services arguably being blaming and critical of the children's behaviour. It has also been argued that referring to children as prostitutes implies an element of choice (Eaton, 2019). Reframing the children as victims of exploitation allowed for a move towards a more child-focused and compassionate view. This led to a focus on child-protection rather than responding from a criminaljustice perspective (Beckett \& Pearce, 2018).

CSE is currently defined in the UK as being a form of sexual abuse that has a differentiating element of an exchange between the child and the perpetrator(s): 
Child sexual exploitation is a form of child sexual abuse. It occurs where an individual or group takes advantage of an imbalance of power to coerce, manipulate or deceive a child or young person under the age of 18 into sexual activity (a) in exchange for something the victim needs or wants and/or (b) for the financial advantage or increased status of the perpetrator or facilitator. The victim may have been sexually exploited even if the sexual activity appears consensual. (Department for Education, 2017, p.5).

Eaton (2019) posits that there is a marked difference between how CSE is defined compared to the UK government's definition of Child Sexual Abuse (CSA) (HM Government, 2018), which is described as:

(CSA) involves forcing or enticing a child or young person to take part in sexual activities, not necessarily involving a high level of violence, whether or not the child is aware of what is happening. The activities may involve physical contact, including assault by penetration (for example, rape or oral sex) or non-penetrative acts such as masturbation, kissing, rubbing and touching outside of clothing. They may also include non-contact activities, such as involving children in looking at, or in the production of, sexual images, watching sexual activities, encouraging children to behave in sexually inappropriate ways, or grooming a child in preparation for abuse (including via the internet). (p.103)

The lack of reference to the harm or trauma experienced by the child within the definition of CSE suggests that it is not fully representative of their experience as a victim and survivor of abuse (Eaton, 2019).

In the United States of America (USA), the Commercial Sexual Exploitation of Children (CSEC) is often used interchangeably with the terms 'Child Sex Trafficking' and 'Domestic Minor Sex Trafficking' (Barnert et al., 2017). The United Nations defines the act of trafficking as:

The recruitment, transportation, transfer, harboring or receipt of persons, by means of the threat or use of force or other forms of coercion (...) or of the giving or receiving of payments or benefits to achieve the consent of a person having control over another person for the purpose of exploitation. (United Nations, 2000, Article 3, paragraph a).

Trafficking can occur both internationally and domestically, and does not require the physical relocation of a person. It may also relate to the transfer of a person to a 
different perpetrator for the purpose of exploitation (International Labour Organisation, 2009).

In 2015, a comparison of international definitions of CSE was commissioned by the UK's Department for Education. The review concluded that although there are slightly different definitions globally, there is a shared understanding that CSE involves an adult abusing their power in order to sexually exploit a child (Cameron et al., 2015).

CSE is described by the Department for Education (2017) as a complex type of sexual abuse, the risk indicators of which are often misinterpreted as typical teenage behaviours, which can lead to difficulties in identifying and working with the children affected. Although child sexual abuse typically occurs within the home environment, sexual exploitation tends to occur externally to the child's family, within their local community. Children can be sexually exploited in a variety of ways, through sexual activities that are physical or without physical contact, which can occur in person, on the phone or internet, or through a combination of both (Department for Education, 2017).

The children's charity Barnardo's has compiled several comprehensive documents regarding CSE. Their writings suggest that there are a range of 'models' which include different types of scenarios that children may experience when being sexually exploited (Barnardo's, 2017). An example of this is the 'boyfriend' model, whereby children are groomed by a perpetrator who behaves as though they are the child's boyfriend. Another example is the 'party' model, where children are enticed to a party which is actually a place where other perpetrators will be waiting to exploit them. Barnardo's suggest that the models can be used as a framework to guide the assessment of CSE, however they stress that each child's experience is diverse and may involve a complex array of models.

\section{Prevalence of CSE}

Detecting CSE can be impeded by the grooming methods employed by perpetrators, which can mean that children are not always able to recognise that they are being abused. In 2005, the International Labour Organisation (ILO) estimated that there were two and a half million people being trafficked at any one time, with $43 \%$ being 
for the purpose of sexual exploitation, and that up to half of all trafficked persons are children (ILO, 2005).

The prevalence of CSE is currently unclear in the UK; however professionals are advised that they should work from the assumption that CSE is occurring in all areas of the UK and can affect all children (Department for Education, 2017). It is difficult to ascertain the prevalence of CSE globally, with different estimates varying significantly between countries depending on their approach to quantification.

It is currently recommended within the 2017 guidance from the UK's Department for Education that children between the ages of 12-15 are most at risk of CSE although children outside of this age range should not be overlooked. Furthermore, although young girls are more likely to be subjected to CSE, boys are also at risk but may be less likely to disclose their experiences.

\section{The Impact of CSA}

Compared with the research on CSA, the evidence base on CSE is in its infancy. After several highly publicised criminal cases within the last ten years in the UK, the level of public and professional awareness of CSE has escalated. There is an increased awareness of both the factors that may increase a child's vulnerability to CSE and the related warning signs (Beckett \& Pearce, 2018). However, there are still significant gaps in understanding how to provide psychological support to children who have experienced sexual exploitation. It is important to consider how the psychological impact of CSE and the additional transactional element that it involves may differ from or share similarities with CSA, in order to improve and consolidate psychologically informed approaches to intervention.

In 1985, Finkelhor and Browne devised the traumagenic model as a framework for understanding how CSA affects children. This traumagenic model presents the core elements of the psychological impact of CSA as: betrayal, powerlessness, stigmatisation and traumatic sexualisation (Finkelhor \& Browne, 1985). A review of the research on the impact of CSA was conducted by Tyler in 2002, concluding that the short-term effects of CSA included suicidal behaviour and ideation, posttraumatic stress disorder (PTSD) and behavioural difficulties. 


\section{Aim and Rationale of the Literature Review}

The existing evidence base regarding CSE is limited in comparison with that on CSA, and as yet there has been no systematic search or collation of the research in relation to the psychological impact of CSE. This review aims to explore, appraise and synthesise the literature to ascertain the shared themes that emerge in order to better understand the experiences of sexually exploited children and the areas required for future research.

The search strategy will be explained, including the terms and the inclusion and exclusion criteria. The papers that resulted from the literature search will be critically appraised and common themes will be discussed in relation to their meaning from a clinical perspective.

\section{Method}

A systematic strategy was employed for this literature review. Following some preliminary scoping searches, it was clear that there were no existing reviews focusing directly on the psychological experiences of children who have experienced sexual exploitation. The initial search question was: "What is known about the psychological and trauma-based impact of being sexually exploited in childhood?"

\section{$\underline{\text { Search Strategy }}$}

A Boolean String formula that would encapsulate the main concepts of the question was designed, with exclusion terms to rule out irrelevant papers. The search string used was the result of an initial search of the literature in order to best represent the relevant terms most frequently used:

- "child sexual exploitation" OR "child sex trafficking" OR "child prostitut*" OR (“child sex* abuse" AND exploit*)

\section{AND}

- trauma* OR psych* $^{*}$

The electronic databases searched included: 
- CINAHL (The Cumulative Index to Nursing and Allied Health Literature)

- PsycARTICLES

- PsycINFO

- Science Direct

- Scopus

In order to counteract possible publication bias, grey literature searches were also conducted across Staffordshire University Online Academic Repository (Store), Ethos Online Theses and Google Scholar. No relevant publications were found within the grey literature. Searches were limited to English-language, with no time or location based limiters; all articles were searched within their full-text.

From 1981 (the earliest publication across the databases) to $30^{\text {th }}$ May 2019, this yielded 1056 results, with 954 articles screened by title and abstract after removing 102 duplicates. This left 140 articles that were assessed for eligibility by reading the full text, using the inclusion and exclusion criteria outlined in Tables 1 and 2.

\section{Table 1}

Inclusion criteria for article eligibility

The paper is published in a peer-reviewed journal.

The paper is in the English language.

The paper is focused on CSE and not CSA, with differentiations made between participants if focused on both.

The paper is related to the psychological impact or trauma experienced during or after CSE.

The participants' experiences of sexual exploitation occurred when they were children or adolescents. 


\section{Table 2}

Exclusion criteria for article eligibility

The paper is a letter, summary or opinion piece.

The paper focuses on adult experiences of sexual exploitation.

The paper focuses on other types of trafficking, such as for labour.

The paper is solely related to the physical health impacts of CSE.

It is unclear whether participants were children when experiencing sexual exploitation.

It is unclear whether participants had experienced CSE or CSA.

The paper is focused only on the prevalence of CSE.

The paper is focused only on vulnerability or risk factors for CSE.

The paper is focused only on services or interventions for CSE with no mention of psychological, mental health or trauma aspects.

After evaluating the full texts against the criteria, eight papers were found to be appropriate. The reference lists of the included articles were then searched to find other papers that were relevant, yielding a further four papers. In total 12 papers were included in the literature review. The literature search process is detailed in Figure 1. 


\section{Quality Assessment}

The 12 included papers were critically appraised and then quality assessed using different tools depending on their methodology:

1. Observational quantitative papers - Strengthening the Reporting of Observational Studies in Epidemiology (STROBE) - Cross-sectional and case-control checklists (von Elm et al., 2008).

2. Qualitative papers - the Critical Appraisal Skills Programme (CASP) Qualitative Checklist (CASP, 2018).

These particular tools were chosen as they are well-established methods of conducting critical reviews in an efficient and thorough manner (Nadelson \& Nadelson, 2014; von Elm et al., 2008). An overall percentage was generated for each study to indicate quality. An example of appraising studies with the STROBE and the CASP can be found in Appendices B and C, respectively.

It is acknowledged that the use of different tools does not allow for direct comparison of the quality scores. However, indirectly comparing studies using the percentages of the score on the relevant tool has been deemed sufficient based on the assumption that concepts across the different methodologies can be translated (Lincoln \& Guba, 1985). This also allowed the use of already established appraisal tools. 
Figure 1.

Flowchart Detailing the Literature Search Process

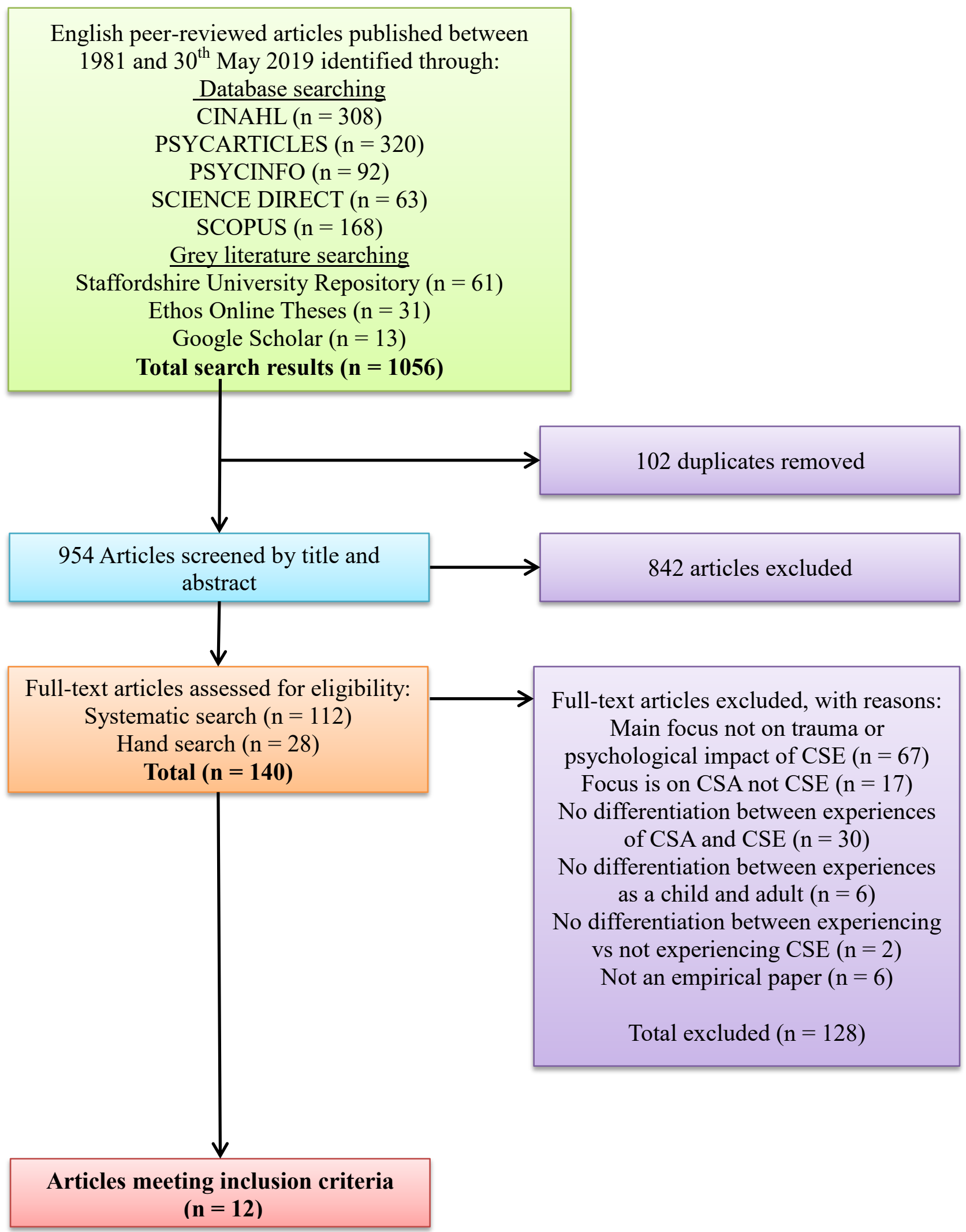




\section{Results}

Of the 12 papers that were critically appraised for the purposes of the literature review, nine were quantitative (five cross-sectional and four comparing two groups) and three were qualitative (using ethnographic and narrative approaches). Eight of the studies in this review recruited from the United States of America (USA), two from Sweden, one from Ethiopia, and one from Nepal. It is therefore hard to discern the overall generalisability of the findings due to the variety of different cultural attitudes, beliefs and responses regarding CSE. There were no British studies on this particular topic.

\section{Summary of Findings}

A summary of each study, including design and findings, is highlighted in Table 3. The data extraction table also includes each study's strengths and limitations, alongside the quality assessment percentage score. 


\section{Table 3}

Data Extracted From the 12 Studies Included In the Review

\begin{tabular}{|c|c|c|c|c|c|c|c|}
\hline $\begin{array}{l}\text { Author and } \\
\text { Year }\end{array}$ & Title & $\begin{array}{l}\text { Aims and } \\
\text { Location }\end{array}$ & $\begin{array}{l}\text { Method and } \\
\text { Participants (N) }\end{array}$ & Summary of Results & Key strengths & Key limitations & $\begin{array}{l}\text { Quality score } \\
\text { (as } \\
\text { percentage) }\end{array}$ \\
\hline $\begin{array}{l}\text { Basson, } \\
\text { Rosenblatt \& } \\
\text { Haley (2012) }\end{array}$ & $\begin{array}{l}\text { Research To Action: } \\
\text { Sexually Exploited } \\
\text { Minors (SEM) } \\
\text { Needs And } \\
\text { Strengths }\end{array}$ & $\begin{array}{l}\text { To build a wider } \\
\text { body of } \\
\text { knowledge about } \\
\text { SEM. Illustrate } \\
\text { how } \\
\text { characteristics } \\
\text { are responses to } \\
\text { trauma. Provide a } \\
\text { fuller description } \\
\text { of their mental } \\
\text { health needs. } \\
\text { USA }\end{array}$ & $\begin{array}{l}\text { Observational - } \\
\text { cross sectional and } \\
\text { descriptive. } \\
\text { Using CANS-CSE } \\
\text { assessment tool } \\
\text { (Lyons et al 2013) } \\
\mathrm{N}=113 \text {. } \\
\text { Aged 10-24. }\end{array}$ & $\begin{array}{l}75 \% \text { had already } \\
\text { experienced child abuse } \\
\text { or neglect before CSE. } \\
\text { Prevalence of mental } \\
\text { health needs: Depression } \\
76 \% \text {, Anxiety 55\%, } \\
\text { attachment disorder, } \\
51 \% \text { oppositional } \\
\text { behaviour } 46 \% \text { mood } \\
\text { regulation } 43 \% \text {, } \\
\text { somatization } 8 \% \text {, } \\
\text { psychosis } 4 \% \text {, and } \\
\text { eating difficulties } 2 \% \text {. } \\
\text { Less than half } \\
\text { recognised that their } \\
\text { exploiter was not acting } \\
\text { in their best interest. } \\
24 \% \text { reported trauma } \\
\text { bonding. Strengths - } \\
\text { creativity } 66 \% \text {, self- } \\
\text { expression } 64 \% \text {, } \\
\text { resiliency } 42 \%\end{array}$ & $\begin{array}{l}\text { Gained informed } \\
\text { consent. } \\
\text { Also looked at } \\
\text { children's strengths. }\end{array}$ & $\begin{array}{l}\text { No clear } \\
\text { explanation of } \\
\text { data collection } \\
\text { process and } \\
\text { scoring of all } \\
\text { measures. } \\
\text { Do not report how } \\
\text { they reached } \\
\text { sample size. } \\
\text { Discussion section } \\
\text { is unclear and } \\
\text { does not report } \\
\text { any limitations or } \\
\text { comment on } \\
\text { external validity. }\end{array}$ & $68 \%$ \\
\hline $\begin{array}{l}\text { Cecchet \& } \\
\text { Thoburn } \\
(2014)\end{array}$ & $\begin{array}{l}\text { The Psychological } \\
\text { Experience Of Child } \\
\text { And Adolescent Sex }\end{array}$ & $\begin{array}{l}\text { To better } \\
\text { understand } \\
\text { factors }\end{array}$ & $\begin{array}{l}\text { Qualitative - } \\
\text { narrative } \\
\text { methodology. }\end{array}$ & $\begin{array}{l}27 \text { themes were } \\
\text { synthesised into } 11 \\
\text { categories: child abuse, }\end{array}$ & $\begin{array}{l}\text { Narrative approach } \\
\text { allowed survivors to } \\
\text { tell their own story. }\end{array}$ & $\begin{array}{l}\text { Participants self- } \\
\text { selected to take } \\
\text { part which may }\end{array}$ & $80 \%$ \\
\hline
\end{tabular}




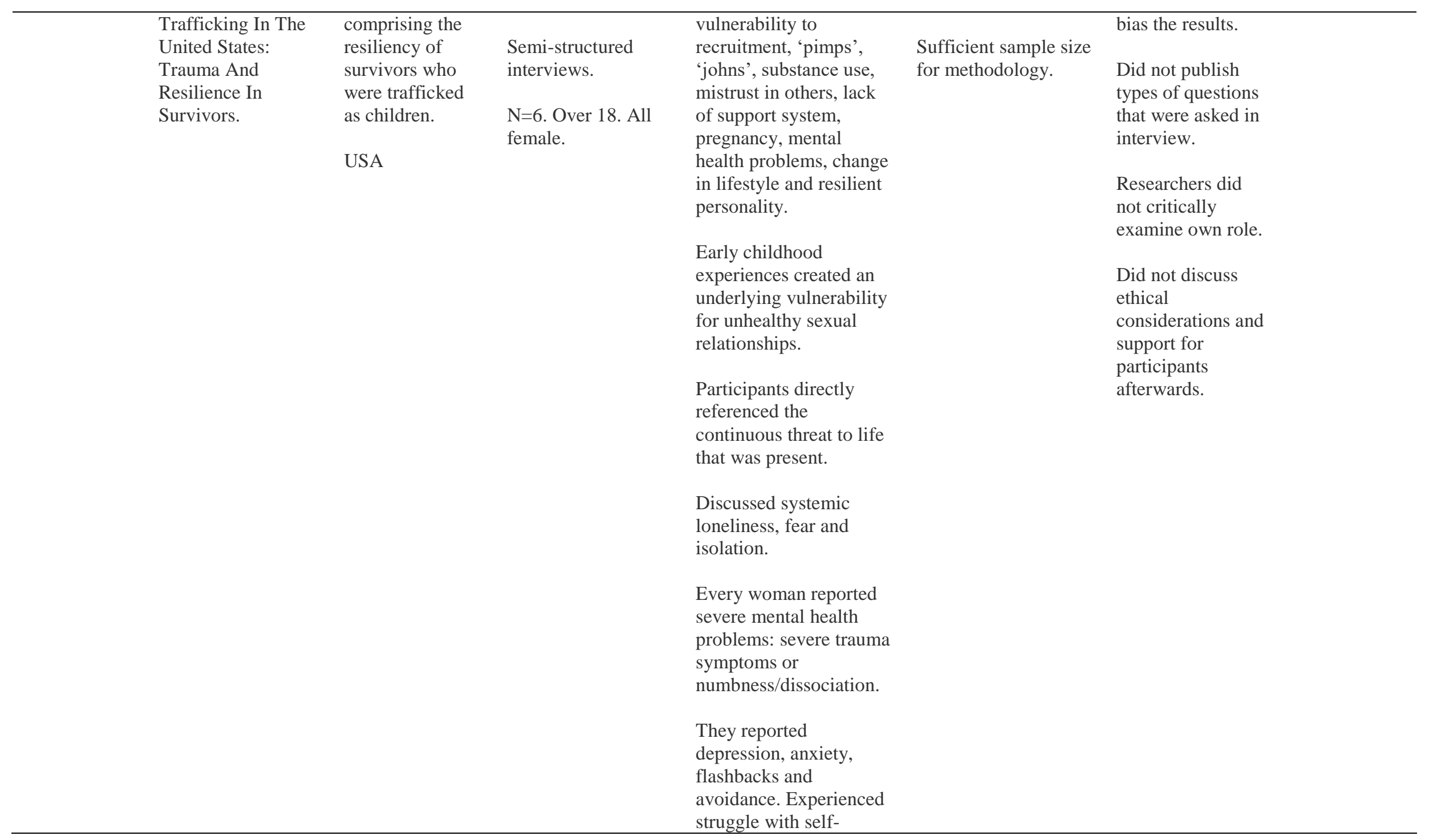


forgiveness.

Five out of six women

now participate in their

communities and are

\begin{tabular}{|c|c|c|c|c|c|c|}
\hline $\begin{array}{l}\text { Cole, Sprang, } \\
\text { Lee \& Cohen } \\
(2014)\end{array}$ & $\begin{array}{l}\text { To explore } \\
\text { whether youths } \\
\text { who have been } \\
\text { sexually } \\
\text { exploited will be } \\
\text { more likely to be } \\
\text { involved in the } \\
\text { criminal justice } \\
\text { system, more } \\
\text { likely to have } \\
\text { functional } \\
\text { impairments and } \\
\text { whether they are } \\
\text { more likely to } \\
\text { have clinically } \\
\text { significant levels } \\
\text { of PTSD and } \\
\text { higher rates of } \\
\text { behaviour } \\
\text { difficulties. } \\
\text { USA }\end{array}$ & $\begin{array}{l}\text { Observational - case } \\
\text { control. Comparing } \\
\text { baseline intake data } \\
\text { from Trauma } \\
\text { Network Core Data } \\
\text { Set } \\
\text { Data rated by } \\
\text { clinicians on } \\
\text { Indicators of } \\
\text { severity for } \\
\text { problems, CSE and } \\
\text { clinical problems } \\
\text { were recoded to } \\
\text { dichotomous } \\
\text { variables of yes/no. } \\
\text { Trauma History } \\
\text { Profile and PTSD-RI } \\
\text { (Steinberg et al } \\
2004 \text { ). CBCL } \\
\text { (parent/caregiver } \\
\text { rated) } \\
\mathrm{N}=43 \text { (control } \\
\mathrm{N}=173 \text { using logistic } \\
\text { regression } \\
\text { propensity score } \\
\text { matching) }\end{array}$ & $\begin{array}{l}\text { CSE group had higher } \\
\text { rates of involvement } \\
\text { with detention centres, } \\
\text { hospital emergency } \\
\text { rooms and self-help } \\
\text { groups. } \\
\text { CSE group had higher } \\
\text { rates of substance use } \\
\text { and running away. } \\
\text { Significantly higher } \\
\text { prevalence of sexual } \\
\text { behaviour problems, } \\
\text { conduct disorder, } \\
\text { general behaviour } \\
\text { problems, dissociation. } \\
\text { CSE group had higher } \\
\text { overall PTSD score. } \\
\text { More likely to have a } \\
\text { clinically significant } \\
\text { score on avoidance } \\
\text { subscale. Nearly all of } \\
\text { CSE group was in } \\
\text { clinically significant } \\
\text { range for re- } \\
\text { experiencing and } \\
\text { hyperarousal subscales. }\end{array}$ & $\begin{array}{l}\text { Propensity score } \\
\text { matching decreased } \\
\text { confounding bias and } \\
\text { reduced comparison } \\
\text { group down to reduce } \\
\text { type } 1 \text { error. } \\
\text { Clear hypotheses. } \\
\text { Sampled from wide } \\
\text { range of trauma } \\
\text { centres across the } \\
\text { USA (43). }\end{array}$ & $\begin{array}{l}\text { Yes/no question } \\
\text { regarding CSE } \\
\text { involvement not } \\
\text { sensitive enough } \\
\text { to pick up all } \\
\text { incidences of CSE } \\
\text { - some may have } \\
\text { been missed thus } \\
\text { underestimating } \\
\text { prevalence. } \\
\text { Propensity score } \\
\text { matching limits } \\
\text { generalisability to } \\
\text { CSE youth who } \\
\text { were similar on } \\
\text { demographic } \\
\text { variables. }\end{array}$ & $92 \%$ \\
\hline
\end{tabular}




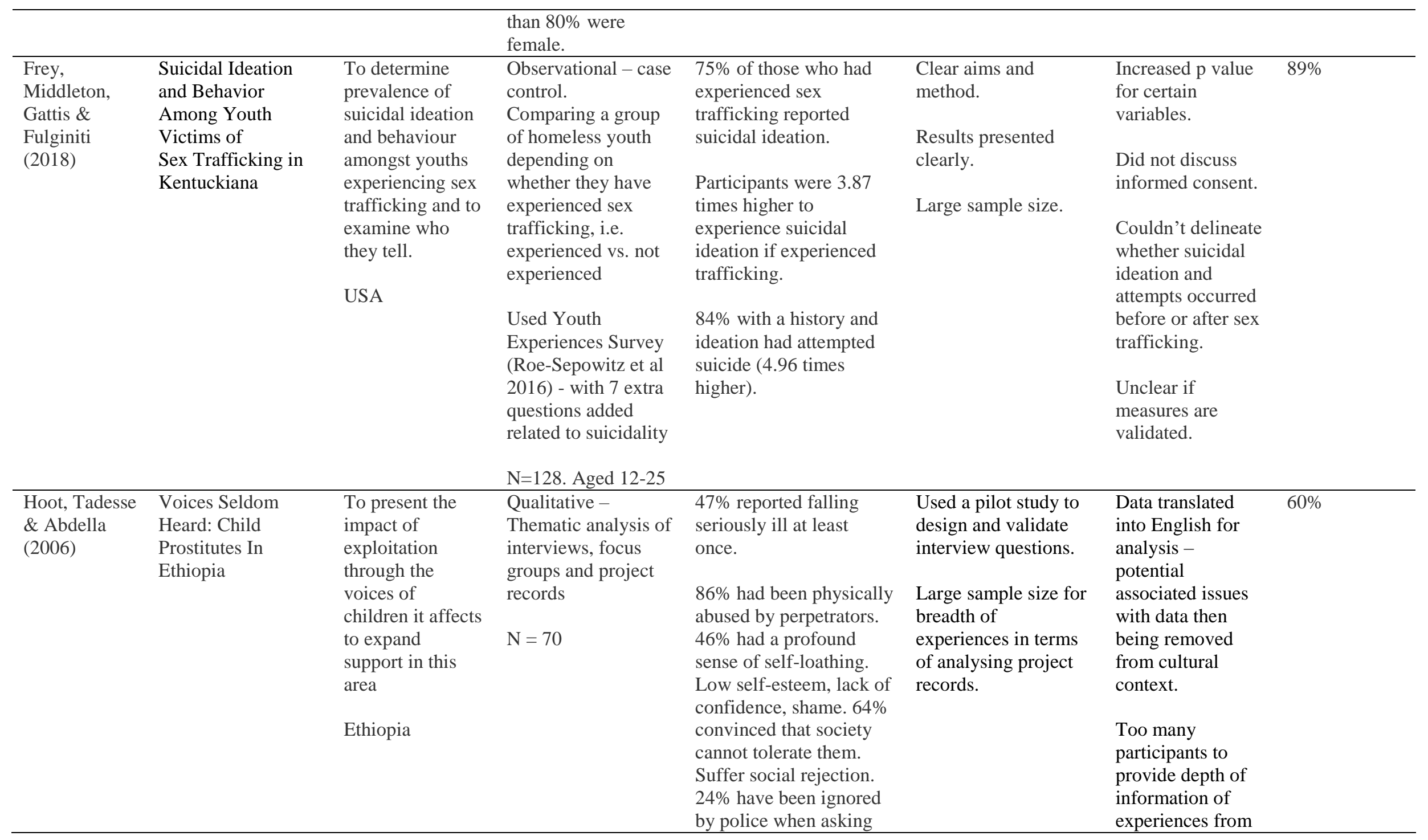




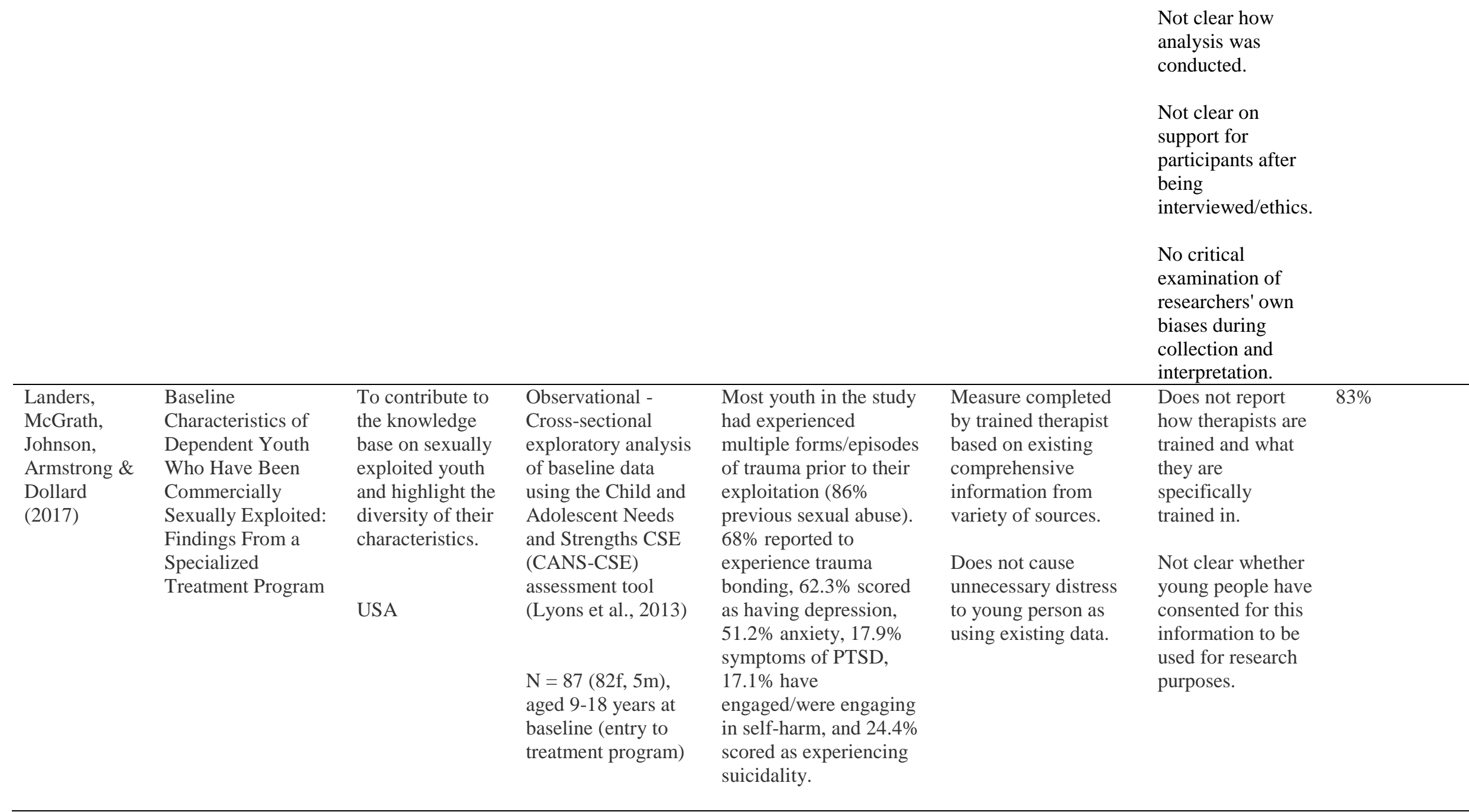




\begin{tabular}{|c|c|c|c|c|c|c|c|}
\hline & & & & $\begin{array}{l}\text { Strengths - 35\% reported } \\
\text { talents and hobbies, } \\
37.6 \% \text { reported } \\
\text { spirituality, } 38.9 \% \\
\text { resiliency, } 47 \% \\
\text { resourcefulness. }\end{array}$ & & & \\
\hline $\begin{array}{l}\text { O'Brien, } \\
\text { White \& } \\
\text { Fraga Rizo } \\
(2017)\end{array}$ & $\begin{array}{l}\text { Domestic Minor } \\
\text { Sex Trafficking } \\
\text { Among Child } \\
\text { Welfare-Involved } \\
\text { Youth: An } \\
\text { Exploratory Study } \\
\text { Of Correlates. }\end{array}$ & $\begin{array}{l}\text { Explore whether } \\
\text { there are } \\
\text { significant } \\
\text { relationships } \\
\text { between } \\
\text { Domestic Minor } \\
\text { Sex Trafficking } \\
\text { (DMST) and } \\
\text { demographic or } \\
\text { psychosocial } \\
\text { factors and other } \\
\text { outcomes. } \\
\text { USA }\end{array}$ & $\begin{array}{l}\text { Observational - case } \\
\text { control at two time } \\
\text { points. Comparing } \\
\text { youth who had/did } \\
\text { not have a history of } \\
\text { DMST. } \\
\text { National survey of } \\
\text { child and adolescent } \\
\text { well-being. Used } \\
\text { waves } 1 \text { and } 2 \text { (2008 } \\
\text { and 2009). } \\
\text { Dependent variables } \\
\text { - five well-being } \\
\text { questions, two } \\
\text { behavioural problem } \\
\text { questions on CBCL, } \\
\text { one PTSD subscale } \\
\text { from trauma } \\
\text { symptom checklist. } \\
\text { Measured substance } \\
\text { use and self- } \\
\text { perceived life } \\
\text { expectancy on a } \\
\text { scale. } \\
\text { N=814. (38 had } \\
\text { experienced DMST). } \\
\text { Aged 10-17. }\end{array}$ & $\begin{array}{l}\text { No difference found } \\
\text { between groups for } \\
\text { gender or race. } \\
\text { Youth with DMST } \\
\text { significantly more likely } \\
\text { to report running away } \\
\text { and substance use } \\
\text { problems and } \\
\text { externalising scores on } \\
\text { CBCL higher. } \\
\text { DMST youth had higher } \\
\text { scores on PTSD } \\
\text { subscale. }\end{array}$ & $\begin{array}{l}\text { Using existing data so } \\
\text { less intrusive for } \\
\text { children. } \\
\text { Used children's self- } \\
\text { report so first hand } \\
\text { perceptions. } \\
\text { Variables set out } \\
\text { clearly despite } \\
\text { complexity of } \\
\text { analysis over two } \\
\text { time points. }\end{array}$ & $\begin{array}{l}\text { Not clear whether } \\
\text { all measures were } \\
\text { validated. } \\
\text { No discussion of } \\
\text { informed consent. } \\
\text { External validity } \\
\text { not discussed. } \\
\text { Small number } \\
\text { compared to } \\
\text { whole sample ( } 38 \\
\text { out of } 814 \text { ). } \\
\text { Cannot infer } \\
\text { causality of } \\
\text { DMST. } \\
\text { Only used one } \\
\text { yes/no question as } \\
\text { an indicator for } \\
\text { history of DMST. }\end{array}$ & $93 \%$ \\
\hline
\end{tabular}




\begin{tabular}{|c|c|c|c|c|c|c|c|}
\hline $\begin{array}{l}\text { Shaw, Lewis, } \\
\text { Chitiva \& } \\
\text { Pangilinan } \\
\text { (2017) }\end{array}$ & $\begin{array}{l}\text { Adolescent Victims } \\
\text { Of Commercial } \\
\text { Sexual Exploitation } \\
\text { Versus Sexually } \\
\text { Abused } \\
\text { Adolescents. }\end{array}$ & $\begin{array}{l}\text { To explore the } \\
\text { difference } \\
\text { between victims } \\
\text { of CSE and other } \\
\text { sexually abused } \\
\text { adolescents. } \\
\text { USA }\end{array}$ & $\begin{array}{l}\text { Observational - case } \\
\text { control. } \\
\text { Compared children } \\
\text { who had } \\
\text { experienced CSE vs } \\
\text { those who had } \\
\text { experienced CSA. } \\
\text { Reviewed mental } \\
\text { health records. Child } \\
\text { Behaviour Checklist } \\
\text { (parent or guardian). } \\
\text { Youth Self Report } \\
\text { on behavioural } \\
\text { problems and } \\
\text { Trauma symptom } \\
\text { checklist completed } \\
\text { by young person. } \\
\text { Charts reviewed to } \\
\text { extract data on } \\
\text { abuse, sexual } \\
\text { experiences, history } \\
\text { of mental health } \\
\text { problems, and use of } \\
\text { psychiatric } \\
\text { medication. } \\
\text { N= 25 (control = 25) }\end{array}$ & $\begin{array}{l}\text { CSE group more likely } \\
\text { to have drug history, } \\
\text { running away and issues } \\
\text { with police. Higher } \\
\text { incidence of mood } \\
\text { disorders and } \\
\text { behavioural disorders. } \\
\text { Lower incidence of } \\
\text { depressive disorders. } \\
\text { At discharge CSE group } \\
\text { had higher incidence of } \\
\text { mood disorders and } \\
\text { PTSD. } \\
\text { CSE group scored as } \\
\text { having more difficulties } \\
\text { across several domains } \\
\text { on CBCL - and more } \\
\text { diverse and complex } \\
\text { mental health } \\
\text { difficulties. } \\
\text { CSE group were more } \\
\text { likely to be withdrawn } \\
\text { and depressed. }\end{array}$ & $\begin{array}{l}\text { Used existing data to } \\
\text { reduce intrusion. } \\
\text { Used standardised } \\
\text { measures. } \\
\text { Mixture of self-report } \\
\text { carer reports and } \\
\text { reviewing records } \\
\text { allowed triangulation } \\
\text { of data. }\end{array}$ & $\begin{array}{l}\text { Did not report } \\
\text { informed consent } \\
\text { procedures. } \\
\text { Problematic } \\
\text { language - } \\
\text { described children } \\
\text { as 'more } \\
\text { disturbed'. } \\
\text { No rationale for } \\
\text { exclusion criteria. } \\
\text { No rationale for } \\
\text { study size. } \\
\text { No mention of } \\
\text { external validity, } \\
\text { time period, or } \\
\text { disclosure of } \\
\text { funding. } \\
\text { Small sample size. }\end{array}$ & $73 \%$ \\
\hline $\begin{array}{l}\text { Sprang \& } \\
\text { Cole (2018) }\end{array}$ & $\begin{array}{l}\text { Familial Sex } \\
\text { Trafficking of } \\
\text { Minors: Trafficking } \\
\text { Conditions, Clinical } \\
\text { Presentation, and }\end{array}$ & $\begin{array}{l}\text { To describe the } \\
\text { clinical } \\
\text { presentation of } \\
\text { victims of CSE, } \\
\text { and assess the }\end{array}$ & $\begin{array}{l}\text { Observational - } \\
\text { Cross-sectional } \\
\text { exploratory analysis } \\
\text { of clinical record } \\
\text { database. }\end{array}$ & $\begin{array}{l}\text { All cases involved } \\
\text { family members as the } \\
\text { trafficker. Mean severity } \\
\text { of abuse was high } \\
(\mathrm{M}=14.66) . \text { Other forms }\end{array}$ & $\begin{array}{l}\text { Validated and } \\
\text { standardised } \\
\text { measures. } \\
\text { Moderately equal }\end{array}$ & $\begin{array}{l}\text { Lack of } \\
\text { generalisability to } \\
\text { children who have } \\
\text { experienced non- } \\
\text { familial }\end{array}$ & $88 \%$ \\
\hline
\end{tabular}




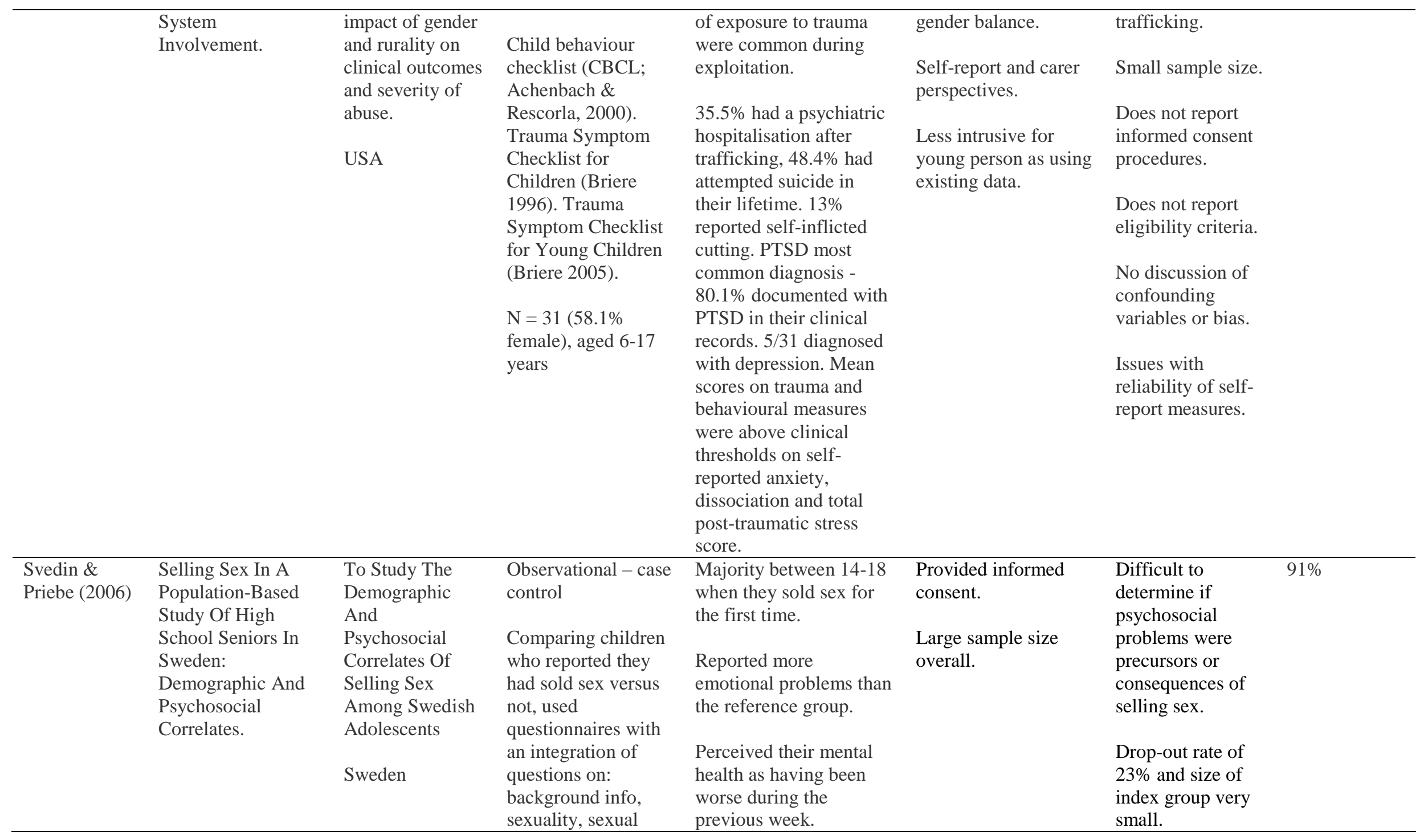




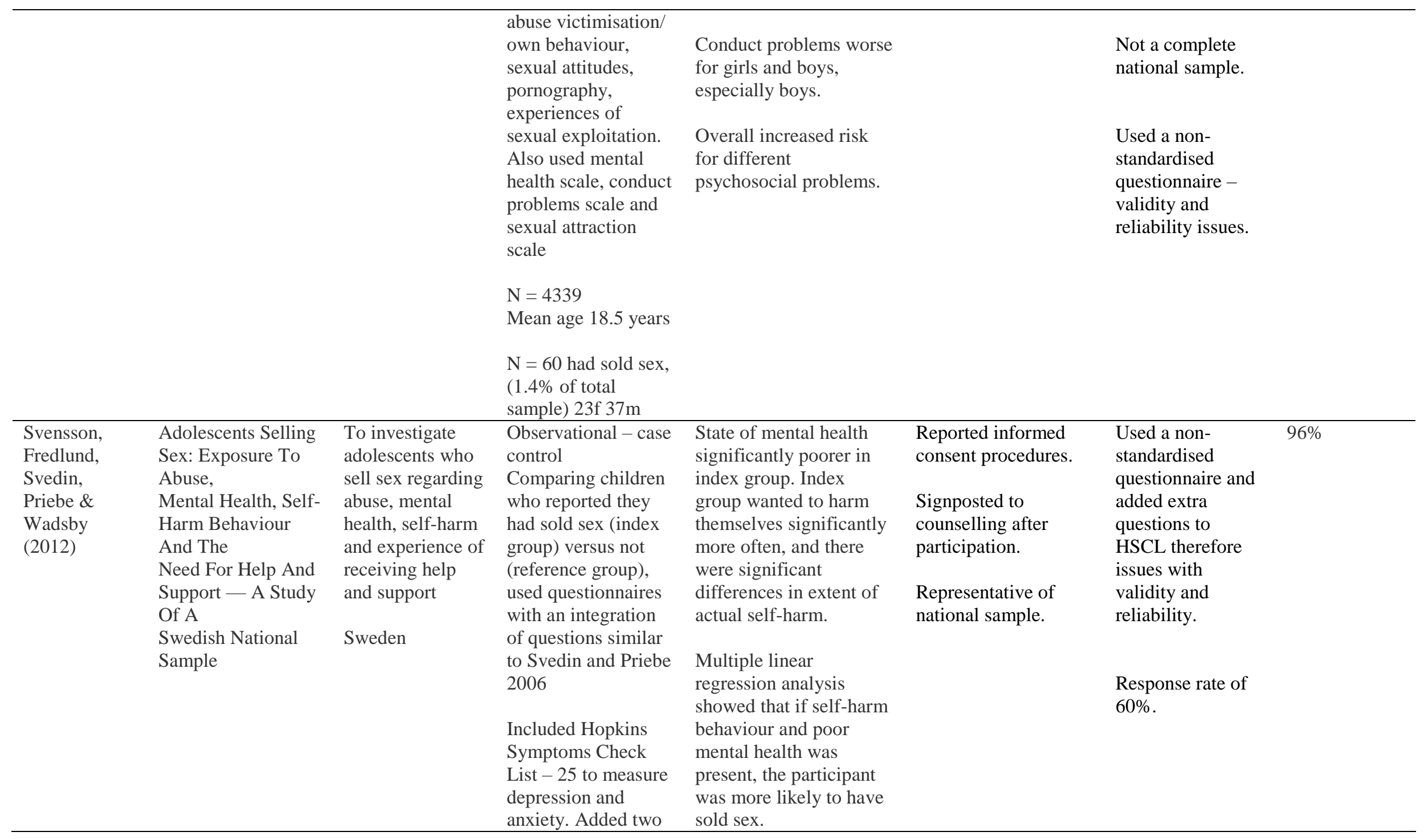




\begin{tabular}{|c|c|c|c|c|c|c|}
\hline & & & $\begin{array}{l}\mathrm{N}=3498 \\
\text { Mean age } 18.3 \text { years } \\
\mathrm{N}=51 \text { had sold sex, } \\
(1.5 \% \text { of total } \\
\text { sample) }\end{array}$ & & & \\
\hline $\begin{array}{l}\text { Volgin, } \\
\text { Shakespeare- } \\
\text { Finch \& } \\
\text { Schochet } \\
(2018)\end{array}$ & $\begin{array}{l}\text { Posttraumatic } \\
\text { Distress, Hope, and } \\
\text { Growth in Survivors } \\
\text { of } \\
\text { Commercial Sexual } \\
\text { Exploitation in } \\
\text { Nepal }\end{array}$ & $\begin{array}{l}\text { Explore the } \\
\text { potential for post } \\
\text { traumatic growth } \\
\text { and distress in } \\
\text { girls and women } \\
\text { who have } \\
\text { experienced } \\
\text { sexual } \\
\text { exploitation. }\end{array}$ & $\begin{array}{l}\text { Qualitative - } \\
\text { observations of } \\
\text { group programme } \\
\text { (week } 2 \text { and week 6) } \\
\text { and individuals in a } \\
\text { residential setting, } \\
\text { used artwork, } \\
\text { narrative interviews, } \\
\text { behavioural } \\
\text { observations and } \\
\text { dance. } \\
\text { Thematic analysis } \\
\text { conducted on } \\
\text { transcripts } \\
\text { Data from larger } \\
\text { ethnographic project } \\
\text { N=26 females, aged } \\
\text { 13-18 years }\end{array}$ & $\begin{array}{l}\text { Themes at week } 2 \text { - } \\
\text { medically unexplained } \\
\text { physical symptoms. } \\
\text { At least one person } \\
\text { every week experiencing } \\
\text { some form of physical } \\
\text { pain. Anxiety was } \\
\text { observed in a number of } \\
\text { participants. } \\
\text { Distress over the loss of } \\
\text { family. } \\
\text { Emergence of empathy, } \\
\text { compassion and post } \\
\text { traumatic growth - } \\
\text { relating to others, } \\
\text { personal strength and } \\
\text { new possibilities. This } \\
\text { theme continued at week } \\
6 .\end{array}$ & $\begin{array}{l}\text { Drew on multiple } \\
\text { sources of data. } \\
\text { Use of interpreter. } \\
\text { Researcher embedded } \\
\text { within culture as part } \\
\text { of ethnographic } \\
\text { approach. }\end{array}$ & $\begin{array}{l}\text { Recruitment } \\
\text { process and } \\
\text { informed consent } \\
\text { not explained. } \\
\text { Process of } \\
\text { collecting the data } \\
\text { not clear. } \\
\text { No critical } \\
\text { analysis of } \\
\text { researcher's own } \\
\text { role when } \\
\text { collecting and } \\
\text { interpreting data. }\end{array}$ \\
\hline
\end{tabular}




\section{Research Quality}

Using the mean average score, the overall quality of the papers was rated as:

- Quantitative observational - 86\%

- Qualitative-63\%

All of the papers were rated at $50 \%$ or above, no papers were excluded based on their quality appraisal score.

Aims and methodology. All of the studies indicated their aims and objectives, providing sufficient relevant theoretical information in order to provide a rationale for their research. All of the studies had similar aims of exploring existing data or experiences in order to consolidate the growing evidence base. The methodological approaches chosen for both the qualitative and quantitative studies were deemed to be appropriate in relation to their particular aims.

Research design. Research designs were assessed as being suitable for all of the studies; however, the majority did not justify their chosen methodology in relation to their research question, which may have been due to word limits within their respective publication guidelines.

Selection processes and recruitment. All three of the qualitative papers used purposive sampling which was appropriate for their particular aims and approaches. Seven of the quantitative papers used existing data from services with which the participants were already involved, and the remaining two papers used opportunity sampling from larger populations of students nationally. Some of the sample sizes, either the overall sample or the index group, were low, leading to issues with statistical power and generalisability (O'Brien, et al., 2017; Shaw et al., 2017; Sprang \& Cole, 2018; Svedin \& Priebe, 2006; Svensson et al., 2012). In one study the sample size was too large for the qualitative approach selected as it did not seem to allow for the depth and richness of participants' experiences to be explored fully (Hoot et al., 2006).

Some of the studies were not clear about their recruitment processes or their rationale for certain participant eligibility criteria (Shaw et al., 2017; Sprang \& 
Cole, 2018; Volgin et al., 2018). Typical areas that lacked detail included how participants were selected to take part and explanations for the sample size, and whether this had been pre-determined or arrived at naturally. This paucity of information regarding the recruitment protocols increases the risk of selection bias and limits the replicability of the studies.

Data collection and measures. The majority of the studies omitted some key information outlining their methodological processes. Landers et al., (2017) did not report any information about the training that clinicians completing the measures had received, or their professional background. Volgin et al.'s (2018) qualitative methodology was unclear in terms of how the focus groups and other forms of expression (e.g. art work and dance) were collected as data and how this was then thematically analysed alongside the interview data. Additionally, Basson et al. (2012) did not clearly explain their processes of data collection and how measures were scored; and Cecchet and Thoburn (2014) did not report any of the questions used in their semi-structured interviews.

Although several of the studies relied on self-report measures, which may lack reliability due to subjectivity and social desirability bias, some triangulated the self-report data alongside carer and professional reports, strengthening their overall findings (Sprang \& Cole, 2018; Shaw et al. 2017). The majority of the studies utilised validated measures; however some added extra questions to the measures or devised their own questionnaires, affecting the validity and reliability of their results (Frey et al. 2018; O'Brien et al., 2017; Svedin \& Priebe, 2006; Svensson et al. 2012). In all of the quantitative studies, the measures used were described adequately; however a limitation of some of the studies that compared children who had experienced CSE with other reference groups, was their use of binary 'yes or no' questions in order to group participants (Cole et al. 2014; Frey et al., 2018; O'Brien et al., 2017; Svedin \& Priebe, 2006; Svensson et al. 2012). Using a binary fixed choice question allowed the researchers to ascertain the incidence of CSE among the participants but limited the level of detail and complexity in the data.

Ethical consideration. A significant limitation of six of the quantitative and one of the qualitative studies was the lack of reporting of the informed consent of the participants, and it is unclear whether they were aware of their data being used for 
research purposes (Cole et al. 2014; Frey et al., 2018; O’Brien et al., 2017; Landers et al., 2017; Sprang \& Cole, 2018; Shaw et al. 2017; Volgin et al., 2018). Several of the studies outlined their processes for signposting after participation in order to reduce the risk of harm. However, the majority of the studies did not discuss how participants would be safeguarded throughout the process and how any risk assessments would be conducted prior to taking part. The language of Shaw et al. (2017) was problematic, referring to the children who had experienced CSE as "more disturbed" than their counterparts who had not experienced CSE. This terminology is not in keeping with the current drive towards a less pathologising approach to working with CSE. Four of the studies did not report if they had received ethical approval.

Data analysis and rigour. In all three qualitative papers, there were no critical analyses of the researchers' own roles in terms of how their biases may have influenced their data collection and analysis. Across the quantitative papers, the procedures for their statistical and descriptive analyses were outlined, but there was a lack of acknowledgement of confounding variables throughout the studies which led to a lack of rigour.

Results and interpretation. As all of the quantitative studies used an observational design, it was not possible to infer causality of experiencing CSE on the participants' psychological difficulties or trauma. This was acknowledged as a limitation in most of the studies; however, as this is an under researched area, the studies have still contributed towards the developing evidence base. Furthermore, many of the quantitative studies did not discuss the generalisability or external validity of their results. Overall, it was difficult to delineate the children's difficulties from their experiences of CSE and the researchers were unable to ascertain which occurred first, and some of the studies lacked recognition of this issue. All 12 of the studies summarised their results and findings in a balanced and clear manner, making links to the existing literature. Most of the included studies discussed the clinical implications of their findings. 


\section{Synthesis of Findings}

The findings of the 12 studies included in this review were synthesised to generate several themes about the psychological impact of CSE and the trauma that children experience. A thorough inspection of the results and their clinical implications highlighted four themes that represent the key information known in this area.

Overall mental health difficulties. All 12 of the studies were in agreement that children exploited sexually are likely to be experiencing psychological difficulties. In Landers et al. (2017), 62\% of the children were experiencing depression and $51 \%$ anxiety, with $18 \%$ presenting with symptoms of Post-Traumatic Stress Disorder (PTSD). Sprang and Cole (2018) reported that $36 \%$ of their participants had been admitted to a psychiatric hospital after being trafficked for sexual exploitation. They also found that $80 \%$ of participants had a diagnosis of PTSD recorded in their clinical records, and their mean scores for self-reported anxiety, dissociation, and PTSD stress scores were all above the clinical thresholds. Semistructured interviews with women who had been sex trafficked as children found that every woman reported severe mental health problems, including trauma symptoms of numbness, avoidance, flashbacks and dissociation (Cecchet \& Thoburn, 2014). The women in this study also reported experiencing depression and anxiety.

When comparing children who have experienced CSE with control groups, several studies found that children who scored higher on PTSD scales, were more likely to experience avoidance, re-experiencing of their trauma and hyperarousal, higher levels of dissociation, more behavioural problems, a higher incidence of mood difficulties, more complex mental health difficulties, more likely to be withdrawn and depressed, and more likely to rate their own mental health as worse (Cole et al., 2014; O’Brien et al., 2017; Shaw et al., 2017; Svensson et al., 2012; Svedin \& Priebe, 2006).

Volgin et al. (2018) shared similar results in their qualitative project with survivors of sexual exploitation in Nepal, observing significant levels of anxiety and distress in their participants. This study was the only study to report participants' 
experiences of medically unexplained physical symptoms being related to their distress, which was a significant theme within their findings.

Self-harm and suicide. Several of the studies suggested that children subjected to sexual exploitation may engage in self-harming behaviour, and may also experience suicidal ideation and attempt to end their own lives. Landers et al. (2017) reported that $17 \%$ of participants had previously - or were currently - selfharming and $24 \%$ of the sample were assessed as being at low to moderate risk of suicide. Sprang and Cole (2018) also found that $48 \%$ of participants had attempted to end their own lives, with $13 \%$ reporting that they had self-harmed by cutting. In a study on homeless children, Frey et al. (2018) compared the experiences of those who had been sexually exploited with those who had not, with $75 \%$ of children in the CSE group reporting suicidal ideation. They concluded that children were 3.87 times more likely to experience suicidal ideation if they had been trafficked for sex. They also found that $84 \%$ of children who had a history of trafficking and experienced suicidal ideation had attempted suicide, a rate 4.96 times higher than their counterparts. Similarly, Svensson et al. (2012) found that children who reported selling sex were more likely to want to harm themselves and showed significant differences in the extent of their self-harming behaviour compared to the control group. Within this study, a multiple regression analysis suggested that if self-harming behaviour and mental health difficulties were present, the participant was more likely than not to have sold sex.

Are difficulties a precursor or consequence of CSE? Children who have experienced CSE are extremely likely to have already experienced multiple episodes and different forms of trauma prior to being sexually exploited. Landers et al. (2017) found that $86 \%$ of the children in a CSE treatment program had already experienced sexual abuse prior to being sexually exploited. Sprang and Cole (2018) also found that $97 \%$ of their sample had experienced sexual assault aside from sexual exploitation and 58\% had been physically assaulted. Additionally, Basson et al. (2012) explored data from CSE service providers, and suggested that $75 \%$ of their sample had already experienced abuse or neglect before the sexual exploitation. In their thematic analysis of interviews with children from Ethiopia, Hoot et al. reported that $86 \%$ of the children had been physically abused. 
Strengths and resilience. Some of the studies included in this review also measured children's strengths and resilience as well as their difficulties. Despite often experiencing severe forms of sexual, physical, and emotional abuse prior to and during the exploitation, children are able to demonstrate a variety of strengths, highlighting their resilience. In Landers et al. (2017), 47\% of participants were found to have shown resourcefulness, $39 \%$ were reported as showing resilience, $38 \%$ found strength in their spirituality and $35 \%$ of participants reported engaging with their talents and hobbies. Cecchet and Thoburn (2014) found that five out of the six survivors of CSE that they interviewed demonstrated strength through their participation in their communities in order to support others experiencing sexual exploitation. Basson et al. (2012) conducted an observational study of children in CSE services and found that $66 \%$ continued to express their creativity and $42 \%$ were reported as resilient. Similarly, in 2018 Volgin et al. measured post-traumatic growth in Nepalese children, reporting an emergence of empathy, personal strength and the ability to remain hopeful about the future.

\section{Discussion}

Four key themes emerged from the synthesis of the findings. All 12 papers included in the review shared similar findings, demonstrating that children who have experienced sexual exploitation are likely to have experienced additional forms of trauma, have psychological difficulties related to their traumatic experiences and experience suicidal ideation and self-harm, but, despite this, also display significant strengths and resilience.

\section{Theoretical considerations}

The findings of the current review echo the Department for Education's claims that children who are sexually exploited experience poorer mental health outcomes (Department for Education, 2017). The review confirmed that CSE survivors are likely to have similar, if not more complex, psychological difficulties in comparison to those found in children who have been sexually abused without the element of exchange (Tyler, 2002). These difficulties include anxiety, depression, 
PTSD and trauma-related symptoms, behavioural problems, self-harming and suicidality.

It is theorised within the wider literature that resilience is a key factor in adapting to traumatic situations and is the most common response (Bonanno, 2005). The current review has also highlighted that CSE survivors demonstrate resilience and present with individual strengths; this is likely to support them in coping with the abuse they have been subjected to during the exploitation process.

\section{Clinical Implications}

The findings indicate that children who have experienced CSE are likely to present at health and social care services with a myriad of complex difficulties that may have existed prior to - or have been exacerbated by - their exploitation. This is important when considering service responses to these children as it strengthens the current move away from responding punitively and recognises that the children are subjects of abuse and not sex-workers or prostitutes. The findings also suggest that professionals working with CSE victims should be aware of how their exploitative experiences may have damaging psychological effects, and how this may increase the risk of self-harming or suicidal behaviour. It is clear from all of the studies that CSE survivors have often been affected by abuse prior to exploitation, which strengthens a preventative approach to avoid already abused children from being sexually exploited (Beckett \& Pearce, 2018).

\section{$\underline{\text { Limitations }}$}

An entirely systematic review would endeavour to have more than one reviewer in order to improve the reliability of the search strategy and appraisal process. Furthermore this would strengthen the narrative synthesis as the themes would be corroborated by a second reviewer.

It was necessary to limit the search strategy to exclude studies only referring to CSA, due to the large amount of studies this would return that would mostly be irrelevant to the current review question. There is a risk that this will have missed studies that have included people who have experienced CSE but referred to the broader terminology of CSA. An attempt to mitigate against this was conducting 
all of the searches within the full-texts of articles, with the aim of picking up more relevant terms within the study information.

The current review aimed to explore what is known about the psychological impact of CSE. However, from most of the findings it was difficult to clearly distinguish the effects of CSE from the vulnerability factors, given that most of the children already had extensive trauma histories (Landers et al. 2017; Sprang \& Cole, 2018).

The studies included are predominantly quantitative. Although this allows for increased external validity and generalisability of the findings with the increased sample sizes and some use of standardised measures, it means that rich, in-depth data about the children's interpretations of their difficulties and how they had made sense of their traumatic experiences is missed. Furthermore, all of the quantitative papers were observational studies which do not determine the direction of the relationship between CSE and mental health difficulties.

It was surprising that there were no relevant studies found that had been conducted in the UK. Given that the majority of studies were conducted in the USA, the generalisability of the findings is affected to some extent. Despite this, similar findings were reported across different countries, settings and methodologies, therefore it could be argued that the psychological impact of trauma experienced before and during CSE may translate across different cultures and contexts. This may therefore increase the generalisability of the findings when considered in a synthesised manner.

\section{Directions for Future Research}

The ongoing issues of differentiating the effects of CSE from other forms of trauma, and the recent changes in definition and approaches to CSE in the UK, may be an underlying influence upon the lack of standardised operating procedures or guidance for CSE services at a national level (Beckett \& Pearce, 2018). Currently in England, children who are at risk of experiencing or have experienced CSE are often supported by specialist local authority outreach teams, who work with third sector organisations such as Barnardo's and Catch 22. Some police forces also have specialist CSE teams. Community services are designed to assess and work alongside young people to "reduce" the risk towards themselves through education 
about consent, relationships and safe sex. There are also specialist residential homes that are designed to offer more intensive therapeutic support for young people who have experienced CSE at such an extent to which they have been placed into residential care in order to keep them safe. There are considerable variations in the services that may be offered to a young person depending on where they live in the UK, with categorisations differing across areas such as by age, whether the abuse was online or offline, and whether the child knew the abuser (Beckett \& Pearce, 2018).

In 2017, an evidence scope was published with the aim of reviewing and appraising the relevant evidence in order to propose six key principles that would increase the effectiveness of CSE services:

1. Young people must be at the centre and should not be held responsible for their harm or their safety.

2. CSE is complex; therefore the response cannot be simple or linear. Responses need to be based on evidence from a wide range of sources of expertise.

3. No agency can address CSE in isolation; collaboration is essential.

4. Knowledge is crucial.

5. Communities and families are valuable assets, and are likely to need support.

6. Effective services require resilient and supported practitioners. (Research in Practice, 2017, p.83)

Beckett and Pearce (2017) suggest that children and young people who have experienced sexual violence should be given the opportunity to participate in service development. Warrington (2016) also suggests that empowerment through participation can enhance recovery from sexual abuse. Therefore it is suggested that the added involvement of young people within any future research in this area is inherently valuable and important, with the majority of approaches in the current review suggesting that children are not always directly asked about their experiences. Rather, there appears to be a reliance on drawing conclusions from existing quantitative data instead. Allowing young people to discuss their own 
thoughts and experiences would not only provide a space for their (often subjugated) voices (Warrington, 2013), but hopefully empower them by giving them an opportunity to express their ideas about the design of services at the centre of their recovery.

Given the findings of the current review in terms of children's psychological needs, and the gap in knowledge around how CSE services should operate in order to address these needs, it is suggested that future research should investigate the views of young people using these services and the professionals who support them.

\section{Conclusion}

The 12 papers reviewed have provided valuable contributions towards the growing evidence base for CSE and its effects on the children involved. All papers were of sufficient quality, above $50 \%$, although a significant quality limitation was the lack of informed consent and consideration of the risks to participants. Papers found similar results concerning the damaging psychological impact of trauma and demonstrated how children involved in CSE are likely to be experiencing significant mental health difficulties. The methodology used did not allow for the delineation of CSE from mental health difficulties, nor could causality be inferred from these approaches. Furthermore, as children are likely to have experienced multiple forms of trauma alongside the sexual exploitation, it was not possible to differentiate the effects of CSE from the current findings. Further research is needed in order to continue to fully understand the needs of children who have experienced CSE and how their experiences can contribute to service design and interventions. 


\section{References}

Barnardo's. (2017). Working with children who are victims or at risk of sexual exploitation: Barnardo's model of practice. Barnardo's. Retrieved May 18, 2019, from https://www.scie-socialcareonline.org.uk/working-withchildren-who-are-victims-or-at-risk-of-sexual-exploitation-barnardosmodel-of-practice/r/a11G000000ORBRCIA5

Barnert, E. S., Dudovitz, R., Nelson, B. B., Coker, T. R., Biely, C., Li, N. \& Chung, P. (2017). How does incarcerating young people affect their adult health outcomes? Pediatrics, 139(2), 2016-2624. https://doi.org/10.1542/peds.2016-2624

Basson, D., Rosenblatt, E., \& Haley, H. (2012). Research to action: Sexually exploited minors (SEM) needs and strengths. West Coast Children's Clinic. Retrieved May 18, 2019, from http://www.westcoastcc.org/WCC_SEM_Needs-and-Strengths_FINAL.pdf

Beckett, H., \& Pearce, J. (2018). Understanding and responding to Child Sexual Exploitation. Routledge.

Bonanno, G. A. (2005). Resilience in the face of potential trauma. Current Directions in Psychological Science, 14(3), 135-

38. https://doi.org/10.1111/j.0963-7214.2005.00347.x

Cameron, G., Mendez Sayer, E., Thomson, L., \& Wilson, S. (2015). Child Sexual Exploitation: A study of international comparisons. The Virtual Staff College.

Retrieved April 21, 2019, from https://thestaffcollege.uk/wpcontent/uploads /CSE_main_final_publish_1.0.pdf

Critical Appraisal Skills Programme. (2018). CASP qualitative research checklist. Retrieved May 19, 2019, from http://www.casp-uk.net/casp-tools-checklists

Cecchet, S. J., \& Thoburn, J. (2014). The psychological experience of child and adolescent sex trafficking in the United States: Trauma and resilience in 
survivors. Psychological Trauma: Theory, Research, Practice, and Policy, 6(5), 482-493. https://doi.org/10.1037/a0035763

Cole, J., Sprang, G., Lee, R., \& Cohen, J. (2014). The trauma of commercial sexual exploitation of youth: A comparison of CSE victims to sexual abuse victims in a clinical sample. Journal of Interpersonal Violence, 31, 122-146. https://doi.org/10.1177/0886260514555133

Department for Education. (2017). Child sexual exploitation: definition and a guide for practitioners, local leaders and decision makers working to protect children from child sexual exploitation. Department for Education. Retrieved May 18, 2019 from https://www.gov.uk/government/publications/child-sexual$\underline{\text { exploitation-definition-and-guide-for-practitioners }}$

Eaton. J. (2019). Critical perspectives: child sexual exploitation approaches and practice. Retrieved August 9, 2019, from https://irp$\underline{\text { cdn.multiscreensite.com/f9ec73a4/files/uploaded/Critical\%20Perspectives }}$ \%20of\%20CSE\%20Approaches\%20and\%20Practice\%20Eaton\%202019\% 20VictimFocus\%20FINAL.pdf

Finkelhor, D., \& Browne, A. (1985). The traumatic impact of Child Sexual Abuse: A conceptualisation. American Journal of Orthopsychiatry, 55(4), 530-541. https://doi.org/10.1111/j.1939-0025.1985.tb02703.x

Frey, L. M., Middleton, J., Gattis, M. N., \& Fulginiti, A. (2018). Suicidal ideation and behavior among youth victims of sex trafficking in Kentuckiana. Crisis: The Journal of Crisis Intervention and Suicide Prevention, 40(4), 240-248. https://doi.org/10.1027/0227-5910/a000557

Frost, N. (2019). Providing support and therapy for victims and survivors of child sexual exploitation. Journal of Public Mental Health, 18(1), 38-45. https://doi.org/10.1108/JPMH-07-2018-0051

Harris, J., Roker, D., Shuker, L., Brodie, I., D’Arcy, K., Dhaliwal, S., Pearce, J. (2017). Evaluation of the Alexi project 'hub and spoke' programme of CSE service development. University of Bedfordshire. Retrieved May 18. 2019, 
from https://www.beds.ac.uk/media/87236/final-report-alexi-projectevaluation.pdf

HM Government. (2018). Working together to safeguard children. Retrieved August 9, 2019, from https://assets.publishing.service.gov.uk/government/u ploads/system/uploads/attachment_data/file/779401/Working_Together_to $\underline{\text { Safeguard-Children.pdf }}$

Hoot, J., Tadesse, S. \& Abdella, R. (2006). Voices seldom heard. Child prostitutes in Ethiopia. Journal of Children and Poverty, 12(2), 129-139. https://doi.org/10.1080/10796120600879558

International Labour Organization. (2005). A global alliance against forced labour - Global report on forced labour 2005. International Labour Organisation. Retrieved April 13, 2019, from https://www.ilo.org/global/publications/books/WCMS_0818 $\underline{\text { 82/lang--en/index.htm }}$

International Labour Organization. (2009). Training manual to fight trafficking in children for labour, sexual and other forms of exploitation. International Labour Organisation. Retrieved April 13, 2019, from https://www.ilo.org/ip ec/areas/Traffickingofchildren/WCMS_111537/lang--en/index.htm

Jay, A. (2014). Independent inquiry into Child Sexual Exploitation in Rotherham: 1997-2013. Rotherham Metropolitan Borough Council. Retrieved April 13, 2019, from https://www.rotherham.gov.uk/downloads/download/139/indep endent_inquiry_into_child_sexual_exploitation_in_rotherham_1997_\%E2 $\underline{\% 80 \% 93 \_2013}$

Landers, M., McGrath, K., Johnson, M. H., Armstrong, M. L., \& Dollard, N. (2017). Baseline characteristics of dependent youth who have been commercially sexually exploited: findings from a specialized treatment program. Journal of Child Sexual Abuse, 26(6), 692-709. https://doi.org/10.1080/10538712.2017.1323814

Lincoln, Y. S., \& Guba, E. G. (1985). Naturalistic inquiry. Sage Publications. 
Nadelson, S., \& Nadelson, L. S. (2014). Evidence-based practice article reviews using CASP tools: a method for teaching EBP. Worldviews on EvidenceBased Nursing, 11(5), 344-346. https://doi.org/10.1111/wvn.12059

O'Brien, J. E., White, K., \& Fraga Rizo, C. (2017). Domestic minor sex trafficking among child welfare-involved youth: an exploratory study of correlates. Child Maltreatment, 22(3), 265-274. https://doi.org/10.1177/107755951770 $\underline{9995}$

Pearce, J. (2017). Preventing child sexual exploitation. In P. Dolan, \& N. Frost (Eds.), The Routledge Handbook of Global Child Welfare, (pp. 153-164). Routledge.

Research in Practice. (2017). Working effectively to address child sexual exploitation: An evidence scope. Research in Practice. Retrieved June 9, 2018, from https://www.researchinpractice.org.uk/media/2613/cse_evidenc escopeupdateoct17_v2.pdf

Sexual Offences Act. (2003). Retrieved August 9, 2019, from http://www.legislation.gov.uk/ukpga/2003/42/pdfs/ukpga_20030042_en.pdf

Shaw, J., Lewis, J. E., Chitiva, H. A., \& Pangilinan, A. R. (2017). Adolescent victims of commercial sexual exploitation versus sexually abused adolescents. Journal of the American Academy of Psychiatry and the Law, 45(3), 325-331. https://www.ncbi.nlm.nih.gov/pubmed/28939730

Sprang, G., \& Cole, J. (2018). Familial sex trafficking of minors: trafficking conditions, clinical presentation, and system involvement. Journal of Family Violence, 33, 185-195. https://doi.org/10.1007/s10896-018-9950-y

Svedin, C. G., \& Priebe, G. (2006). Selling sex in a population-based study of high school seniors in Sweden: Demographic and psychosocial correlates. Archives of Sexual Behaviour, 36, 21-32. https://doi.org/10.1007\%2Fs10508-006-9083-x

Svensson, F., Fredlund, C., Svedin, C. G., Priebe, G., \& Wadsby, M. (2013). Adolescents selling sex: exposure to abuse, mental health, self-harm, 
behaviour and the need for help and support. A study of a Swedish national sample. Nordic Journal of Psychiatry, 67(2), 81-88.

https://doi.org/10.3109/08039488.2012.679968

Tyler, K. A. (2002). Social and emotional outcomes of childhood sexual abuse: a review of recent research. University of Nebraska Sociology Department Faculty Publications, 58. https://doi.org/10.1016/S1359-1789(01)00047-7

United Nations. (2000). Organised Crime Policy. Retrieved April 182019 from https://www.unodc.org/unodc/en/organized-crime/intro/UNTOC.html

Warrington, C. (2013). Partners in care? Sexually exploited young people's inclusion and exclusion from decision making. In M. Melrose, \& J. Pearce (Eds.) Critical Perspectives on Child Sexual Exploitation and Related Trafficking, (pp.110-124). Palgrave Macmillan.

Warrington, C. (2016). Young person-centred approaches in child sexual exploitation: Building self-efficacy and promoting participation. Research in Practice. Retrieved June 8, 2019, from https://www.portsmoutheducation partnership.co.uk/wp-content/uploads/2017/11/Rip_CSE_frontline_briefing _updated.pdf

Volgin, R. N., Shakespeare-Finch, J., \& Shochet, I. M. (2018). Posttraumatic distress, hope, and growth in survivors of commercial sexual exploitation in Nepal. Traumatology, 25(3), 181-188. https://doi.org/10.1037/trm0000174

von Elm, E., Altman, D. G., Egger, M., Pocock, S. J., Gøtzsche, P. C., \& Vandenbroucke, J. P. (2008). STROBE initiative. Strengthening the reporting of observational studies in epidemiology. Journal of Clinical Epidemiology, 61(4), 344-349. https://doi.org/10.1016/j.jclinepi.2007.11.00 


\section{Appendices}

Appendix A: Journal Submission Guidelines..................................................... 48

Appendix B: Example of STROBE Checklist Scoring......................................... 56

Appendix C: Example of CASP Checklist Scoring.............................................. 60 
Appendix A: Submission Guidelines for Child Abuse and Neglect: The International Journal

\section{CHILD ABUSE \& NEGLECT}

The International Journal

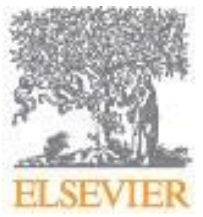

AUTHOR INFORMATION PACK

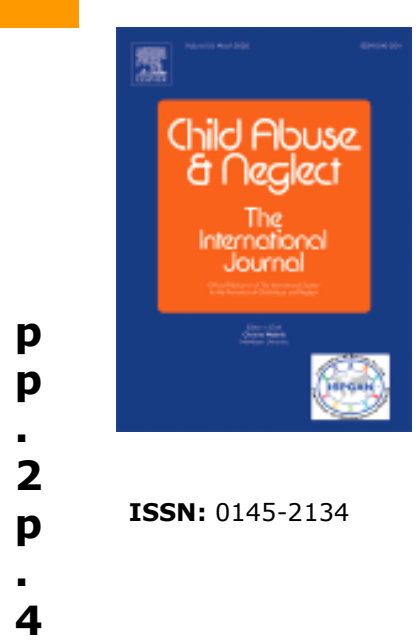

\section{DESCRIPTION}

Child Abuse \& Neglect is an international and interdisciplinary journal publishing articles on child welfare, health, humanitarian aid, justice, mental health, public health and social service systems. The journal recognizes that child protection is a global concern that continues to evolve. Accordingly, the journal is intended to be useful to scholars, policymakers, concerned citizens, advocates, and professional practitioners in countries that are diverse in wealth, culture, and the nature of their formal child protection system. Child Abuse \& Neglect welcomes contributions grounded in the traditions of particular cultures and settings, as well as global perspectives. Article formats include empirical reports, theoretical and methodological reports and invited reviews.

\section{AUDIENCE}

Includes but is not limited to: Economists, Historians, Planners, Political Scientists, Ethicists, Legal Scholars, Political Theorists, Theologians Psychologists, Lawyers, Psychiatrists, Nurses, Social Workers, Sociologists, Public Health Workers, Law Enforcement, Educators, Pediatricians and Anthropologists.

\section{IMPACT FACTOR}




\section{GUIDE FOR AUTHORS}

\section{Studies in humans and animals}

If the work involves the use of human subjects, the author should ensure that the work described has been carried out in accordance with The Code of Ethics of the World Medical Association (Declaration of Helsinki) for experiments involving humans. The manuscript should be in line with the Recommendations for the Conduct, Reporting, Editing and Publication of Scholarly Work in Medical Journals and aim for the inclusion of representative human populations (sex, age and ethnicity) as per those recommendations. The terms sex and gender should be used correctly.

Authors should include a statement in the manuscript that informed consent was obtained for experimentation with human subjects. The privacy rights of human subjects must always be observed.

All animal experiments should comply with the ARRIVE guidelines and should be carried out in accordance with the U.K. Animals (Scientific Procedures) Act, 1986 and associated guidelines, EU Directive 2010/63/EU for animal experiments, or the National Institutes of Health guide for the care and use of Laboratory animals (NIH Publications No. 8023, revised 1978) and the authors should clearly indicate in the manuscript that such guidelines have been followed. The sex of animals must be indicated, and where appropriate, the influence (or association) of sex on the results of the study.

\section{Declaration of interest}

All authors must disclose any financial and personal relationships with other people or organizations that could inappropriately influence (bias) their work. Examples of potential competing interests include employment, consultancies, stock ownership, honoraria, paid expert testimony, patent applications/registrations, and grants or other funding. Authors must disclose any interests in two places: 1 . A summary declaration of interest statement in the title page file (if double-blind) or the manuscript file (if single-blind). If there are no interests to declare then please state this: 'Declarations of interest: none'. This summary statement will be ultimately published if the article is accepted.

2. Detailed disclosures as part of a separate Declaration of Interest form, which forms part of the journal's official records. It is important for potential interests to be declared in both places and that the information matches. More information.

\section{Submission declaration and verification}

Submission of an article implies that the work described has not been published previously (except in the form of an abstract, a published lecture or academic thesis, see 'Multiple, redundant or concurrent publication' for more information), that it is not under consideration for publication elsewhere, that its publication is approved by all authors and tacitly or explicitly by the responsible authorities where the work was carried out, and that, if accepted, it will not be published elsewhere in the same form, in English or in any other language, including electronically without the written consent of the copyrightholder. To verify originality, your article may be checked by the originality detection service Crossref Similarity Check.

Preprints

Please note that preprints can be shared anywhere at any time, in line with Elsevier's sharing policy. Sharing your preprints e.g. on a preprint server will not count as prior publication (see 'Multiple, redundant or concurrent publication' for more information).

Inclusive language acknowledges diversity, conveys respect to all people, is 
sensitive to differences, and promotes equal opportunities. Articles should make no assumptions about the beliefs or commitments of any reader, should contain nothing which might imply that one individual is superior to another on the grounds of race, sex, culture or any other characteristic, and should use inclusive language throughout. Authors should ensure that writing is free from bias, for instance by using 'he or she', 'his/her' instead of 'he' or 'his', and by making use of job titles that are free of stereotyping (e.g. 'chairperson' instead of 'chairman' and 'flight attendant' instead of 'stewardess').

\section{Changes to authorship}

Authors are expected to consider carefully the list and order of authors before submitting their manuscript and provide the definitive list of authors at the time of the original submission. Any addition, deletion or rearrangement of author names in the authorship list should be made only before the manuscript has been accepted and only if approved by the journal Editor. To request such a change, the Editor must receive the following from the corresponding author: (a) the reason for the change in author list and (b) written confirmation (e-mail, letter) from all authors that they agree with the addition, removal or rearrangement. In the case of addition or removal of authors, this includes confirmation from the author being added or removed.

Only in exceptional circumstances will the Editor consider the addition, deletion or rearrangement of authors after the manuscript has been accepted. While the Editor considers the request, publication of the manuscript will be suspended. If the manuscript has already been published in an online issue, any requests approved by the Editor will result in a corrigendum.

\section{Article transfer service}

This journal is part of our Article Transfer Service. This means that if the Editor feels your article is more suitable in one of our other participating journals, then you may be asked to consider transferring the article to one of those. If you agree, your article will be transferred automatically on your behalf with no need to reformat. Please note that your article will be reviewed again by the new journal. More information.

\section{Copyright}

Upon acceptance of an article, authors will be asked to complete a 'Journal Publishing Agreement' (see more information on this). An e-mail will be sent to the corresponding author confirming receipt of the manuscript together with a 'Journal Publishing Agreement' form or a link to the online version of this agreement.

Subscribers may reproduce tables of contents or prepare lists of articles including abstracts for internal circulation within their institutions. Permission of the Publisher is required for resale or distribution outside the institution and for all other derivative works, including compilations and translations. If excerpts from other copyrighted works are included, the author(s) must obtain written permission from the copyright owners and credit the source(s) in the article. Elsevier has preprinted forms for use by authors in these cases.

For gold open access articles: Upon acceptance of an article, authors will be asked to complete an 'Exclusive License Agreement' (more information). Permitted third party reuse of gold open access articles is determined by the author's choice of user license.

\section{Author rights}

As an author you (or your employer or institution) have certain rights to reuse your work. More information.

Elsevier supports responsible sharing

Find out how you can share your research published in Elsevier journals. 
the research and/or preparation of the article and to briefly describe the role of the sponsor(s), if any, in study design; in the collection, analysis and interpretation of data; in the writing of the report; and in the decision to submit the article for publication. If the funding source(s) had no such involvement then this should be stated.

\section{Open access}

Please visit our Open Access page for more information.

\section{Language (usage and editing services)}

Please write your text in good English (only American usage is accepted, as dictated by APA style). Authors who feel their English language manuscript may require editing to eliminate possible grammatical or spelling errors and to conform to correct scientific English may wish to use the English Language Editing service available from Elsevier's WebShop (http://webshop.elsevier.com/languageediting/) or visit our customer support site (https://service.elsevier.com) for more information.

\section{Submission}

Our online submission system guides you stepwise through the process of entering your article details and uploading your files. The system converts your article files to a single PDF file used in the peer-review process. Editable files (e.g., Word, LaTeX) are required to typeset your article for final publication. All correspondence, including notification of the Editor's decision and requests for revision, is sent by e-mail.

\section{Submit your article}

Please submit your article via http://ees.elsevier.com/chiabuneg/

\section{PREPARATION}

\section{Peer review}

This journal operates a double blind review process. All contributions will be initially assessed by the editor for suitability for the journal. Papers deemed suitable are then typically sent to a minimum of two independent expert reviewers to assess the scientific quality of the paper. The Editor is responsible for the final decision regarding acceptance or rejection of articles. The Editor's decision is final. More information on types of peer review.

\section{Double-blind review}

This journal uses double-blind review, which means the identities of the authors are concealed from the reviewers, and vice versa. More information is available on our website. To facilitate this, please include the following separately:

Title page (with author details): This should include the title, authors' names, affiliations, acknowledgements and any Declaration of Interest statement, and a complete address for the corresponding author including an e-mail address. Blinded manuscript (no author details): The main body of the paper (including the references, figures, tables and any acknowledgements) should not include any identifying information, such as the authors' names or affiliations.

Use of word processing software

It is important that the file be saved in the native format of the word processor used. The text should be in single-column format. Keep the layout of the text as simple as possible. Most formatting codes will be removed and replaced on processing the article. In particular, do not use the word processor's options to justify text or to hyphenate words. However, do use bold face, italics, subscripts, superscripts etc. When preparing tables, if you are using a table grid, use only one grid for each individual table and not a grid for each row. If no grid is used, use tabs, not spaces, to align columns. The electronic text should be prepared in a way very similar to that of conventional manuscripts (see also the Guide to Publishing with Elsevier). Note that source files of figures, tables and text graphics will be required whether or not you embed your figures in the text. See also the section on Electronic artwork. 
To avoid unnecessary errors you are strongly advised to use the 'spell-check' and 'grammar-check' functions of your word processor.

\section{Length and Style of Manuscripts}

Full-length manuscripts should not exceed 35 pages total (including abstract, text, references, tables, and figures), double spaced with margins of at least 1 inch on all sides and a standard font (e.g., Times New Roman) of 12 points (no smaller).

Instructions on preparing tables, figures, references, metrics, and abstracts appear in the Publication Manual of the American Psychological Association (6th edition).

For helpful tips on APA style, click here.

\section{Article structure}

\section{Subdivision}

Divide your article into clearly defined sections. Three levels of headings are permitted. Level one and level two headings should appear on its own separate line; level three headings should include punctuation and run in with the first line of the paragraph.

\section{Introduction}

State the objectives of the work and provide an adequate background, avoiding a detailed literature survey or a summary of the results.

\section{Essential title page information}

- Title. Concise and informative. Titles are often used in information-retrieval systems. Avoid abbreviations and formulae where possible.

- Author names and affiliations. Please clearly indicate the given name(s) and family name(s) of each author and check that all names are accurately spelled. You can add your name between parentheses in your own script behind the English transliteration. Present the authors' affiliation addresses (where the actual work was done) below the names. Indicate all affiliations with a lower- case superscript letter immediately after the author's name and in front of the appropriate address. Provide the full postal address of each affiliation, including the country name and, if available, the e-mail address of each author.

- Corresponding author. Clearly indicate who will handle correspondence at all stages of refereeing and publication, also post-publication. This responsibility includes answering any future queries about Methodology and Materials.

Ensure that the e-mail address is given and that contact details are kept up to date by the corresponding author.

- Present/permanent address. If an author has moved since the work described in the article was done, or was visiting at the time, a 'Present address' (or 'Permanent address') may be indicated as a footnote to that author's name. The address at which the author actually did the work must be retained as the main, affiliation address. Superscript Arabic numerals are used for such footnotes. 


\section{Highlights}

Highlights are optional yet highly encouraged for this journal, as they increase the discoverability of your article via search engines. They consist of a short collection of bullet points that capture the novel results of your research as well as new methods that were used during the study (if any). Please have a look at the examples here: example Highlights.

Highlights should be submitted in a separate editable file in the online submission system. Please use 'Highlights' in the file name and include 3 to 5 bullet points (maximum 85 characters, including spaces, per bullet point).

Abstract

Abstracts should follow a structured format of no more than 250 words including the following sections: Background, Objective, Participants and Setting, Methods, Results (giving specific effect sizes and their statistical significance), and Conclusions.

\section{Keywords}

Immediately after the abstract, provide a maximum of 6 keywords, using American spelling and avoiding general and plural terms and multiple concepts (avoid, for example, 'and', 'of'). Be sparing with abbreviations: only abbreviations firmly established in the field may be eligible. These keywords will be used for indexing purposes.

Formatting of funding sources

List funding sources in this standard way to facilitate compliance to funder's requirements:

Funding: This work was supported by the National Institutes of Health [grant numbers xxxx, yyyy]; the Bill \& Melinda Gates Foundation, Seattle, WA [grant number zzzz]; and the United States Institutes of Peace [grant number aaaa].

It is not necessary to include detailed descriptions on the program or type of grants and awards. When funding is from a block grant or other resources available to a university, college, or other research institution, submit the name of the institute or organization that provided the funding.

If no funding has been provided for the research, please include the following sentence:

This research did not receive any specific grant from funding agencies in the public, commercial, or not-for-profit sectors.

\section{Footnotes}

The use of footnotes in the text is not permitted. Footnoted material must be incorporated into the text.

Table footnotes indicate each footnote in a table with a superscript lowercase letter.

\section{Tables}

Please submit tables as editable text and not as images. Tables can be placed either next to the relevant text in the article, or on separate page(s) at the end. Number tables consecutively in accordance with their appearance in the text and place any table notes below the table body. Be sparing in the use of tables and ensure that the data presented in them do not duplicate results described elsewhere in the article. Please avoid using vertical rules and shading in table cells. 
Citation in text

Please ensure that every reference cited in the text is also present in the reference list (and vice versa). Any references cited in the abstract must be given in full. Unpublished results and personal communications are not recommended in the reference list, but may be mentioned in the text. If these references are included in the reference list they should follow the standard reference style of the journal and should include a substitution of the publication date with either 'Unpublished results' or 'Personal communication'. Citation of a reference as 'in press' implies that the item has been accepted for publication.

\section{Web references}

As a minimum, the full URL should be given and the date when the reference was last accessed. Any further information, if known (DOI, author names, dates, reference to a source publication, etc.), should also be given. Web references can be listed separately (e.g., after the reference list) under a different heading if desired, or can be included in the reference list.

\section{Data references}

This journal encourages you to cite underlying or relevant datasets in your manuscript by citing them in your text and including a data reference in your Reference List. Data references should include the following elements: author name(s), dataset title, data repository, version (where available), year, and global persistent identifier. Add [dataset] immediately before the reference so we can properly identify it as a data reference. The [dataset] identifier will not appear in your published article.

References in a special issue

Please ensure that the words 'this issue' are added to any references in the list (and any citations in the text) to other articles in the same Special Issue.

\section{Reference management software}

Most Elsevier journals have their reference template available in many of the most popular reference management software products. These include all products that support Citation Style Language styles, such as Mendeley. Using citation plug-ins from these products, authors only need to select the appropriate journal template when preparing their article, after which citations and bibliographies will be automatically formatted in the journal's style. If no template is yet available for this journal, please follow the format of the sample references and citations as shown in this Guide. If you use reference management software, please ensure that you remove all field codes before submitting the electronic manuscript. More information on how to remove field codes from different reference management software.

Users of Mendeley Desktop can easily install the reference style for this journal by clicking the following link:

http://open.mendeley.com/use-citation-style/child-abuse-and-neglect

When preparing your manuscript, you will then be able to select this style using the Mendeley plug- ins for Microsoft Word or LibreOffice.

\section{Reference style}

Text: Citations in the text should follow the referencing style used by the American Psychological Association (view the APA Style Guide). You are referred to the Publication Manual of the American Psychological Association, Sixth Edition, ISBN 978-1-4338-0561-5.

List: references should be arranged first alphabetically and then further sorted chronologically if necessary. More than one reference from the same author(s) in the same year must be identified by the letters 'a', 'b', 'c', etc., placed after the year of publication.

[dataset] Oguro, M., Imahiro, S., Saito, S., Nakashizuka, T. (2015). Mortality data for Japanese oak wilt disease and surrounding forest compositions. 
Mendeley Data, v1. http://dx.doi.org/10.17632/ xwj98nb39r.1.

Examples:

Reference to a journal publication:

Van der Geer, J., Hanraads, J. A. J., \& Lupton, R. A. (2010). The art of writing a scientific article.

Journal of Scientific

Communications, 163, 51-59.

Reference to a book:

Strunk, W., Jr., \& White, E. B. (2000). The elements of style. (4th ed.). New York, NY: Longman. Reference to a chapter in an edited book:

Mettam, G. R., \& Adams, L. B. (2009). How to prepare an electronic version of your article. In $\mathrm{B}$.

S. Jones, \& R. Z. Smith (Eds.), Introduction to the electronic age (pp. 281-304). New York, NY: E- Publishing.

\section{Supplementary material}

Supplementary material such as applications, images and sound clips, can be published with your article to enhance it. Submitted supplementary items are published exactly as they are received (Excel or PowerPoint files will appear as such online). Please submit your material together with the article and supply a concise, descriptive caption for each supplementary file. If you wish to make changes to supplementary material during any stage of the process, please make sure to provide an updated file. Do not annotate any corrections on a previous version. Please switch off the 'Track Changes' option in Microsoft Office files as these will appear in the published version. 


\section{Appendix B: Example of STROBE Checklist Scoring}

STROBE Statement-Checklist of items that should be included in reports of cross-sectional studies

\begin{tabular}{|c|c|c|}
\hline & $\begin{array}{l}\text { Item } \\
\text { No }\end{array}$ & Recommendation \\
\hline \multirow[t]{2}{*}{ Title and abstract } & \multirow[t]{2}{*}{1} & (a) Indicate the study's design with a commonly used term in the title or the abstract \\
\hline & & $\begin{array}{l}\text { (b) Provide in the abstract an informative and balanced summary of what was done } \\
\text { and what was found }\end{array}$ \\
\hline \multicolumn{3}{|l|}{ Introduction } \\
\hline Background/rationale & 2 & Explain the scientific background and rationale for the investigation being reported \\
\hline Objectives & 3 & State specific objectives, including any prespecified hypotheses \\
\hline \multicolumn{3}{|l|}{ Methods } \\
\hline Study design & 4 & Present key elements of study design early in the paper \\
\hline Setting & 5 & $\begin{array}{l}\text { Describe the setting, locations, and relevant dates, including periods of recruitment, } \\
\text { exposure, follow-up, and data collection }\end{array}$ \\
\hline Participants & 6 & $\begin{array}{l}\text { (a) Give the eligibility criteria, and the sources and methods of selection of } \\
\text { participants }\end{array}$ \\
\hline Variables & 7 & $\begin{array}{l}\text { Clearly define all outcomes, exposures, predictors, potential confounders, and effect } \\
\text { modifiers. Give diagnostic criteria, if applicable }\end{array}$ \\
\hline $\begin{array}{l}\text { Data sources/ } \\
\text { measurement }\end{array}$ & $8^{4}$ & $\begin{array}{l}\text { For each variable of interest, give sources of data and details of methods of } \\
\text { assessment (measurement). Describe comparability of assessment methods if there is } \\
\text { morc than one group }\end{array}$ \\
\hline Bias & 9 & Describe any efforts to address potential sources of bias \\
\hline Study size & 10 & Explain how the study size was arrived at \\
\hline Quantitative variables & 11 & $\begin{array}{l}\text { Explain how quantitative variables were handled in the analyses. If applicable, } \\
\text { describe which groupings were chosen and why }\end{array}$ \\
\hline \multirow[t]{5}{*}{ Statistical methods } & \multirow[t]{5}{*}{12} & (a) Describe all statistical methods, including those used to control for confounding \\
\hline & & (b) Describe any methods used to examine subgroups and interactions \\
\hline & & (c) Explain how missing data were adidressed \\
\hline & & (d) If applicable, describe analytical methods taking account of sampling strategy \\
\hline & & (e) Describe any sensitivity analyses \\
\hline \multicolumn{3}{|l|}{ Results } \\
\hline \multirow[t]{3}{*}{ Participants } & \multirow[t]{3}{*}{$13^{*}$} & $\begin{array}{l}\text { (a) Report numbers of individuals at each stage of study eg numbers potentially } \\
\text { eligible, examined for eligibility, confimed eligible, included in the study, } \\
\text { completing follow-up, and analysed }\end{array}$ \\
\hline & & (b) Give reasons for non-participation at each stage \\
\hline & & (c) Consider use of a flow diagram \\
\hline \multirow[t]{2}{*}{ Descriptive data } & \multirow[t]{2}{*}{$14^{*}$} & $\begin{array}{l}\text { (a) Give characteristics of study participants (eg demographic, clinical, social) and } \\
\text { information on exposures and potential confounders }\end{array}$ \\
\hline & & (b) Indicate number of participants with missing data for each variable of interest \\
\hline Outcome data & $15^{*}$ & Report numbers of outcome events or summary measures \\
\hline \multirow[t]{3}{*}{ Main results } & \multirow[t]{3}{*}{16} & $\begin{array}{l}\text { (a) Give unadjusted estimates and, if applicable, confounder-adjusted estimates and } \\
\text { their precision (eg, } 95 \% \text { confidence interval). Make clear which confounders were } \\
\text { adjusted for and why they were included }\end{array}$ \\
\hline & & (b) Report category boundaries when continuous variables were categorized \\
\hline & & $\begin{array}{l}\text { (c) If relevant, consider translating estimates of relative risk into absolute risk for a } \\
\text { meaningful time period }\end{array}$ \\
\hline Other analyses & 17 & $\begin{array}{l}\text { Report other analyses done-eg analyses of subgroups and interactions, and } \\
\text { sensitivity analyses }\end{array}$ \\
\hline
\end{tabular}


WHAT IS VALUED FROM CHILD SEXUAL EXPLOITATION SERVICES? 57

\begin{tabular}{|c|c|c|}
\hline \multicolumn{3}{|l|}{ Discussion } \\
\hline Key results & 18 & Summarise key results with reference to study objectives \\
\hline Limitations & 19 & $\begin{array}{l}\text { Discuss limitations of the study, taking into account sources of potential bias or } \\
\text { imprecision. Discuss both direction and magnitude of any potential bias }\end{array}$ \\
\hline Interpretation & 20 & $\begin{array}{l}\text { Give a cautious overall interpretation of results considering objectives, limitations, } \\
\text { multiplicity of analyses, results from similar studies, and other relevant evidence }\end{array}$ \\
\hline Gencralisability & 21 & Discuss the generalisability (external validity) of the study results \\
\hline \multicolumn{3}{|c|}{ Other information } \\
\hline Funding & 22 & $\begin{array}{l}\text { Give the source of funding and the role of the funders for the present study and, if } \\
\text { applicable, for the original study on which the present article is based }\end{array}$ \\
\hline
\end{tabular}

*Give information separately for exposed and unexposed groups.

Note: An Explanation and Elaboration article discusses each checklist item and gives methodological background and published examples of transparent reporting. The STROBE checklist is best used in conjunction with this article (freely available on the Web sites of PLoS Medicine at http://www. plosmedicine.org/, Annals of Internal Medicine at http:/www,annals.org/, and Epidemiology at http://www.epidem.com/). Information on the STROBE Initiative is available at www.strobe-statement,org. 
Critical appraisal - Landers, Me Grath, Johnson, Armshong + Dohlard 2017.

- STROBE - cross-sectional checklist

la) design nor indicated in title or abstract $x$ (0)

b) abstrat balanced summary, could be more detcilled $\checkmark$ (1)

2) background and rationase is reported $\checkmark$ (1)

3) objectives clearly set out in introduction $v$ (1)

4) explains the design is an explovatory analysis of baseline data $\vee$ (1)

5) setting - Miami (location) - date 2013-2015

6) Criteria + selection process

7) outcomes are defined-trauma, symptoms the $v$ (1)

8) CANS- CSE measure explained + collection clear $V$ (1)

9) no discussion of efforts to address bias $x$ (0)

10) doesn't explain how $n=87$ was amied at $x$. (0)

11) Variables - descripttive analyses explained $\checkmark$ (1)

12) a) NIA

b) NIA

c) highlighed where missing data had been removed $V$ (1)

d) $N / A$

t) $N / A$ 
13)a) numbers clearly outlined for each variable $\checkmark$ (1)

b) no mention of why some questions weren't answered $V(1)$ c) NIA - flow diagram nor requitd

14)a) demographics are descuissed

b) missing data shown $V$ (1)

15) outcomes reponed $\checkmark$ (1)

16)a) $N I A$

b) $N I A$

c) NIA

17) NIA

18) Key results summarised $\checkmark$ (1)

19) Limirations are nor reponed $x$ (0)

20) overall interpreration - linked to evidence $\checkmark$ (1)

21) generalisability / external validity not discussed $x$ (0)

22) funding is reponed $\checkmark$ (1)

otal $\quad 19$ out of 23




\section{Appendix C: Example of CASP Checklist Scoring}
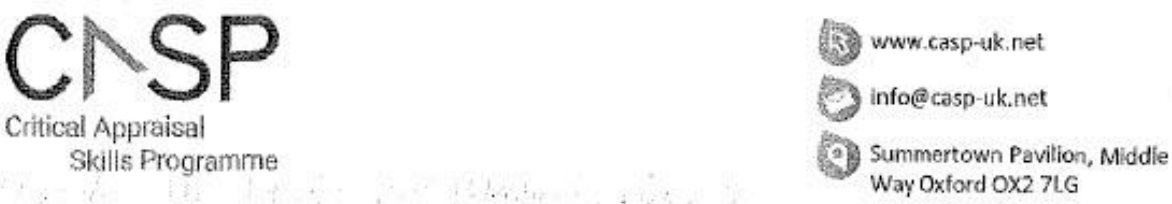

CASP Checklist: 10 questions to help you make sense of a Qualitative research

How to use this appraisal tool: Three broad issues need to be considered when appraising a qualitative study:
$\Lambda$ Are the results of the study valid? (Section A)
$N$ what are the results? $\quad$ (Section $B$ )
N. Will the results help locally? . (Section C].

The 10 questions on the following pages are designed to help you think about these issues systematically. The first two questions are screening questions and can be answered quickly. If the answer to both is "yes", it is worth proceeding with the remaining questions. There is some degree of overlap between the questions, you are asked to record a "yes", "no" or "can't tell" to most of the questions. A number of italicised prompts are given after each question. These are designed to remind you why the question is important. Record your reasons for your answers in the spaces provided.

About: These checklists were designed to be used as educational pedagogic tools, as part of a workshop setting, therefore we do not suggest a scoring system. The core CASP checklists (randomised controlled trial \& systematic review) were based on JAMA 'Users' guides to the medical literature 1994 (adapted from Guyatt GH, Sackett DL, and Cook DJ), and piloted with health care practitioners.

For each new checklist, a group of experts were assembled to develop and pilot the checklist and the workshop format with which it would be used. Over the years overall adjustments have been made to the format, but a recent survey of checklist users reiterated that the basic format continues to be useful and appropriate.

Referencing: we recommend using the Harvard style citation, i.e.: Critical Appraisal Skills Programme (2018). CASP (insert name of checklist i.e. Qualitative) Checkfist. [online] Available at: URL. Accessed: Dote Accessed.

(C) CASP this work is licensed under the Creative Commons Attribution - Non-CommercialShare A like. To vlew a copy of this license, visit http://creativecommons.org/licenses/by-ncsa/3.0/ www.casp-uk.net 


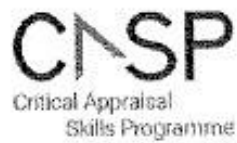

Paper for appraisal and reference: Volg in ... Shakespeare - funch and Schocher Section A: Are the results valid?

1. Was there a cleat statement of the aims of the research?

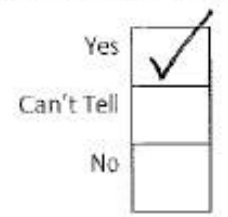

HINT: Consider

- what was the goal of the research - why it was thought important

- its relevance

Comments: post-traumatic growth and distress

lasger ethnographic project in Nepal

2. Is a qualitative methodolony

appropriate?

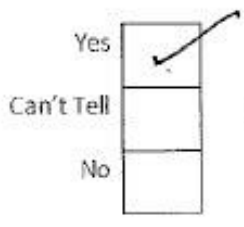

If the research seeks to intorpret or illuminate the actions and/or subjective experiences of research participants

- Is qualitative research the right methodology for addressing the research goal

Comments:

concerned with the Subjective experences of givis and women who have experienced sexual exploitation

Is it warth continuing?

3. Was the research design appropriate to address the aims of the research?

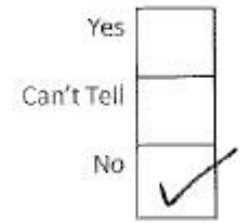

HINT: Consider - if the researcher has justified the research design (e.g. have they discussed how they decided which method to use)

Comments:

this was nor discussed / justified 


\section{CNSP}

Sikills Programme

4. Was the recruitment strategy appropriate to the aims of the research?

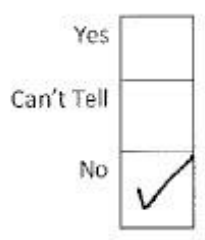

HINT: Consider

- If the researcher has explained how the participants were selected - If they explained why the participants they selected were the most appropriate to provide access to the type of knowledge sought by the study

- If there are any discussions around recruitment (e.g. why some peaple chose not to take part)

\section{Comments: \\ did not explain how participants were selected or approached, and did nor repor if any chose not to take part}

5. Was the data collected in a way that addressed the research issue?

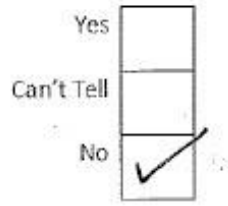

- If the researcher has justified the methods

- If the researcher has made the method explicit le.g. for interview method, is there an indication of how interviews are conducted, or did they use a topic guide) - If methods were modified during the study. If so, has the researcher explained how and why - If the form of data is clear (e.g. tape recordings, video material, notes etc.] - If the researcher has discussed saturation of data

\section{not fully clear how data was collected, variety} of forms-not all explained 


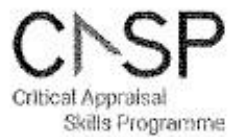

6. Has the relacionship between researcher and participants been adequately considered?

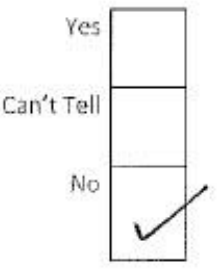

HINT: Conside

- If the researcher critically examined their own role, potential bias and influerce during (a) formulation of the research questions (b) data collection, including sample recruitment and cholce of Ioration

- How the researcher responded to events during the study and whether they considered the implications of any changes in the research design

Comments:

no critical analysis of own role in collecting data / interpretations

Section $B$ : What axe the results?

7. Have ethical issues been taken into consideration?

$$
\begin{aligned}
& \text { Yes } \square \text { HINT: Consider } \\
& \text { study) }
\end{aligned}
$$

\section{did nor discuss how informed consent was acheired}


8. Was the data analysis sufficiently rigorous?

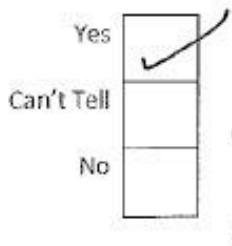

HINT: Conside

- If there is an indepth description of the

analysis proress

- If thematic analysis is used. If so, is it clear how the categories/themes were derived

from the data

- Whether the researcher explains how the date presented were selected from the original sample to demonstrate the analysis process

- If sufficient data are presented to support the findings

- To what extent contradictory data are taken into account

- Whether the researcher critically examined their awn role, potential bias and influence during analysis and selection of clata for presentation

\section{process of analysis described in detai - thematic}

9. Is there a clear statement of findings?

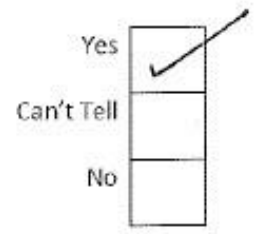

HINT: Consider whether - If the findings are explicit - If there is adequate discussion of the evidence both for and against the researcher's arguments

- If the researcher has discussed the credibility of their findings le.s. triangulation, respondent validation, more than one analyst,

- If the findings are discussed in relation to the original research question

$$
\text { discussed in detail t illustrated with quotes }
$$




\section{$\mathrm{C} S \mathrm{SP}$ \\ Skils Programine}

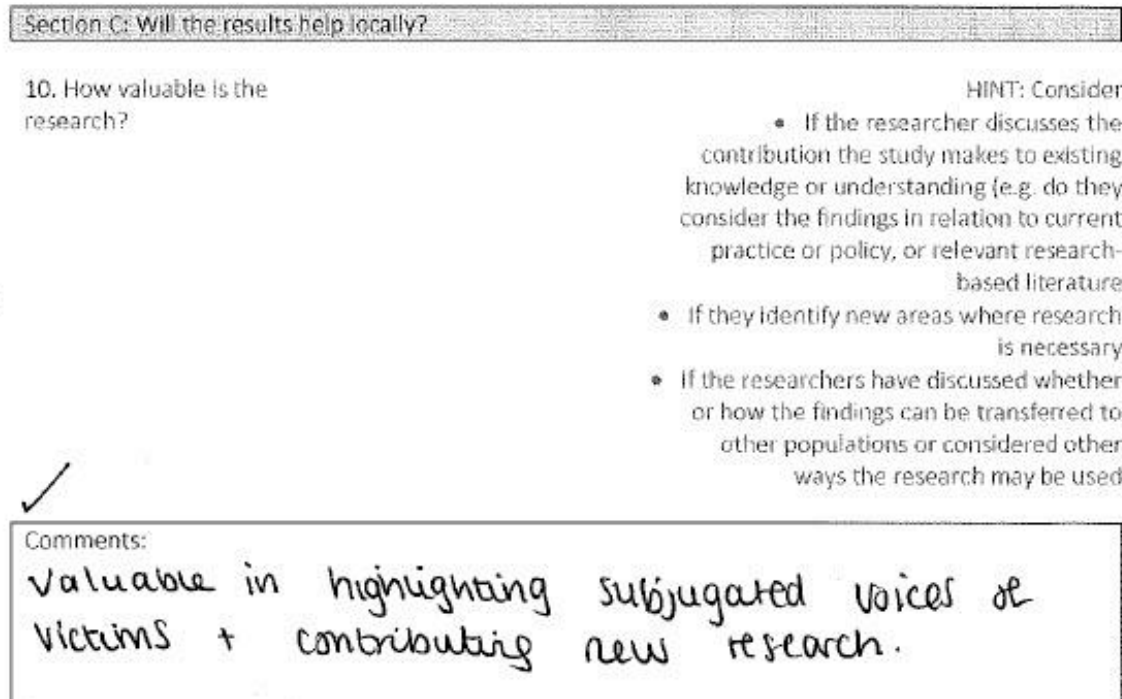

toral - 5 out of 10 
Chapter Two: Empirical Paper

'Using Q-methodology to explore what is valued from child sexual exploitation services: The importance of safety'

\author{
Jennifer Barrow
}

Professional Doctorate in Clinical Psychology

School of Life Sciences and Education, Staffordshire University

Word Count: 7997 


\begin{abstract}
Child Sexual Exploitation (CSE) is a complex national and international issue requiring specialist multi-agency support. There is some evidence that survivors of CSE are likely to experience mental health difficulties and have long-term additional psychological needs in response to their trauma. However, the evidence regarding services and interventions for these difficulties is limited. The present study explored the viewpoints of key stakeholders, such as young people and frontline staff members, about CSE services.
\end{abstract}

Participants were recruited from services that support young people who have experienced CSE. The sample consisted of 18 participants, nine young people and nine professionals. Q-methodology was used to investigate subjective viewpoints regarding this specific topic. Statements related to CSE interventions and services were collected from the existing literature and validated to form a Q-set. Participants sorted the Q-set from most to least important. Completed Q-sorts were subjected to factor analysis using Q-methodology software.

Three factors were identified: (1) The importance of safety and attunement, (2) Managing trauma and mental health difficulties and (3) Family, normality, and a relaxed approach. All three factors emphasised the importance of safety and trusting relationships between young people and professionals.

These three factors identified key areas that service design would benefit from considering. Primarily, young people are likely to benefit from specialist support provided by services which promote a relational approach to effectively meet the psychological needs of their service users. It is proposed that clinical psychologists are one of the disciplines that would be well placed to support this development.

Keywords: Child sexual exploitation, child sexual abuse, protection, service design, q-methodology 


\section{Introduction}

\section{Defining Child Sexual Exploitation}

In the United Kingdom (UK), Child Sexual Exploitation (CSE) is defined as a form of Child Sexual Abuse (CSA) that includes an exchange between the child and perpetrator(s), involving a power imbalance in order to coerce the child into some form of sexual activity (Department for Education, 2017). The differentiating feature is the 'exchange' of some form between the young person and perpetrator(s) - in which the young person receives something in return for the sexual activity (for example alcohol), or the activity prevents something negative from happening to the young person (Beckett et al., 2017). CSE was historically defined as 'child prostitution' in the UK, until 2005 when the English and Welsh governments moved towards a protective approach to working with young people and away from a criminal justice response (Beckett \& Pearce, 2018). To differentiate further between CSE and CSA, the Department for Education (2017) have emphasised that cases are only defined as CSE if the 'exchange' is core to the issue, rather than incidental such as the receipt a gift or treat from an abuser in the case of CSA. This differentiation is difficult to ascertain in practice, blurring the lines between the two different but related forms of sexual abuse.

The concept of an 'exchange' can be offensive to people who have experienced CSE as it may imply that the abuse was reciprocal (Woodhouse, 2018). Although this study focuses on young people, it is recognised that CSE is unquestionably instigated by perpetrators (Department for Education, 2017). Beckett et al. (2017) emphasise the view that although the young person may receive something as part of the 'exchange', the power imbalance must not be overlooked.

Due to the hidden nature, evolving definitions, and difficulty capturing CSE in some crime reporting procedures, the prevalence of CSE in the UK is currently unconfirmed (Barnardo's, 2011; Research in Practice, 2017). A further layer of complexity is added when young people involved do not consider themselves as being abused or exploited (Beckett et al., 2017). Chase and Statham (2005) reviewed the available literature and statistical data regarding the scale of CSE in 2003, and reported that it was difficult to quantify. It has previously been estimated that the number of young people being sexually exploited ranges from 2000 to 5000 per year 
(Barrett, 1998; Bluett et al., 2000). The Department for Education (2017) advises that professionals should practice as though CSE is occurring in all areas of the UK and that any child can be affected. CSE is a complex issue, requiring specialist input across all sectors, including health, social care, education, the police, and third-sector organisations (Department for Education, 2017; HM Government, 2018). Within the context of the UK, experiences of CSE are considerably varied, but may be characterised by gang involvement, or being coerced into sexual activity (online or offline) with one or more perpetrators under the guise of being in a relationship with the lead perpetrator (Beckett et al. 2017).

\section{Support for Survivors of CSE}

It is essential to clarify the above differences between CSE and CSA to support practitioners in recognising when CSE is occurring and to highlight opportunities to practice in a way that recognises the complexity of the situation. It has been suggested by Beckett et al. (2017) that, when a young person is in receipt of something from a perpetrator, it becomes more difficult to identify the presence of abuse. Furthermore, the absence of a clear definition for CSE, and how it differs from an unhealthy adolescent sexual relationship, may potentially be influencing the current difficulties with implementing service guidance. This is further exacerbated by the complexity of CSE, as the variety of support that is offered from different sectors suggests that there is no clearly focused intervention pathway for young people, which could be unhelpful. Following a number of highly publicised legal cases, such as the investigation into Rotherham Metropolitan Borough Council in the Jay report (2014), awareness of the factors contributing to a young person's vulnerability has increased and the research evidence-base has started to develop (Beckett \& Pearce, 2018). However, there are ongoing barriers to fully understanding effective ways of working with young people who have experienced sexual exploitation and, consequently, how evidence-based practice can be embedded into service design and development (Department for Education, 2016).

There are currently differences in the services offered to young people in England who are at risk of, or have experienced, CSE (Beckett \& Pearce, 2018). Young people are initially assessed by specialised multi-agency teams that usually sit within the police or local authority, for example the EXIT team in Bolton, Greater 
Manchester (Bolton Safeguarding Children, 2020). Assessments focus on the future risk of the young person experiencing CSE and the extent of any historical or ongoing exploitation (HM Government, 2018). Alongside safeguarding processes, some young people may receive specialist outreach support in conjunction with third sector organisations, such as Barnardo's. These multi-agency teams are often key providers of support. Community outreach support is designed to work from a preventative position with young people, by reducing the risk of initial or repeated CSE and building resilience. The aim of this support is to reduce potential or repeated risk through an educational model by disrupting relationships between young people and perpetrators, for example by teaching young people about safe sex and consent (Barnardo's, 2017). Young people who have already experienced CSE may also be supported by third-sector organisations to access counselling and engage with criminal justice proceedings.

In 2016, the Department for Education commissioned a study into residential CSE support, finding that residential homes tend to offer intensive therapeutic support alongside an educational model (Department for Education, 2016). The study also concluded that there are increasing numbers of CSE tools and educational programmes being developed, which require further evaluation in order to support guidance on effective practice. It is suggested that as residential services are working with young people who may be highly-traumatised, there is a need for long-term trauma-informed support. This study also highlighted that working with families is an often overlooked but important aspect of care. Overall the study recommended that effective practice should be similar to residential services in general, by working to build relational safety, meaningfully involving young people in decisions about their care and placing an emphasis on efficient inter-agency working. Frost (2019) also emphasised the importance of building trust, based upon interviews with professionals working in CSE services.

CSE survivors may share similar difficulties with other young people who have been placed under Local Authority care (Looked After Children), such as responses to traumatic experiences or insecure attachments (Hickle, 2019; Luxmoore, 2019). Herman (1992) recommends that recovery from trauma should be placed within the context of interpersonal relationships, suggesting that recovery is positively influenced by psychological safety. It is also advised that residential services for 
Looked After Children utilise therapeutic models of care that are underpinned by attachment theory, such as those developed by Kim Golding (Golding et al., 2009). In his theory of attachment, Bowlby proposes that human interpersonal relationships are defined by the emotional bond between a baby and their primary caregiver (Bowlby, 1969). A secure attachment between a baby and their caregiver is characterised by a feeling of psychological connectedness, allowing for the caregiver to be fully attuned to the baby's physical, social and emotional needs (Ainsworth, 1973). Golding et al. (2009) highlight that insecure attachment can affect a young person's ability to develop trusting relationships with carers and can impact their psychological wellbeing, recommending that attachment principles are integrated into the delivery of residential care.

\section{$\underline{\text { Service Development }}$}

Access to CSE interventions is not always readily available to those who need it. One issue underlying some of the responses to young people who have experienced CSE are victim-blaming judgements, such as labelling the child as promiscuous or troublesome, rather than troubled (Bedford, 2015). It has been proposed that in order for CSE services to be successful, there should be a decrease in 'risk behaviours' such as running away, and that young people should be more able to recognise and protect themselves from exploitative relationships (Barnardo's, 2017). Hallett (2016) argues that there is a significant need to address the complex issues underpinning CSE and "to open up the possibility of interventions beyond narrow child protection responses" (pp. 2150). The guidance for practitioners from the Department for Education (2017) highlights the importance of relationship-based care that moves away from a blaming position. There has been some shift in focus since 2006 towards a more protective and trauma-informed approach, but outcome data suggests that there is more work to be done in improving services (Research in Practice, 2017).

To support ongoing service development as part of the Greater Manchester CSE project, a scoping exercise of available CSE services and interventions was completed in 2015 and further revised in 2017 by Research in Practice. Whilst exploring the most useful aspects of how services have responded to CSE, there is currently "no one gold standard model" for service design and delivery, and that 
there is a need for more coherent, evidence-based intervention strategies (Research in Practice, 2017, p. 14). Furthermore, Pearce (2014) reported that many services have not responded to the service recommendations that have been set out in statutory guidance.

\section{$\underline{\text { A Role for Clinical Psychology }}$}

It is recommended that all practitioners, at any level and working for any agency, must be capable of recognising and responding to CSE (Pearce, 2014). Additionally, professionals who are working with CSE survivors should have an understanding of psychological needs, as children who have experienced CSE are likely to be experiencing complex difficulties that may have existed prior to their exploitation and then further complicated by it (Beckett et al., 2017).

Clinical psychologists are largely based in public healthcare settings or non-CSE specific third sector organisations; therefore, their direct input into specialist CSE services is not always possible. Their input appears to be particularly unavailable if young people do not meet the threshold to access statutory mental health services. However, there are increasing numbers of clinical psychologists working within local authority social care teams and specialist CSE residential services, who are well placed to support effective service design that incorporates psychological thinking and approaches (Golding et al., 2009).

$\underline{\text { Aim }}$

It is important to explore how CSE services should operate effectively and meet the psychological needs of young people who have experienced and, quite possibly, been traumatised by CSE. It is necessary, therefore, to investigate the views of young people about how they experience accessing and using these services. Warrington (2013, 2016) argued that empowerment through participation can help young people in their recovery from CSE by allowing a space for their often subjugated voices.

The aim of this study is to give young people an opportunity to voice their views on CSE services and to further understand the variety of perspectives of both young people engaging with CSE services and the staff members that work alongside them. The viewpoints of these key stakeholders can then be used to aid service design and delivery. 


\section{Epistemological position}

The main author in this study holds a social constructionist epistemological position, believing that all individuals construct their own reality as they learn from social interactions and observations of others (Berger \& Luckmann, 1966). This position emphasises the existence of multiple realities and is in concordance with the principle aim of Q methodology, which is to explore and value subjective viewpoints (Watts \& Stenner, 2012).

\section{Method}

\section{$\underline{\text { Ethics }}$}

After peer-review of the study protocol, ethical approval was granted by the sponsor, Staffordshire University (Appendix B). Support with the recruitment and conduct of the research was then confirmed by three organisations approached by the researcher. Following participation, people were given two weeks to withdraw their data using their individual randomised number. No participants withdrew their consent for their data to be included.

For young people under the age of 16 who had consented to participate, either parents or social workers also provided their consent. For ethical reasons, young people in distress or significantly self-harming were excluded from the recruitment process, to reduce potential further distress.

\section{$\underline{\text { Design }}$}

The present study used a cross-sectional design. Within Q-methodology, statements relating to the research topic (the Q-set) are sorted onto a grid (the Q-sort). Ranking the Q-set (e.g. from most to least important) allows the exploration of how people construct meaning and develop an overall viewpoint. By analysing whether their viewpoints differ or are similar to each other, it is possible to reduce these individual viewpoints into common factors (Watts \& Stenner, 2005). Through generating statements from research, guidance and the media, Q-Methodology draws upon information already available within the general discourse. This reduces researcher 
bias by ensuring that the statements chosen for the Q-set are not solely related to the researcher's own position, but are derived from the population in question.

The Q-sort is an interactive task that can be carried out with children and adults, as well as being suitable for both service users and professionals. This allows for a direct comparison of data from a range of different stakeholders. Most importantly, Q-methodology aims to ensure that all voices are heard, including those that would be otherwise subjugated, such as the voices of children or members of staff who are not routinely asked their opinion about services. Such views are considered in equal weight as the views that are more often amplified in research and practice, such as those of senior clinicians.

Employing this methodology - which uses generalised rather than personal statements - meant that young people were not asked to disclose their own stories or details of how they arrived into services. This was to enable them to feel safer in expressing their views. It is a sensitive method that fits with the complex and often traumatic experiences that occur within CSE.

\section{$\underline{\text { Recruitment }}$}

The research sites were across three organisations, consisting of residential CSE care homes, community outreach CSE support and a child psychology social enterprise service. Services were based across the North and West Midlands regions of the UK. Extensive liaison with staff members and service managers regarding risk was conducted throughout the recruitment process, including before, during and after data collection. The researcher initially visited services to introduce themselves and provided study information sheets (Appendices $C$ and D), with young people aged 13 to 18 and staff members invited to take part. After a minimum period of two weeks, service managers were contacted to identify the young people who had expressed an interest. Service managers were responsible for the risk assessment of the identified participants' psychological wellbeing, to ensure their safety throughout the recruitment and data collection process. All young people identified were assessed as able to participate in the study. The researcher then returned to research sites to conduct the data collection. If they were willing to participate, the consent forms (Appendices E and F) were given for signature. Separate information sheets and consent forms were used for the young people and professionals to ensure the 
information was accessible for each. For those younger than 16, social workers or parents completed the relevant section of the consent form. One young person opted out upon the researcher returning to their service.

\section{$\underline{\text { Participants }}$}

The purposive sample consisted of 18 participants $(n=18)$, nine participants were young people who were engaging with CSE services and nine participants were professionals. Tables 1 and 2 demonstrate the sample characteristics.

\section{Table 1}

Sample Characteristics - Young People $(n=9)$

\begin{tabular}{lll}
\hline Characteristic & Category & $\begin{array}{l}\text { Number of } \\
\text { participants }\end{array}$ \\
\hline Gender & Female & 8 \\
& Male & 1 \\
\hline Age & 15 & 3 \\
& 16 & 4 \\
& 17 & 1 \\
& 18 & 1 \\
\hline
\end{tabular}




\section{Table 2}

Sample Characteristics - Professionals $(n=9)$

\begin{tabular}{lll} 
Characteristic & Category & $\begin{array}{l}\text { Number of } \\
\text { participants }\end{array}$ \\
\hline Gender & Female & 9 \\
& Male & 0 \\
\hline Age & $18-30$ & 4 \\
& $31-50$ & 4 \\
& $50-65$ & 1 \\
\hline Role & Residential Care Worker & 1 \\
& Outreach Worker & 1 \\
& Outreach Team Manager & 1 \\
& Assistant Psychologist & 3 \\
& Volunteer and Research & 1 \\
& Coordinator & \\
Clinical Psychologist & 1 \\
Counselling Psychologist & 1 \\
\hline
\end{tabular}

\section{$\underline{\text { Materials }}$}

A fundamental element of Q-methodology is the development of the Q-set, which should be representative of the chosen topic (van Exel \& de Graaf, 2005) and derived from a range of different sources (Stephenson, 1953). The researcher gathered statements from reviewing the CSE literature, adopting an inductive approach based on the themes emerging. Duplicates were removed, resulting in the generation of 45 statements. Feedback on the statements was provided by: a clinical psychologist based in a CSE service, peers familiar with Q-methodology, the researcher's Q-methodology supervisor, and an adult who had historically engaged with CSE services. This strengthened both the content and face validity of the statements and improved readability. Statements were refined to include their further suggestions; forming the concourse and bringing the final Q-set to 54 (see Appendix G). Each statement was printed onto square cards of equal size, and numbered 1 to 54 on the reverse. Velcro was used to place the squares onto a Q-grid and rearrange 
them with ease. The Q-grid was marked out onto an A0 size board in the shape of a normal distribution curve, with 11 columns ranked from -5 (least important) to +5 (most important), as depicted in Figure 1.

\section{Figure 1}

Blank Q-grid

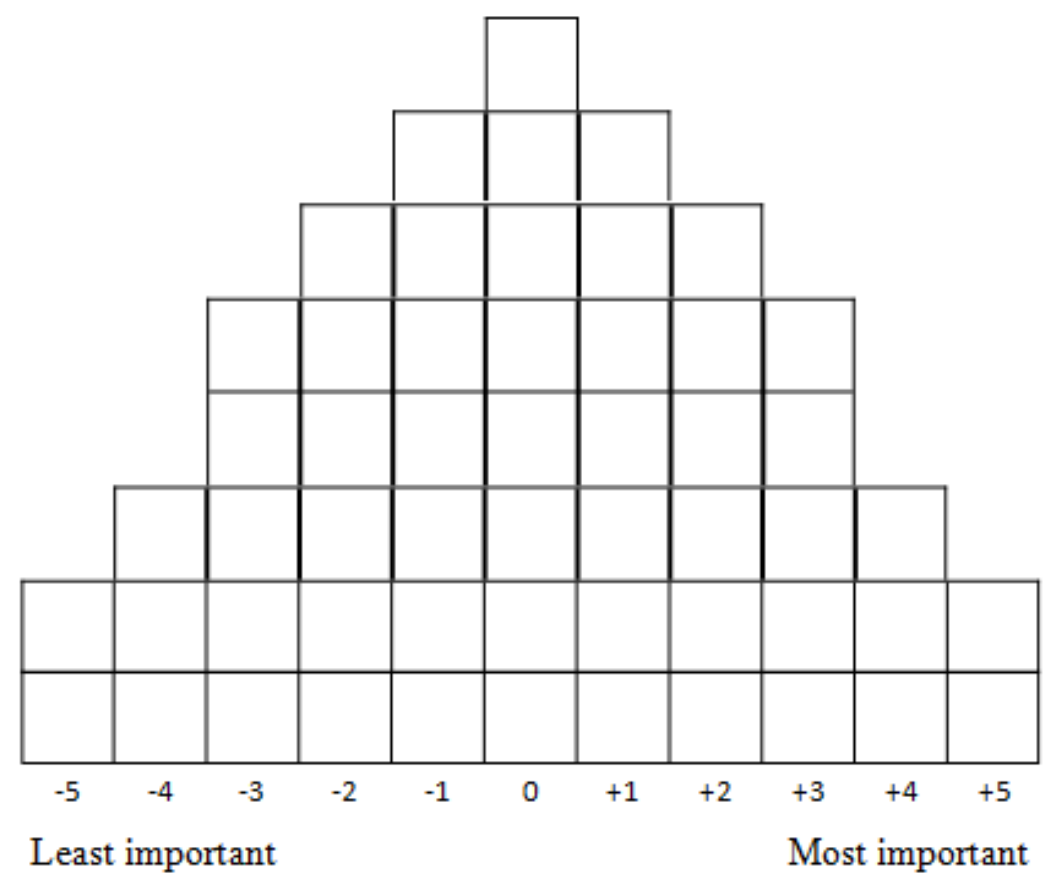

A brief demographic questionnaire recorded participants' age, gender, and their professional role where applicable (Appendix H) to support the interpretation of the factors emerging from the analysis, such as by looking at whether a particular viewpoint was more frequently expressed by professional participants. A supplementary questionnaire (Appendix I) was also used after the sorting process to elicit reflections on the process of completing the task and provide a space to explain their reasoning for statement rankings if desired. Participants were also given the opportunity to add their suggestions for any other aspects of CSE services or interventions that the researcher may have missed from the Q-set. 


\section{$\underline{\text { Procedure }}$}

The researcher initially completed the demographic questionnaire with participants. The Q-sort process required participants to read through each of the 54 statements and to allocate them into one of three categories based on their own views and experiences; the three categories were 'most important', 'least important' or 'indifferent/unsure'. Participants were then asked to rank the importance of the statements within the three categories into which they had initially sorted them. First, they ranked their 'most important' statements by placing them onto the Q-grid, then, their 'least important' statements, and, finally, their 'indifferent' statements. Participants were asked to complete the sort in a forced choice manner, i.e. putting only one statement in each box and only placing statements within the confines of the grid. This approach was chosen in order to make the sorting process as simple as possible and to standardise the procedure across participants.

Following the Q-sort, the researcher completed the supplementary questionnaire, noting down key responses from participants verbatim. These responses were related to the process of the Q-sort and/or any further experiences of CSE services that they wished to share, without pressure or expectation from the researcher. The researcher then recorded each sort on a spreadsheet using the numbers on the reverse of the statements.

\section{Method of analysis}

Using Q-methodology, the inter-subjective beliefs of young people and staff members associated with CSE services, regarding the most important aspects of services and interventions were investigated. In contrast to typical factor analysis, Qmethodology views the participants as the variables instead of the statements. Therefore, each individual Q-sort is compared with another in a by-person factor analysis, resulting in the emergence of factors that are characterised by similar viewpoints. Individual Q-sorts that significantly load onto a factor are combined to provide an average configuration that is representative of each of the sorts included. This is known as the ideal factor array and provides the starting point for the meaningful interpretation of the factor (Watts \& Stenner, 2005). 


\section{Results}

\section{Data Analysis}

The 54 statements of the Q-set and the 18 completed Q-sorts were entered into a software programme designed to conduct Q-methodology analysis, Ken-Q (version 1.0.6. Banasick, 2019). Relationships between the different Q-sorts are indicated by the correlation calculations depicted in Table 3. The threshold for a significant correlation was calculated to be $\geq 0.27$ using the formula from Brown (1980): $p<0.05$ $=1.96 \times(1 / \sqrt{ }$ number of statements in Q-set $)=1.96 \times(1 / \sqrt{ } 54)$. Each Q-sort, other than Q-sort 14, significantly correlated with at least four other Q-sorts, demonstrating similarity across the viewpoints.

Using the Ken-Q software (Banasick, 2019), Q-sort data was then subjected to a factor analysis to highlight any latent variables that would explain the relationships between the sorts (Howitt \& Cramer, 2010). Reducing large numbers of variables (in this case, 18 Q-sorts of 54 statements) into factors allows for the extraction of themes that illustrate the key viewpoints (Stephenson, 1953). Centroid factor analysis identified seven possible factors from the dataset (Table 4). 


\section{Table 3}

Correlation Matrix

\begin{tabular}{|c|c|c|c|c|c|c|c|c|c|c|c|c|c|c|c|c|c|c|}
\hline Q-sort & 1 & 2 & 3 & 4 & 5 & 6 & 7 & 8 & 9 & 10 & 11 & 12 & 13 & 14 & 15 & 16 & 17 & 18 \\
\hline 1 & 1.00 & 0.18 & $0.44 *$ & 0.18 & $0.32 *$ & 0.17 & $0.31 *$ & $0.36^{*}$ & -0.05 & $0.42 *$ & 0.26 & $0.31 *$ & $0.39 *$ & 0.03 & $0.27 *$ & $0.38 *$ & $0.38 *$ & 0.24 \\
\hline 2 & & 1.00 & $0.32 *$ & $0.69 *$ & 0.23 & $0.43^{*}$ & $0.38 *$ & $0.45^{*}$ & $0.34 *$ & $0.65^{*}$ & $0.41 *$ & $0.37 *$ & 0.19 & 0.03 & 0.10 & 0.20 & 0.16 & $0.27 *$ \\
\hline 3 & & & 1.00 & 0.21 & -0.07 & 0.14 & 0.17 & $0.27 *$ & -0.07 & $0.32 *$ & 0.24 & 0.02 & 0.11 & 0.00 & 0.23 & $0.36^{*}$ & $0.41 *$ & 0.17 \\
\hline 4 & & & & 1.00 & $0.31^{*}$ & $0.49 *$ & $0.48 *$ & $0.47 *$ & $0.32 *$ & $0.44 *$ & $0.56^{*}$ & $0.44^{*}$ & $0.34 *$ & 0.06 & 0.08 & $0.31 *$ & 0.07 & $0.45^{*}$ \\
\hline 5 & & & & & 1.00 & $0.42 *$ & $0.43 *$ & $0.32 *$ & 0.09 & $0.28 *$ & 0.20 & $0.42 *$ & $0.53 *$ & 0.24 & 0.14 & 0.18 & 0.14 & $0.37 *$ \\
\hline 6 & & & & & & 1.00 & $0.47 *$ & $0.50 *$ & $0.40^{*}$ & $0.36^{*}$ & $0.38 *$ & $0.53 *$ & $0.37 *$ & 0.26 & 0.12 & $0.29 *$ & 0.13 & $0.56^{*}$ \\
\hline 7 & & & & & & & 1.00 & $0.63 *$ & $0.44^{*}$ & $0.40 *$ & $0.64 *$ & $0.65^{*}$ & $0.41 *$ & 0.08 & 0.09 & $0.36^{*}$ & -0.03 & $0.39 *$ \\
\hline 8 & & & & & & & & 1.00 & $0.41^{*}$ & $0.46^{*}$ & $0.48 *$ & $0.54 *$ & $0.46^{*}$ & -0.14 & $0.31 *$ & $0.42 *$ & -0.04 & $0.51 *$ \\
\hline 9 & & & & & & & & & 1.00 & $0.32 *$ & $0.41^{*}$ & $0.41^{*}$ & 0.13 & -0.01 & 0.08 & 0.13 & -0.15 & 0.21 \\
\hline 10 & & & & & & & & & & 1.00 & $0.38 *$ & $0.35^{*}$ & $0.35^{*}$ & -0.01 & 0.12 & $0.28 *$ & 0.18 & 0.24 \\
\hline 11 & & & & & & & & & & & 1.00 & $0.67 *$ & $0.44^{*}$ & -0.05 & 0.15 & $0.36^{*}$ & 0.19 & $0.44 *$ \\
\hline 12 & & & & & & & & & & & & 1.00 & $0.44 *$ & 0.05 & 0.06 & $0.29 *$ & 0.09 & $0.43 *$ \\
\hline 13 & & & & & & & & & & & & & 1.00 & 0.17 & $0.32 *$ & $0.46^{*}$ & 0.24 & $0.46^{*}$ \\
\hline 14 & & & & & & & & & & & & & & 1.00 & 0.01 & 0.02 & 0.17 & 0.01 \\
\hline 15 & & & & & & & & & & & & & & & 1.00 & 0.10 & $0.35^{*}$ & 0.23 \\
\hline 16 & & & & & & & & & & & & & & & & 1.00 & $0.29 *$ & $0.43 *$ \\
\hline 17 & & & & & & & & & & & & & & & & & 1.00 & 0.07 \\
\hline 18 & & & & & & & & & & & & & & & & & & 1.00 \\
\hline
\end{tabular}




\section{Table 4}

Seven Factor Model of Unrotated Factor Loadings

\begin{tabular}{llll} 
Factor & Eigenvalue & $\begin{array}{l}\text { \% of Explained } \\
\text { Variance }\end{array}$ & $\begin{array}{l}\text { Cumulative \% of } \\
\text { Explained Variance }\end{array}$ \\
\hline 1 & 5.6842 & 31 & 31 \\
\hline 2 & 1.4463 & 8 & 39 \\
\hline 3 & 1.0783 & 6 & 45 \\
\hline 4 & 0.2388 & 1 & 46 \\
\hline 5 & 0.7453 & 4 & 50 \\
\hline 6 & 0.5406 & 3 & 53 \\
\hline 7 & 0.4311 & 2 & 52
\end{tabular}

The Kaiser-Guttman criteria suggest that only Eigenvalues above 1 should be of interest and thus interpreted (Guttman, 1954; Kaiser, 1960; Watts \& Stenner, 2012). Furthermore, an acceptable factor solution should account for more than 35 - $40 \%$ of the variance according to Watts and Stenner (2012). Taking these criteria into account, a three-factor model should therefore be extracted from the current dataset, accounting for $45 \%$ of the variance. The three factors extracted were subjected to varimax orthogonal rotation, in order to maximise their differences and ensure that each factor is statistically independent (Field, 2016). The three extracted factors and the variance they explain after rotation ( $46 \%$ in total) is depicted in Table 5, alongside the factor loadings of each Q-sort. 


\section{Table 5}

Extracted Factor Loadings

\begin{tabular}{|c|c|c|c|c|}
\hline Q-sort & $\begin{array}{l}\text { Participant } \\
\text { Pseudonym }\end{array}$ & Factor 1 & Factor 2 & Factor 3 \\
\hline 1 & Wendy & 0.1971 & $0.5841 *$ & 0.2127 \\
\hline 2 & Mia & $0.6827^{*}$ & 0.2518 & -0.0839 \\
\hline 3 & Samuel & 0.1136 & $0.7144^{*}$ & -0.1116 \\
\hline 4 & Maisie & $0.6637 *$ & 0.2093 & 0.1199 \\
\hline 5 & Jade & 0.2735 & 0.0646 & $0.58 *$ \\
\hline 6 & Diana & $0.5827 *$ & 0.0583 & 0.4446 \\
\hline 7 & Tara & $0.7606^{*}$ & 0.0072 & 0.2547 \\
\hline 8 & Caroline & $0.6615^{*}$ & 0.2627 & 0.2088 \\
\hline 9 & Isla & $0.5797 *$ & -0.1506 & -0.0267 \\
\hline 10 & Janine & $0.552^{*}$ & 0.4243 & 0.0032 \\
\hline 11 & Sasha & $0.715^{*}$ & 0.1739 & 0.1335 \\
\hline 12 & June & $0.6868^{*}$ & -0.0422 & 0.3708 \\
\hline 13 & Tina & 0.3077 & 0.3101 & $0.6111^{*}$ \\
\hline 14 & Amelia & -0.0708 & 0.0375 & $0.2978 *$ \\
\hline 15 & Heather & 0.085 & $0.2885^{*}$ & 0.2313 \\
\hline 16 & Kelly & 0.342 & 0.3264 & 0.282 \\
\hline 17 & Molly & -0.1268 & $0.6451 *$ & 0.2263 \\
\hline 18 & Maria & 0.4462 & 0.1359 & 0.453 \\
\hline$\%$ of Explained & & 25 & 11 & 10 \\
\hline Variance & & & & \\
\hline
\end{tabular}

The Ken-Q software (Banasick, 2019) conducts an automatic process which flags the significant Q-sorts for each factor, demonstrated with an asterisk in Table 5. Use of Brown's (1980) formula of calculating significance for each sort $(\mathrm{p}<0.05=$ $\geq 0.27$ ), i.e. a factor loading of 0.27 or above, indicates that some of the Q-sorts would load significantly onto more than one factor. However, the factor with the 
highest loading has been chosen for each participant, as their viewpoint will be aligned more closely to that particular factor.

\section{$\underline{\text { Factor Interpretation }}$}

Within the analysis completed by Ken-Q (Banasick, 2019), a factor array is produced to represent the ideal estimate of the viewpoint of each factor, created using the Q-sorts that significantly load onto only one factor (Appendix J). This supports the process of interpreting the factors and meaningfully explaining the results (Watts \& Stenner, 2012). Z-scores are generated to allow for comparison of statements across factors (Appendix K). Participants' comments from the post-sort questionnaires have been used to aid the interpretation of each factor, using pseudonyms as depicted in Table 5, followed by either YP (young person) or PR (professional).

\section{Factor 1: The importance of safety and attunement}

Factor 1 explains $25 \%$ of the variance in the model, with the highest Eigenvalue of 5.6842 and therefore the strongest statistical strength. The idealised Q-sort for Factor 1 is depicted in Appendix L. Nine Q-sorts loaded onto this factor, including six professionals and three young people, all were female.

The viewpoint in this factor focuses on the relationship between young people in CSE services and the professionals working with them. Safety was paramount to the participants who loaded onto this factor, with June (PR) stating "increasing safety is fundamental". Having a safe place to live, in a non-judgemental environment, was deemed crucial, alongside support that is flexible to each young person's needs: "support should be different for each child", Isla (YP) and "rigid systems don't support a complex issue", Mia (YP). Q-sorts loading onto this factor highlighted the significance of connection and a sense of being taken care of by professionals, with support for a focus on feelings rather than behaviour and a preference for longer-term support, highlighting the need for staff members to stay involved even if the young person may initially push them away. It seemed that comfort and trust within relationships were preferred over practical or educational support, with a focus on reliability and consistency and young people being allowed to talk about their experiences when they feel ready. Sasha (PR) stated 
"young people need to learn that you will always be there no matter what, they are looking for a connection that they can feel". Q-sorts that were aligned with this viewpoint also prioritised support that allows for the involvement of young people in making decisions about their care and being involved in their care planning with support to understand the boundaries of confidentiality, further emphasising the key element of attunement to their individualised needs.

Within this factor, there was a clear disagreement with the use of educational videos about CSE and a suggestion that they may make young people feel emotionally unsafe, Janine (YP) stated "the videos bring everything back, there's no way I'd get through it" and Caroline (PR) also remarked "the right videos can be appropriate, but it's a risk if the wrong people are using them, they can be hugely damaging”. Reduced access to social media and the internet was also rated as least important in services, Maisie (PR) claimed "they're always going to find a way to access social media regardless", Mia (YP) also suggested "reducing access to social media won't necessarily reduce any risk". Other aspects, such as life story work, work on sex education or education about risks, were clearly valued less than the more implicit relational elements of support; however, participants did value the option to see a psychologist, perhaps for more informal support.

\section{Factor 2: Trust, trauma and mental health}

Factor 2 explains $11 \%$ of the variance in the model, with an Eigenvalue of 1.4463. The idealised Q-sort for Factor 2 is depicted in Appendix M. Four Q-sorts loaded onto this factor, including three young people (one male and two female) and one female professional.

This factor is representative of the view that the most important features of services are related to specifically building trust in order to deal with traumatic experiences related to CSE, in a consistent way and over a longer period of time. Samuel (YP) discussed the idea that "trauma is the seed where it all comes from". Heather (YP) also stated that "consistency helps, changing over staff means you might not be able to cope after you've already opened up to someone else". Q-sorts in this factor also valued the use of individual sessions focused on mental health problems, support with self-harm and support to reduce drug and alcohol use. Molly (YP) reported "mental health support and therapy is important for me". An 
understanding of the circumstances that may have led to a young person being exploited was deemed to be important, perhaps through the use of life story work to understand their whole life journey. Education about the risks of sexual exploitation was valued higher in this factor, perhaps with the understanding that this would reduce the likelihood of future traumatic experiences. There was an appreciation of the importance of working with social workers; however this was not the case in terms of working with the police or school staff. Samuel (YP) suggested that "working with the police takes the focus away from the young person, support for them is more important".

There was slightly more value in reducing access to social media in this factor however supervision to use social media was clearly deemed to be least important in the Q-sorts of this factor. Throughout the factor there appeared to be more disagreement with restrictive practices and boundaries, perhaps due to the priority based on building trust first and foremost. Support to catch up with school-work was evidently not important to the participants who loaded onto this factor, Wendy (PR) stated "education is important but school-work is not a priority. The therapeutic side is the most important" and Heather (YP) suggested "we don't need school-work ... some kids might not be interested in school". This factor also suggests that focusing on feelings rather than behaviour and support that focuses on sex education were not valued by the participants who significantly loaded onto this factor. This may be a protective mechanism, due to the difficult feelings associated with traumatic experiences that would need to be processed carefully and therapeutically. In this factor there was less support for staff members staying involved even when pushed away in comparison to Factors 1 and 3, which may be related to difficulties with trusting others and accepting connection.

\section{Factor 3: Family, normality, and a relaxed approach}

Factor 3 explains $10 \%$ of the variance in the model, with an Eigenvalue of 1.0783. The idealised Q-sort for Factor 3 is depicted in Appendix N. Three Q-sorts loaded onto this factor, they were all completed by female young people.

Some aspects of this factor were similar to Factors 1 and 2, in that there was a clear emphasis on building trusting relationships with staff, characterised by reliability and consistency, and a safe place to live. For example, Jade (YP) stated "if there's 
no trust there, then it's not going to work is it". However, this factor is unique in the prioritisation of a return to normality for young people, with more value placed on a relaxed approach to their care, with support to have a daily routine valued highest in this factor. This was also demonstrated by the higher value placed upon more informal support from staff, by just listening to young people and doing fun activities with them. This factor also showed more support for the involvement of families in young peoples' care, and the importance of support being available for families. There was also greater emphasis placed on the need for support in reducing anger and to use social media safely, with the consideration that safe use rather than not using social media at all is more sustainable when returning to normality.

Q-sorts in Factor 3 did not value the concept of peer support from other young people or adults who have experienced CSE. Tina (YP) stated "help from another young person could make it worse, I'd feel bad for them", alongside a similar point discussed by participant Jade (YP) "being helped by another young person would cause me more stress by knowing what they'd been through". Similarly to Factor 1, the significance of having the right staff member to work with was also demonstrated within this factor and reduced access to social media and the internet was also deemed to be least important. Jade (YP) "you see all your mates on social media, there's no harm if it's being monitored" and Amelia (YP) "reduced access to social media isn't important because when you leave you won't know what to do". Alongside Factor 2, support to catch up with school work was not valued. Techniques to disrupt the relationships between young people and potential perpetrators of CSE were also deemed to be less important than in other factors. Interestingly, despite the importance placed on the involvement of family within services, the Q-sorts within factor 3 did not value support to help young people move back into the community where they experienced CSE, possibly reflecting a desire to live elsewhere but alongside family.

\section{Comparison of Factors}

The three factors all agreed that professionals building trusting relationships with young people in a safe living environment are fundamental to the delivery of CSE services. There was some mild agreement across factors with the suggestion that 
support should continue after young people turn 18. All three factors were neutral on support to make disclosures and work with police on prosecutions. All three factors deemed crafting and creative activities to be less important.

\section{$\underline{\text { Non-significant Q-sorts }}$}

Two of the Q-sorts did not significantly load onto any of the three extracted factors, suggesting that they held different viewpoints to their 16 counterparts. Both were completed by professionals working in residential services, including one assistant psychologist and a therapeutic care practitioner. Kelly (PR) loaded similarly across all three factors, but not to a significant level. This would suggest that Kelly's perspective was not closely aligned with any one particular viewpoint. Her Q-sort highlighted that she valued life-story work and trauma-focused therapy as being particularly important for young people. Maria (PR) loaded similarly onto both Factors 1 and 3 but neither loading was significant. Maria placed the opportunity for young people to talk when ready and a non-judgemental environment as the most important aspects of services.

\section{Discussion}

A participant sample comprising of nine young people and nine professionals within CSE services completed a Q-sort. Application of Q-methodology led to the emergence of three significant factors: (1) The importance of safety and attunement, (2) Managing trauma and mental health difficulties and (3) Family, normality and a relaxed approach. The three extracted factors explain $46 \%$ of the variance within the Q-sorts. Trust and safety were paramount across all three factors, with a clear emphasis on relational support above other elements of care.

\section{Theoretical Considerations}

The emphasis on safety across the three factors demonstrates that there is a clear value in services designing their approaches in a way that maximises young people's physical, relational and psychological safety. This is in agreement with the Department for Education (2016) report which posits that the welfare of young people who have experienced CSE is dependent upon their sense of safety. This is 
in keeping with the broader evidence base on support for CSA, which proposes that safe and caring therapeutic relationships are fundamental for meaningful engagement with staff and services (Carpenter et al., 2016). Some aspects of the current findings confirm the importance of listening, attunement and routine, as have been suggested by the CSA literature. This study also highlights that the perception of what constitutes safety in relationships and the environment may vary between young people who have experienced CSE. This may be related to the context in which CSE occurs, i.e. with strangers outside of the family network, and the difficulties in disrupting relationships with perpetrators as some young people may not see themselves as victims of abuse.

Factor 1, the strongest factor and therefore the most prominent viewpoint of participants had a clear focus on the relationships between young people and staff members. It was evident that this viewpoint strongly valued connection and attunement to the young people's needs, which is an important factor when considering how to develop secure attachments between young people and their caregivers (Ainsworth, 1973). In interviews with professionals working with young people who have experienced CSE, Frost (2019) found that professionals emphasised the importance of relationships in their clinical practice. Whilst not all of the participants who loaded onto this factor were from a residential setting, this demonstrates that there is value in services having an awareness of relational security and attachment principles, in line with the guidance of Golding et al. (2009).

All three factors did not support the use of risk-focused strategies that are aimed at preventing further exploitation, such as support around reducing or supervising access to social media and the internet. Factor 1 also did not support the use of educational videos depicting reconstructions of real life situations between young people subjected to CSE and CSE perpetrators. In the UK, there are many educational resources that have been developed, such as BAIT by the organisation Recre8 (2015). The videos aim to increase CSE awareness among children and reduce their risks of being exploited, often playing a significant role in interventions (Eaton, 2019). A key figure in the criticism of using CSE videos, Eaton (2018) reported that preventative videos may be vicariously traumatic for young people. Brown et al. (2016) report that there is no evidence to demonstrate 
that watching such videos will reduce the risk of a young person being sexually exploited. It is also important to note that risk-focused strategies are largely focused on preventing CSE from occurring in the first place, and as participants had already experienced CSE it is understandable that they may not prioritise such strategies.

The viewpoint of Factor 2 provided further evidence for the prioritisation of trauma-focused care before education and risk-reduction. This factor also valued the importance of trust between young people and professionals, alongside a consistent approach. In accordance with Herman (1992) and recovery from trauma, trusting relationships are a crucial aspect in supporting them to manage any related mental health difficulties, as well as providing a healthy relational template for navigating future relationships. The viewpoint of this factor also prioritised support for mental health difficulties, self-harm and drug and alcohol use, which evidence suggests can all be linked to traumatic CSE experiences (Department for Education, 2016).

Factor 3 highlighted the importance of involving families of CSE survivors in supporting young people and also having their own specialist support. This is also recommended in the key principles for services developed by Research in Practice (2017) and in the guidance for practitioners developed by the Department of Education (2017). Featherstone et al. (2014) argued that families are often powerless within the current child protection system, as well as already facing other forms of societal or cultural disadvantage. A scope of the evidence surrounding the needs of parents of sexually exploited young people found that statutory practice can lead to parents feeling blamed and excluded from their child's care (Scott \& McNeish, 2017). This factor also emphasised the value of a sense of normality for young people, which was highlighted by the Department for Education (2016) as being one of the main aims for residential services. This was described as "allowing children to be children" (Department for Education, 2016, p.31), achieved by establishing and maintaining predictable routines and supporting young people to develop essential life skills, as would be expected in a typical family environment. 


\section{Clinical Implications}

\section{Service Development}

The three key viewpoints are important for services to consider when planning interventions for, or responses to, young people who have experienced CSE. The results provide further evidence for the ongoing progressive move away from punitive or victim-blaming responses towards an approach characterised by compassion and building trust.

Based on the available evidence and the results of the current study, the following is advised when designing CSE services and support. For CSE prevention, it is important to recognise vulnerable young people as early as possible in a nonblaming way, with an understanding of the complexity of dynamics between the young person and the perpetrator. Pearce (2019) suggests that CSE services and staff are likely to be more effective if their practice is underpinned by clearly defined theoretical approaches. Before and after experiencing CSE, it will be crucial to use relationships to connect with young people by tuning into their psychological needs and making them feel safe, this can be guided by the principles of attachment theory (Golding et al., 2009). Alongside physical safety, this sense of emotional safety can be created by fostering trusting relationships between young people and staff members, in a predictable, caring and non-judgemental environment.

The current focus on preventing further exploitation means that many services are focusing heavily on educational aspects (e.g., healthy relationship work), without recognising and celebrating the implicit relational processes that are occurring between their staff members and young people, which seem to be more highly valued. The literature also suggests that some CSE survivors have already had abusive or traumatic experiences prior to experiencing CSE, highlighting a vulnerability to which the wider network of children's services should be alert. Applying a model of trauma-informed care (Substance Abuse and Mental Health Services Administration, 2014), it is recommended that services adopt a relational approach that makes sense of a young person's presentation within the context of the trauma they are likely to have experienced both during and potentially prior to CSE. Staff members having an awareness of attachment and trauma is crucial in 
order to deliver trauma-informed care that is based on relational security and with an attachment lens.

After CSE has occurred, the findings of the study suggest that educational resources may be re-traumatising. Services need to be mindful of and address any underlying mental health difficulties or trauma. It is also suggested that services should consider re-establishing links with positive communities, particularly working to support families when appropriate, so that young people can return to a sense of normalcy post CSE intervention and have longer-term community resources to tap into. Furthermore, as these recommendations are based upon perspectives taken from a fixed point in time, the type of intervention that is most appropriate may vary across the recovery process.

\section{A Role for Clinical Psychology}

Clinical Psychologists are trained in understanding the influence of individual, systemic and societal factors when assessing and formulating a young person's experiences in order to inform the most appropriate intervention that will meet their psychological needs and recovery from trauma. Clinical Psychologists are also well-placed to support CSE services in implementing a more integrated and attuned psychological response. They are able to balance the need for prevention in response to vulnerability with some young people, and in other cases focusing entirely on a relational and trauma-informed approach by delivering specific individual or group interventions. This is not only based on clinical psychologists' key skills in assessment and intervention, but also on their competencies in supporting and training staff teams, evaluating services and working effectively across agencies (Division of Clinical Psychology, 2010). If services operate within an attachment-based framework, Clinical Psychologists are able to offer supervision, reflective practice and consultation in line with attachment theory, to support staff members in remaining connected and fostering their attachments with young people.

\section{$\underline{\text { Limitations }}$}

The Q-sort is representative of the participant's viewpoint at a particular moment in time; therefore, the results' reliability may be limited because views may change 
over time or depending on the context (Stephenson, 1988). Despite achieving the sample size required for Q-methodology, the method is not predictive therefore the generalisability of the findings should be considered with an element of caution. As the focus of Q-methodology is particularly concerned with the subjective viewpoints of participants, and based upon the meaning they make of the statements in the Q-sort, reliability and generalisability are not as highly prioritised within this methodological approach. The social constructionist position of the researcher also meant that there was more of a priority placed on understanding and exploring the viewpoints that were generated at the time of the Q-sort and post-sort questionnaire, rather than a more positivist position of wanting to uncover an 'objective' truth about views on CSE services. However, given this epistemological position, a potential limitation of the study was the lack of piloting of the statements. This may have led to a language barrier in terms of how participants made sense of the statements, as on two occasions the researcher was asked to explain some of the statements. This may have reduced the depth of their meaning for those participants and may be less reflective of their understanding in the context of their own experiences.

Furthermore, although participants were recruited from three different settings, only one male participated in the study out of a sample of 18 . This is largely representative of the gender balance of both service users and staff members within CSE services. This also highlights the wider issue of the current lack of provision for or knowledge surrounding the experiences of male young people who have been sexually exploited (Josenhans et al., in press).

Another potential limitation of the research is in relation to the researcher's role in how the materials are developed. The lead researcher compiled the statements of the concourse, based on their exploration of the available literature, which may mean that they overlooked themes they deemed to be less significant to the aims of the research. Additionally, the lead researcher's interpretation of the extracted factors will be inherently influenced by their own views and conceptualisations. Within the Q-methodology applied in this research it is impossible to completely remove the influence of bias on behalf of the researcher. In order to partially mitigate against this, the final Q-set was peer-validated and reviewed by the research team, including an expert by experience. The researcher also worked 
through a Q-sort from their own perspective to develop their awareness of their viewpoints, and to have an appreciation of how this may then influence factor interpretation.

\section{Directions for Future Research}

Further testing of these findings, either by replication in different areas or using qualitative methodology to explore viewpoints in more depth is needed. It may also be useful to repeat the study on a longitudinal basis, to not only test whether viewpoints remained stable but perhaps to compare viewpoints in the early stages of engagement with a CSE service and afterwards. It is especially important to continue amplifying the voices of young people, including males, not only in relation to service design but also more broadly capturing their experiences and furthering our understanding of their perspective on what leads to young people being vulnerable to sexual exploitation. Further research could also be conducted into the effectiveness of services that promote a sense of relational safety by mapping the trajectory of young people who engage in such services compared to those who do not.

\section{Conclusion}

The research found three main viewpoints among participants on CSE services: the importance of safety and attunement, managing trauma and mental health difficulties, and family, normality, and a relaxed approach. The factors provide further evidence for the current progression towards child-oriented and traumafocused support and away from a predominantly educational model. There is also support for specific trauma and mental health interventions, and the involvement of families. The recommendation for services to be holding in mind and working with young people's psychological needs was demonstrated, with a suggestion that there is a role for clinical psychologists in supporting this. 


\section{References}

Ainsworth, M. D. S. (1973). The development of infant-mother attachment. In B. Cardwell \& H. Ricciuti (Eds.). Review of child development research, (Vol. 3, pp. 1-94). University of Chicago Press.

Banasick, S. (2019). Ken-Q Analysis (Version 1.0.6). Retrieved January 6, 2019, from: https://shawnbanasick.github.io/ken-q-analysis/

Barnardo's. (2011). Puppet on a string: The urgent need to cut children free from sexual exploitation. Barnardo's. Retrieved August 9, 2019, from: www.barnardos.org.uk/ctf_puppetonastring_report_final.pdf

Barnardo's. (2017). Working with children who are victims or at risk of sexual exploitation: Barnardo's model of practice. Barnardo's. Retrieved May 18, 2019, from https://www.scie-socialcareonline.org.uk/working-withchildren-who-are-victims-or-at-risk-of-sexual-exploitation-barnardos$\underline{\text { model-of-practice/r/a11G000000ORBRCIA5 }}$

Barrett, D. (1998). Young people and prostitution: perpetrators in our midst. International Review of Law, Computers and Technology, 12, 475-486. https://doi.org/10.1080/13600869855315

Beckett, H., Holmes, D., \& Walker, J. (2017). Child sexual exploitation: Definition and guide for professionals. (Extended text). University of Bedfordshire, Research in Practice. Retrieved December 1, 2019, from: www.rip.org.uk/resources/pub lications/practice-tools-and-guides/child-sexual-exploitation-practice-tool2017-open-access/

Beckett, H., \& Pearce, J. (2018). Understanding and responding to child sexual exploitation. Routledge.

Bedford, A. (2015). Serious case review into child sexual exploitation in Oxfordshire: from the experiences of children $a, b, c, d, e$, and $f$. Oxfordshire Safeguarding Children Board. Retrieved December 1, 2019, from: www.oscb.org.uk/wp-content/uploads/SCR-into-CSE-in-OxfordshireFINAL-FOR-WEBSITE.pdf 
Berger, P. L., \& Luckmann, T. (1966). The social construction of reality: A treatise in the sociology of knowledge. Doubleday \& Company.

Bluett, M., Walker, A., Goodman, J., \& Adeyemo, J. (2000). Somewhere safe: Accommodation needs of children and young people at risk on the street. The Children's Society.

Bolton Safeguarding Children. (2018). Child sexual exploitation strategy 20182020. Retrieved April 2, 2020, from: https://www.boltonsafeguardingchildr en.org.uk/downloads/file/95/child-sexual-exploitation-strategy

Bowlby, J. (1969). Attachment. Attachment and loss (Vol. 1). Hogarth Press.

Brown, S. R. (1980). Political subjectivity: Applications of q methodology in political science. Yale University Press.

Brown, S., Brady, G., Franklin, A., Bradley, L., Kerrigan, N., \& Sealey, C. (2016). Child sexual abuse and exploitation: Understanding risk and vulnerability. Early Intervention Foundation. Retrieved December 1, 2019, from https://www.eif.org.uk/files/pdf/child-sexual-abuse-and-exploitation$\underline{\text { understanding-risk-and-vulnerability.pdf }}$

Carpenter, J., Jessiman, T., Patsios, D., Hackett., S. \& Phillips, J. (2016). Letting the future in: A therapeutic intervention for children affected by sexual abuse and their carers: An evaluation of impact and implementation. University of Bristol. Retrieved March 3, 2020. from https://researchinformation.bris.ac.uk/ws/portalfiles/portal/73876820/LTFI_Final_Report_ $\underline{11.02 .16 \mathrm{~b} . \mathrm{pdf}}$

Chase, E., \& Statham, J. (2005) Commercial sexual exploitation of children and young people in the UK - a review. Child Abuse Review, 14(1), 4-25. https://doi.org/10.1002/car.881

Department for Education. (2016). Child sexual exploitation: Support in children's residential homes. Research report. Department for Education. Retrieved December 1, 2019, from: https://assets.publishing.service.gov.uk/governme nt/uploads/system/uploads/attachment_data/file/582354/Child-sexualexploitation-support-in-childrens-homes.pdf 
Department for Education. (2017). Child sexual exploitation: Definition and a guide for practitioners, local leaders and decision makers working to protect children from child sexual exploitation. Department for Education. Retrieved December 1, 2019, from https://assets.publishing.service.gov.uk/ government/uploads/system/uploads/attachment_data/file/591903/CSE_Gui dance_Core_Document_13.02.2017.pdf

Division of Clinical Psychology (2010). The core purpose and philosophy of the profession. The British Psychological Society.

Eaton, J. (2018). Can I tell you what it feels like? Exploring the harm caused by child sexual exploitation (CSE) films. Victim Focus. Retrieved August 9, 2019, from https://irp-cdn.multiscreensite.com/f9ec73a4/files/uploaded/Can \%201\%20tell\%20you\%20what\%20it\%20feels\%20like_CSEfilmsreportJEA $\underline{\text { TONJan2018A.pdf }}$

Eaton. J. (2019). Critical perspectives: Child sexual exploitation approaches and practice. Victim Focus. Retrieved August 9, 2019, from https://irpcdn.multiscreensite.com/f9ec73a4/files/uploaded/Critical\%20Perspectives\% 20of\%20CSE\%20Approaches\%20and\%20Practice\%20Eaton\%202019\%20 VictimFocus\%20FINAL.pdf

Featherstone, B., White, S. \& Morris, K. (2014). Re-imagining child protection: Towards humane social work with families. Policy Press.

Field, A. (2016). Discovering statistics using IBM SPSS statistics ( $4^{\text {th }}$ ed.). Sage.

Frost, N. (2019). Providing support and therapy for victims and survivors of child sexual exploitation. Journal of Public Mental Health, 18(1), 38-45. https://doi.org/10.1108/JPMH-07-2018-0051

Golding, K., Taylor, J. Thorp, D., Berfer, M., \& Stevenson, J. (2009). Looked after children: Improving the psychological well-being of children in the care of the local authority. British Psychological Society.

Guttman, L. (1954). Some necessary conditions for common-factor analysis. Psychometrika, 19(2), 149-161. https://doi.org/10.1007/BF02289162 
Hallett, S. (2016). 'An uncomfortable comfortableness': 'Care', child protection and child sexual exploitation. British Journal of Social Work, 46, $2137-$ 2152. https://doi.org/10.1093/bjsw/bcv136

Herman, J. L. (1992). Trauma and recovery: The aftermath of violence. Basic Books.

Hickle, K. (2019). Understanding trauma and its relevance to child sexual exploitation. In J. Pearce (Ed.). Child sexual exploitation: Why theory matters. (pp. 151-172). Policy Press.

HM Government, (2018). Working together to safeguard children: A guide to inter-agency working to safeguard and promote the welfare of children. HM Government. Retrieved April 13, 2019, from https://assets.publishing.s ervice.gov.uk/government/uploads/system/uploads/attachment_data/file/779 401/Working_Together_to_Safeguard-Children.pdf

Howitt, D. D. \& Cramer, P. D. (2010). Introduction to research methods in psychology, ( $3^{\text {rd }}$ ed.). Prentice Hall.

Jay, A. (2014). Independent inquiry into Child Sexual Exploitation in Rotherham: 1997-2013. Rotherham Metropolitan Borough Council. Retrieved April 13, 2019, from https://www.rotherham.gov.uk/downloads/download/139/indepe ndent_inquiry_into_child_sexual_exploitation_in_rotherham_1997_\% E2\% $\underline{80 \% 93 \_2013}$

Josenhans, V., Kavenagh, M., Smith, S., \& Wekerle, C. (In press). Gender, rights and responsibilities: The need for a global analysis of the sexual exploitation of boys. Child Abuse \& Neglect. https://doi.org/10.1016/j.chiab $\underline{\mathrm{u} .2019 .104291}$

Kaiser, H. F. (1960). The application of electronic computers to factor analysis. Educational and Psychological Measurement, 20(1), 41-151. https://doi.org/10.1177/001316446002000116

Luxmoore, N. (2019). Some psychodynamic understandings of child sexual exploitation. In J. Pearce (Ed.). Child sexual exploitation: Why theory matters. (pp. 133-150). Policy Press. 
Pearce, J. (2014). What's going on to safeguard children and young people from child sexual exploitation: A review of Local Safeguarding Children Boards' work to protect children from sexual exploitation. Child Abuse Review, 23(3), 159-170. https://doi.org/10.1002/car.2269

Pearce, J. (2019). Child sexual exploitation: Why theory matters. Policy Press.

Recre8. (2015). BAIT. Retrieved April 13, 2019 from: http://www.recre8now.co.uk /bait/bait-resource/index.html

Research in Practice. (2017). Working effectively to address child sexual exploitation: An evidence scope. Research in Practice. Retrieved June 9, 2018, from https://www.researchinpractice.org.uk/media/2613/cse_evidenc escopeupdateoct17_v2.pdf

Scott, S. \& McNeish, D. (2017). Supporting parents of sexually exploited young people: An evidence review. Centre of Expertise on Child Sexual Abuse. Retrieved January 7, 2020 from https://www.csacentre.org.uk/researchpublications/supporting-parents/evidence-review-by-sara-scott-and-dimoneish-dmss-research/

Stephenson, W. (1953). The study of behaviour: Q technique and its methodology. University of Chicago Press.

Stephenson, W. (1988). William James, Niels Bohr, and complementarity: IV The significance of time. The Psychological Record, 38(1), 19-35. https://doi.org/10.1007/BF03395004

Substance Abuse and Mental Health Services Administration. (2014). Concept of Trauma and Guidance for a Trauma-Informed Care Approach. U.S. Department of Health and Human Services. Retrieved July 20, 2020, from https://ncsacw.samhsa.gov/userfiles/files/SAMHSA_Trauma.pdf

van Exel , J., \& de Graaf, G. (2005). Q methodology: A sneak preview. Retrieved January 3, 2020, from: http://qmethod.org/articles/vanExel.pdf

Warrington, C. (2013). Partners in care? Sexually exploited young people's inclusion and exclusion from decision making. In M. Melrose, \& J. Pearce 
(Eds.), Critical perspectives on child sexual exploitation and related trafficking. Palgrave Macmillan.

Warrington, C. (2016). Young person-centred approaches in child sexual exploitation: Building self-efficacy and promoting participation. Research in Practice. Retrieved June 8, 2019, from https://www.portsmoutheducation partnership.co.uk/wp-content/uploads/2017/11/Rip_CSE_frontline_briefing _updated.pdf

Watts, S., \& Stenner, P. (2005). Doing Q methodology: Theory, method and interpretation. Qualitative Research in Psychology, 2(1), 67-91. https://doi.org/10.1191/1478088705qp022oa

Watts, S., \& Stenner, P. (2012), Doing Q methodological research: Theory, method and interpretation. Sage Publications.

Woodhouse, S. (2018). Just a child: Britain's biggest child abuse scandal exposed. Blink Publishing. 


\section{Appendices}

Appendix A: Journal Submission Guidance for Authors................................. 101

Appendix B: Ethical Approval from Staffordshire University......................... 105

Appendix C: Participant Information Sheet (Young People)........................... 106

Appendix D: Participant Information Sheet (Professionals)........................... 109

Appendix E: Participant Consent Form (Young People)................................ 112

Appendix F: Participant Consent Form (Professionals)............................... 114

Appendix G: Statements forming the Q-set................................................... 115

Appendix H: Participant Demographic Questionnaire.................................... 118

Appendix I: Post-sort Supplementary Questionnaire....................................... 119

Appendix J: Factor Arrays.......................................................................... 120

Appendix K: Z-score table............................................................................ 122

Appendix L: Idealised Q-sort Factor 1...................................................... 125

Appendix M: Idealised Q-sort Factor 2 .................................................. 126

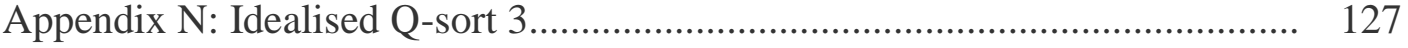




\title{
Appendix A - Journal Submission Guidance for Authors
}

\author{
About the Journal \\ Journal of Child Sexual Abuse is an international, peer-reviewed journal publishing \\ high-quality, original research. Please see the journal's Aims \& Scope for \\ information about its focus and peer-review policy.
}

\section{Peer Review and Ethics}

Taylor \& Francis is committed to peer-review integrity and upholding the highest standards of review. Once your paper has been assessed for suitability by the editor, it will then be double blind peer reviewed by independent, anonymous expert referees. Find out more about what to expect during peer review and read our guidance on publishing ethics.

\section{Preparing Your Paper}

\section{$\underline{\text { Structure }}$}

Your paper should be compiled in the following order: title page; abstract; keywords; main text introduction, materials and methods, results, discussion; acknowledgments; declaration of interest statement; references; appendices (as appropriate); table(s) with caption(s) (on individual pages); figures; figure captions (as a list).

\section{$\underline{\text { Word Limits }}$}

Please include a word count for your paper. A typical paper for this journal should be no more than 30 pages, inclusive of the abstract, tables, references, figure captions, footnotes, endnotes.

\section{$\underline{\text { Style Guidelines }}$}


Please refer to these quick style guidelines when preparing your paper, rather than any published articles or a sample copy.

Please use American spelling style consistently throughout your manuscript.

Please use double quotation marks, except where "a quotation is 'within' a quotation". Please note that long quotations should be indented without quotation marks.

Papers may be submitted in any standard file format, including Word and LaTeX. Figures should be saved separately from the text. The main document should be double-spaced, with one-inch margins on all sides, and all pages should be numbered consecutively. Text should appear in 12-point Times New Roman or other common 12-point font. Submissions should not exceed 30 double-spaced pages, including abstract, references, tables, and figures. Please submit a separate document clearly outlining if: (a) if the author has any financial conflicts of interest, (b) if you have approval from your Institutional Review Board for a study involving animal or human patients, (c) if there are any informed consent notifications to state.

\section{$\underline{\text { Formatting and Templates }}$}

Papers may be submitted in Word or LaTeX formats. Figures should be saved separately from the text. To assist you in preparing your paper, we provide formatting template(s).

Word templates are available for this journal. Please save the template to your hard drive, ready for use. If you are not able to use the template via the links (or if you have any other template queries) please contact us here.

\section{$\underline{\text { References }}$}

Please use this reference guide when preparing your paper.

\section{Checklist: What to Include}

1. Author details. All authors of a manuscript should include their full name and affiliation on the cover page of the manuscript. Where available, please also include ORCiDs and social media handles (Facebook, Twitter or LinkedIn). One 
author will need to be identified as the corresponding author, with their email address normally displayed in the article PDF (depending on the journal) and the online article. Authors' affiliations are the affiliations where the research was conducted. If any of the named co-authors moves affiliation during the peer-review process, the new affiliation can be given as a footnote. Please note that no changes to affiliation can be made after your paper is accepted. Read more on authorship.

2. Should contain an unstructured abstract of 250 words.

3. You can opt to include a video abstract with your article. Find out how these can help your work reach a wider audience, and what to think about when filming.

4. Read making your article more discoverable, including information on choosing a title and search engine optimization.

5. Funding details. Please supply all details required by your funding and grantawarding bodies as follows:

For single agency grants

This work was supported by the [Funding Agency] under Grant [number xxxx].

For multiple agency grants

This work was supported by the [Funding Agency \#1] under Grant [number xxxx]; [Funding Agency \#2] under Grant [number xxxx]; and [Funding Agency \#3] under Grant [number xxxx].

6. Disclosure statement. This is to acknowledge any financial interest or benefit that has arisen from the direct applications of your research. Further guidance on what is a conflict of interest and how to disclose it.

7. Biographical note. Please supply a short biographical note for each author. This could be adapted from your departmental website or academic networking profile and should be relatively brief (e.g., no more than 200 words).

8. Data availability statement. If there is a data set associated with the paper, please provide information about where the data supporting the results or analyses presented in the paper can be found. Where applicable, this should include the 
hyperlink, DOI or other persistent identifier associated with the data set(s). Templates are also available to support authors.

9. Data deposition. If you choose to share or make the data underlying the study open, please deposit your data in a recognized data repository prior to or at the time of submission. You will be asked to provide the DOI, pre-reserved DOI, or other persistent identifier for the data set

10. Supplemental online material. Supplemental material can be a video, dataset, file set, sound file or anything which supports (and is pertinent to) your paper. We publish supplemental material online via Figshare. Find out more about supplemental material and how to submit it with your article.

11. Figures. Figures should be high quality (1200 dpi for line art, 600 dpi for grayscale and 300 dpi for color, at the correct size). Figures should be supplied in one of our preferred file formats: EPS, PDF, PS, JPEG, TIFF, or Microsoft Word (DOC or DOCX) files are acceptable for figures that have been drawn in Word. For information relating to other file types, please consult our Submission of electronic artwork document.

12. Tables. Tables should present new information rather than duplicating what is in the text. Readers should be able to interpret the table without reference to the text. Please supply editable files.

13. Equations. If you are submitting your manuscript as a Word document, please ensure that equations are editable.

14. Units. Please use SI units (non-italicized). 


\section{Appendix B - Ethical Approval from Staffordshire University}

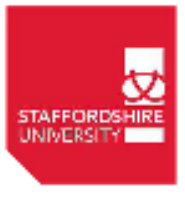

Life Sciences and Education

ETHICAL APPROVAL FEEDBACK

\begin{tabular}{|l|l|}
\hline Researcher name: & Jennifer Barrow \\
\hline Title of Study: & $\begin{array}{l}\text { Investigating the perspectives of young people and staff members on } \\
\text { child sexual exploitation services using Q methodology. }\end{array}$ \\
\hline Status of approval: & Approved \\
\hline
\end{tabular}

Thank you for addressing the committee's comments. Your research proposal has now been approved by the Ethics Panel and you may commence the implementation phase of your study. You should note that any divergence from the approved procedures and research method will invalidate any insurance and liability cover from the University. You should, therefore, notify the Panel of any significant divergence from this approved proposal.

You should arrange to meet with your supervisor for support during the process of completing your study and writing your dissertation.

When your study is complete, please send the ethics committee an end of study report. A template can be found on the ethics BlackBoard site.

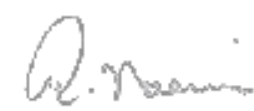

Signed: Dr Roozbeh Naemi

Date: 26.03.2019

Ethics Coordinator

School of Life Sciences and Education 


\title{
Appendix C - Participant Information Sheet (Young People)
}

\section{PARTICIPANT INFORMATION SHEET}

\section{STAFFORDSHIRE \\ UNIVERSITY}

\section{FOR YOUNG PEOPLE}

Version 6/August 2019

Project Title: Investigating the perspectives of young people and staff members on child sexual exploitation services and interventions using $Q$ methodology. Introduction
\end{abstract}

My name is Jennifer Barrow and I'm a trainee clinical psychologist at Staffordshire University.

I am inviting you to be involved in my research project as part of my studies. Before you decide to participate, it is important that you understand why the research is being done and what I will be asking you to do.

Please read the following information carefully and discuss it with others if you wish, or you may ask the researchers if you would like more information or if anything is not clear.

Please take time to decide whether you would like to take part. Thank you for your time.

\section{1) What is the purpose of this study?}

We would like to learn about your views about services for young people who have experienced sexual exploitation. This means looking at what you think is helpful for young people in this situation.

\section{2) Do I have to take part?}

No, it is up to you. If you do decide to take part, you will be given this sheet to keep and you will be asked to sign a consent form. If you are under 16 your guardian (or social worker if relevant for you) will also be asked to sign the form. 
If you take part, we will replace your name with an anonymised participant number which means that your information couldn't be linked to you. If you take part and then would like to withdraw your data, (the information we gather from you during the study), please email or ask the staff that you work with to email the primary researcher or research supervisor and tell them your participant number (see contact details at the bottom of this sheet).

You can withdraw your data until two weeks after you have taken part and you will not be asked to give a reason for wanting to remove your information. After two weeks, you will be unable to withdraw the data as each person's data will have been mixed together.

\section{3) What will I do in the study?}

We would need to meet with you for about 1 hour. During this time you would be given a set of cards with statements on them. The statements will be about services and interventions for young people who have been sexually exploited. We would ask you to rate the statements from most important to least important, and we would show you how to sort them using a grid. We would then ask you some questions about the order you put your statements in. We would not ask you about your history or the individual and personal work you are doing with the service.

\section{4) Why have I been invited to take part?}

We would like to work with staff members and young people within services for young people who have been sexually exploited. We would like to know more about your views on what makes a service helpful and useful.

\section{5) What are the risks in taking part in this study?}

We don't think that there would be any risks to you during the study, but participation in this study may cause emotional distress and anxiety in some people, and if you felt uncomfortable or upset at any point we would stop. We could take a break or we could stop the study completely, you would not be asked why you wanted to stop and we would help you to think about who could support you.

You can talk to someone if you need support by contacting ChildLine by telephone on 08001111 or on their website https://www.childline.org.uk

\section{6) What happens to the information in the study?}

\section{Data Protection Statement}

The data controller for this project will be Staffordshire University, this means that the university will keep the information you give during the study in a safe place, 
and they will keep it for ten years. Your data will be processed in accordance with data protection law and will comply with the General Data Protection Regulation 2016 (GDPR). This means that all information that is collected about you during the course of the study will be kept confidential. This means that nobody would see this except me, and my supervisor Helen.

We will replace your name with an anonymised participant number which means that your information couldn't be linked to you. Once your information is linked to your anonymised number we will destroy your personal information. I will also store the anonymised data on a secure and password protected USB stick.

\section{Contact for further information:}

Primary Researcher

Jennifer Barrow (Trainee Clinical Psychologist) via email at

b024106h@student.staffs.ac.uk

Research supervised by:

Dr Helen Combes - h.a.combes@staffs.ac.uk

Professional Doctorate in Clinical Psychology

Science Centre

Staffordshire University

Leek Road

Stoke-on-Trent

ST4 2DF 
Appendix D - Participant Information Sheet (Professionals)

PARTICIPANT INFORMATION SHEET

FOR PROFESSIONALS

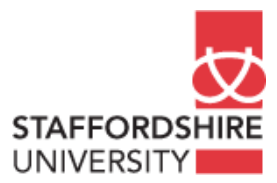

Version 6/August 2019

Project Title: Investigating the perspectives of young people and staff members on child sexual exploitation services and interventions using $Q$ methodology.

\section{Introduction}

You are invited to take part in a research study by Jennifer Barrow of Staffordshire University as part of the award of a Doctorate in Clinical Psychology.

Before you decide to participate it is important that you understand why the research is being done and what the study will involve. Please read the following information carefully and discuss it with others if you wish, or you may ask the researchers if you would like more information or if anything is not clear. Please take time to decide whether you wish to take part. Thank you for your time.

\section{1) What is the purpose of this study?}

We hope to learn about staff member and service user views about CSE services in general, including interventions and approaches, and what is viewed as being effective.

\section{2) Do I have to take part?}

It is entirely up to you. If you do decide to take part, you will be given this sheet to keep and you will be asked to sign a consent form. You will be given a unique participant code to ensure your anonymity. If you take part and then would like to withdraw your data, please email the primary researcher or research supervisor and provide the unique participant code (see contact details below). This will be possible until two weeks after you take part in the study and you will not be asked to give a reason for your withdrawal. After two weeks, your data will have been inputted and analysed. This will mean that you will be unable to withdraw the data as each participant's data will have been integrated.

\section{3) What will I do in the study?}


We would need to meet with you for about 60 minutes. During this time you would be given a set of cards, each of them has a written statement. The statement will relate to CSE services and interventions. We would ask you to rate the statements in the order of most important to least important and to sort them using a grid. We would then offer you two brief questionnaires, one looking at demographics and one to reflect on your experience of sorting the statements.

\section{4) Why have I been invited to take part?}

We would like to work with staff members and young people within CSE services. We would like to know more about your views on CSE service design.

\section{5) What are the risks in taking part in this study?}

We do not foresee there being any risks to you when taking part in the study, but participation may cause emotional distress and anxiety in some individuals. If you do become uncomfortable or would like to stop the study at any time you would be fully supported by the researcher.

You are also able to access support prior to, during, and after your participation in the study by contacting the Samaritans by telephone on 116123 , by email at jo@samaritans.org or in writing to: Freepost RSRB-KKBY-CYJK, PO Box 9090, STIRLING, FK8 2SA.

\section{6) What happens to the information in the study?}

\section{Data Protection Statement}

The data controller for this project will be Staffordshire University. The University will process your personal data for the purpose of the research outlined above and the information will be stored for 10 years as per Staffordshire University Regulations. The legal basis for processing your personal data for research purposes under the data protection law is a 'task in the public interest'. You can provide your consent for the use of your personal data in this study by completing the consent form that has been provided to you.

Your data will be processed in accordance with data protection law and in compliance with General Data Protection Regulation 2016 (GDPR).

All information that is collected about you during the course of the study will be kept confidential. We will replace your name with an anonymised participant number to ensure that your information cannot be identified. Once your information is linked to your anonymised number your personal information will be destroyed by the primary researcher. The primary researcher will also store the anonymised data on a secure and password protected USB stick. 


\section{Contact for further information:}

Primary Researcher

Jennifer Barrow (Trainee Clinical Psychologist) via email at b024106h@student.staffs.ac.uk

Research supervised by:

Dr Helen Combes - h.a.combes@staffs.ac.uk

Professional Doctorate in Clinical Psychology

Science Centre

Staffordshire University

Leek Road

Stoke-on-Trent

ST4 2DF 


\section{Appendix E - Participant Consent Form (Young People)}

\section{PARTICIPANT CONSENT FORM}

FOR YOUNG PEOPLE

Version 3/February 2019

Project Title: Investigating the perspectives of young people and staff members on child sexual exploitation services and interventions using Q methodology.

\section{Name of researcher: Jennifer Barrow}

\section{Please sign your initials in each box}

1) I confirm that I have read and understand the participant information sheet for the above study. I have had the opportunity to consider the information, ask the research team any questions and I have had my questions answered.

2) I understand that I don't have to take part and that I am free to stop the study at any time without giving a reason.

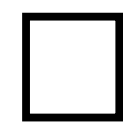

3) I understand that I am free to withdraw my information until two weeks after I take part, without giving a reason.

4) I consent to my answers to the questionnaire being used in the study. This includes directly quoting my responses. No information that identifies me will be taken from these responses.

5) I agree that the information I provide within the study can be used anonymously for the purposes of research and publication (such as in a psychology journal), and that any quotations from this research can be used in the write-up and publication.

6) I agree to take part in the study
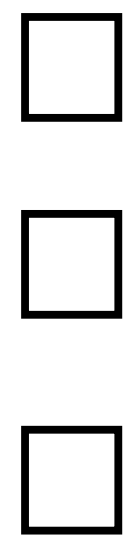

Date: 
Researcher's Name:

Signature:

Date:

Name of guardian/social worker (delete as appropriate):

Having read the information given to:

I consent for them to take part in the above named study

Signature:

Date 
Appendix F - Participant Consent Form (Professionals)

PARTICIPANT CONSENT FORM

FOR PROFESSIONALS

STAFFORDSHIRE

UNIVERSITY

Version 3/February 2019

Project Title: Investigating the perspectives of young people and staff members on child sexual exploitation services and interventions using Q methodology.

\section{Name of researcher: Jennifer Barrow}

\section{Please sign your initials in each box}

1) I confirm that I have read and understand the participant information sheet for the above study. I have had the opportunity to consider the information, ask the research team any questions, and have had my questions answered.

2) I understand that my participation is voluntary and that I am free to stop the study at any time without giving a reason. I

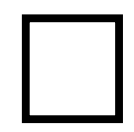
understand that I am free to withdraw my information until two weeks after taking part without giving a reason.

3) I consent to my comments about the Q-sort being used in the study. This includes directly quoting my questionnaire responses. No information that identifies me will be taken from these responses.

4) I agree that the information I provide within the study can be used anonymously for the purposes of research and publication, and that any quotations from this research can be used in the write-up and publication.

5) I agree to take part in the above named study
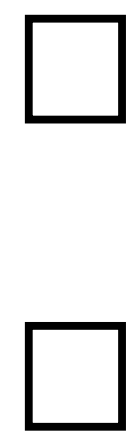


\section{Appendix G - Statements Forming the Q-set}

1 Support that focuses on reducing anger

2 Understanding confidentiality and what will /won't be shared with others

3 Crafting and creative activities

4 Support around physical health including sleep, diet, activity and hygiene

$5 \quad$ Support to catch up with school work

6 Staff sitting with YP and listening to them

$7 \quad$ YP being involved in decisions about their care

$8 \quad$ Staff building trusting relationships with YP

$9 \quad$ YP finding the right staff member to work with

10 Families being involved in YPs' care

11 Support that focuses on YPs' strengths

12 Support over a long period of time

13 Support for families

14 Education about the risks of sexual exploitation

15 A non-judgemental environment

16 Staff spending time with YP in a relaxed way

17 Staff and YP doing fun activities together

18 Support to make disclosures and work with the police on prosecutions

19 Supporting with managing self-harm

20 Groups focused on healthy relationships

21 Support that is flexible to the YP's individual needs

22 Support to continue after YP turns 18 
23 Allowing YP to be as independent as possible

24 Therapy that helps with traumatic experiences

25 Disruption techniques to reduce YP's relationship with potential exploiters

26 Having the option to see a psychologist

27 Staff working with social workers

28 Staff working with the police

29 A safe place to live

30 Being helped by other YP who have been through sexual exploitation

31 Helping YP to move back into their community

32 Support to help with drinking less alcohol

33 Support to stop using drugs

$34 \quad$ YP being involved in writing their care plans

35 Being mentored by adults who have been through sexual exploitation as a child

36 Help with building confidence

37 Staff members staying involved even if YP pushes staff away

38 Support that focuses on sex education

39 One to one sessions with staff on healthy relationships

40 One to one sessions to support with mental health problems

41 Support to not run away as much

42 Support to safely use social media and technology

43 Focusing on YP's feelings rather than their behaviour

44 Allowing YP to talk about their experiences when they feel ready 
45 Staff members that are reliable and consistent

46 Staff members understanding what led to the CSE happening

47 Staff members reacting calmly if YP talks to them about CSE

48 Living somewhere with boundaries

49 Support to have a daily routine

50 Watching videos on staying safe from CSE

51 Life story work to help understand the whole journey from birth (or earlier) to present day, including CSE involvement

52 Staff working with schools

53 Living away from CSE communities

$54 \quad$ Reduced access to social media and internet 
Appendix H - Participant Demographic Questionnaire

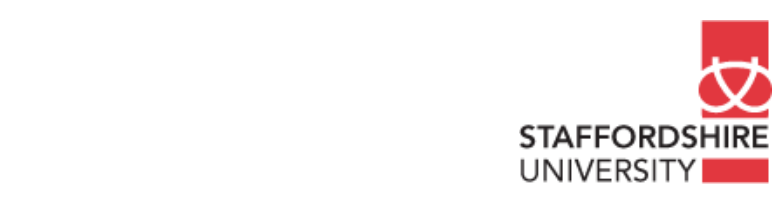

\section{DEMOGRAPHIC QUESTIONNAIRE}

Version 3/February 2019

Project Title: Investigating the perspectives of young people and staff members on child sexual exploitation services and interventions using Q methodology.

Name of researcher: Jennifer Barrow

Participant identifier code:

Please answer the following questions:

Age:

To which gender do you most identify?

For staff members, what is your job role in the service? 
Appendix I - Post-sort Supplementary Questionnaire

\section{SUPPLEMENTARY QUESTIONNAIRE}

Version 3/February 2019

Project Title: Investigating the perspectives of young people and staff members on child sexual exploitation services and interventions using Q methodology.

Name of researcher: Jennifer Barrow

Participant identifier code:

Thank you for completing the Q-sort. Please answer the following questions:

What other factors do you think might be important for services to consider?

How did you find taking part in the research?

Any dither comments or suggestions?

p

p

e

$\mathbf{n}$

d

i

A 


\section{Appendix J - Factor Arrays}

\begin{tabular}{|c|c|c|c|}
\hline \multirow[b]{2}{*}{ Statement } & \multicolumn{3}{|l|}{ Factor Arrays } \\
\hline & Factor 1 & Factor 2 & Factor 3 \\
\hline 1 & -4 & -2 & 2 \\
\hline 2 & 2 & -2 & 1 \\
\hline 3 & -3 & -3 & -3 \\
\hline 4 & -1 & 2 & -1 \\
\hline 5 & -4 & -5 & -4 \\
\hline 6 & 2 & 0 & 3 \\
\hline 7 & 2 & 1 & 2 \\
\hline 8 & 3 & 5 & 5 \\
\hline 9 & 2 & -1 & 3 \\
\hline 10 & -2 & -1 & 4 \\
\hline 11 & 1 & -1 & 0 \\
\hline 12 & 2 & 3 & -1 \\
\hline 13 & 0 & -1 & 2 \\
\hline 14 & -3 & 3 & 2 \\
\hline 15 & 4 & 1 & 1 \\
\hline 16 & 1 & -3 & 3 \\
\hline 17 & 0 & 0 & 3 \\
\hline 18 & 0 & 0 & 0 \\
\hline 19 & 0 & 4 & 1 \\
\hline 20 & -2 & 0 & 1 \\
\hline 21 & 5 & 2 & -2 \\
\hline 22 & 1 & 1 & 1 \\
\hline 23 & -1 & -3 & -2 \\
\hline 24 & 0 & 5 & 2 \\
\hline 25 & 1 & 1 & -1 \\
\hline 26 & 2 & 0 & 0 \\
\hline 27 & 1 & 2 & -1 \\
\hline 28 & -1 & -4 & -2 \\
\hline 29 & 5 & 3 & 5 \\
\hline 30 & -1 & -2 & -5 \\
\hline 31 & -2 & 0 & -5 \\
\hline 32 & -3 & 1 & -3 \\
\hline 33 & -2 & 4 & -1 \\
\hline
\end{tabular}


WHAT IS VALUED FROM CHILD SEXUAL EXPLOITATION SERVICES? 121

\begin{tabular}{|c|c|c|c|}
\hline 34 & 3 & -3 & -2 \\
\hline 35 & -2 & 0 & -3 \\
\hline 36 & 0 & 1 & 0 \\
\hline 37 & 3 & -1 & 3 \\
\hline 38 & -3 & -4 & -2 \\
\hline 39 & -1 & -3 & 1 \\
\hline 40 & 0 & 4 & 1 \\
\hline 41 & -2 & 1 & -1 \\
\hline 42 & -1 & -5 & 0 \\
\hline 43 & 3 & -4 & 4 \\
\hline 44 & 4 & 2 & 0 \\
\hline 45 & 4 & 2 & 4 \\
\hline 46 & 1 & 2 & -1 \\
\hline 47 & 3 & 3 & 0 \\
\hline 48 & -1 & -1 & 0 \\
\hline 49 & 0 & 0 & 2 \\
\hline 50 & -5 & -1 & -2 \\
\hline 51 & -4 & 3 & -3 \\
\hline 52 & 1 & -2 & -3 \\
\hline 53 & -3 & -2 & -4 \\
\hline 54 & -5 & -2 & -4 \\
\hline
\end{tabular}




\section{Appendix K - Z-score Table}

\begin{tabular}{|c|c|c|c|c|}
\hline \multirow{2}{*}{$\begin{array}{l}\text { Statement } \\
\text { Number }\end{array}$} & \multirow{2}{*}{ Statement } & \multirow{2}{*}{$\begin{array}{l}\text { factor } \\
1 \\
\text { Z-score }\end{array}$} & \multirow{2}{*}{$\begin{array}{l}\text { factor } \\
2 \\
\text { Z-score }\end{array}$} & \multirow{2}{*}{$\begin{array}{l}\text { factor } \\
3 \\
\text { Z-score }\end{array}$} \\
\hline & & & & \\
\hline 1 & Support that focuses on reducing anger & -1.61 & -0.73 & 0.69 \\
\hline 2 & Understanding confidentiality and what will /won't be shared with others & 0.78 & -0.74 & 0.32 \\
\hline 3 & Crafting and creative activities & -1.12 & -0.93 & -0.91 \\
\hline 4 & Support around physical health including sleep, diet, activity and hygiene & -0.49 & 0.63 & -0.45 \\
\hline 5 & Support to catch up with school work & -1.15 & -1.68 & -1.55 \\
\hline 6 & Staff sitting with YP and listening to them & 0.84 & -0.23 & 1.33 \\
\hline 7 & YP being involved in decisions about their care & 0.98 & 0.34 & 0.42 \\
\hline 8 & Staff building trusting relationships with YP & 1.62 & 2.19 & 2.17 \\
\hline 9 & YP finding the right staff member to work with & 0.76 & -0.54 & 1.09 \\
\hline 10 & Families being involved in YPs' care & -0.72 & -0.55 & 1.65 \\
\hline 11 & Support that focuses on YPs' strengths & 0.3 & -0.55 & -0.25 \\
\hline 12 & Support over a long period of time & 0.92 & 0.99 & -0.42 \\
\hline 13 & Support for families & -0.24 & -0.58 & 0.74 \\
\hline 14 & Education about the risks of sexual exploitation & -1.13 & 1.18 & 0.77 \\
\hline 15 & A non-judgemental environment & 1.8 & 0.33 & 0.37 \\
\hline 16 & Staff spending time with YP in a relaxed way & 0.1 & -1.19 & 1.48 \\
\hline 17 & Staff and YP doing fun activities together & -0.1 & -0.33 & 1.45 \\
\hline 18 & Support to make disclosures and work with the police on prosecutions & -0.22 & -0.1 & 0.12 \\
\hline 19 & Supporting with managing self-harm & -0.06 & 1.61 & 0.42 \\
\hline 20 & Groups focused on healthy relationships & -0.8 & -0.33 & 0.32 \\
\hline 21 & Support that is flexible to the YP's individual needs & 1.92 & 0.74 & -0.67 \\
\hline 22 & Support to continue after YP turns 18 & 0.36 & 0.56 & 0.42 \\
\hline 23 & Allowing YP to be as independent as possible & -0.36 & -1.16 & -0.59 \\
\hline
\end{tabular}




\begin{tabular}{|c|c|c|c|c|}
\hline 24 & Therapy that helps with traumatic experiences & 0.05 & 2.37 & 0.69 \\
\hline 25 & Disruption techniques to reduce YP's relationship with potential exploiters & 0.27 & 0.4 & -0.42 \\
\hline 26 & Having the option to see a psychologist & 0.54 & -0.3 & 0.07 \\
\hline 27 & Staff working with social workers & 0.1 & 0.64 & -0.25 \\
\hline 28 & Staff working with the police & -0.54 & -1.33 & -0.84 \\
\hline 29 & A safe place to live & 1.97 & 1.35 & 1.75 \\
\hline 30 & Being helped by other YP who have been through sexual exploitation & -0.42 & -0.78 & -2.02 \\
\hline 31 & Helping YP to move back into their community & -0.88 & -0.2 & -1.82 \\
\hline 32 & Support to help with drinking less alcohol & -0.93 & 0.59 & -0.98 \\
\hline 33 & Support to stop using drugs & -0.72 & 1.8 & -0.4 \\
\hline 34 & YP being involved in writing their care plans & 1.11 & -0.94 & -0.71 \\
\hline 35 & Being mentored by adults who have been through sexual exploitation as a child & -0.93 & -0.16 & -1.01 \\
\hline 36 & Help with building confidence & -0.19 & 0.39 & 0 \\
\hline 37 & Staff members staying involved even if YP pushes staff away & 1.06 & -0.47 & 0.86 \\
\hline 38 & Support that focuses on sex education & -1.11 & -1.34 & -0.79 \\
\hline 39 & One to one sessions with staff on healthy relationships & -0.29 & -1.07 & 0.29 \\
\hline 40 & One to one sessions to support with mental health problems & -0.26 & 1.85 & 0.39 \\
\hline 41 & Support to not run away as much & -0.91 & 0.34 & -0.29 \\
\hline 42 & Support to safely use social media and technology & -0.36 & -1.63 & -0.24 \\
\hline 43 & Focusing on YP's feelings rather than their behaviour & 1.25 & -1.63 & 1.57 \\
\hline 44 & Allowing YP to talk about their experiences when they feel ready & 1.68 & 0.69 & -0.12 \\
\hline 45 & Staff members that are reliable and consistent & 1.84 & 0.69 & 1.62 \\
\hline 46 & Staff members understanding what led to the CSE happening & 0.34 & 0.68 & -0.59 \\
\hline 47 & Staff members reacting calmly if YP talks to them about CSE & 1.16 & 0.91 & 0.15 \\
\hline 48 & Living somewhere with boundaries & -0.5 & -0.34 & -0.08 \\
\hline 49 & Support to have a daily routine & 0.02 & 0.24 & 0.67 \\
\hline 50 & Watching videos on staying safe from CSE & -1.8 & -0.52 & -0.64 \\
\hline 51 & Life story work to help understand the whole journey from birth to present day & -1.16 & 1.09 & -0.88 \\
\hline
\end{tabular}


52 Staff working with schools

0.16

$-0.77$

53 Living away from CSE communities

$-0.94$

$-0.69$

$-1.5$

54 Reduced access to social media and internet

$-1.98$

$-0.77$

$-1.8$ 


\section{Appendix L - Idealised Q-Sort Factor 1}

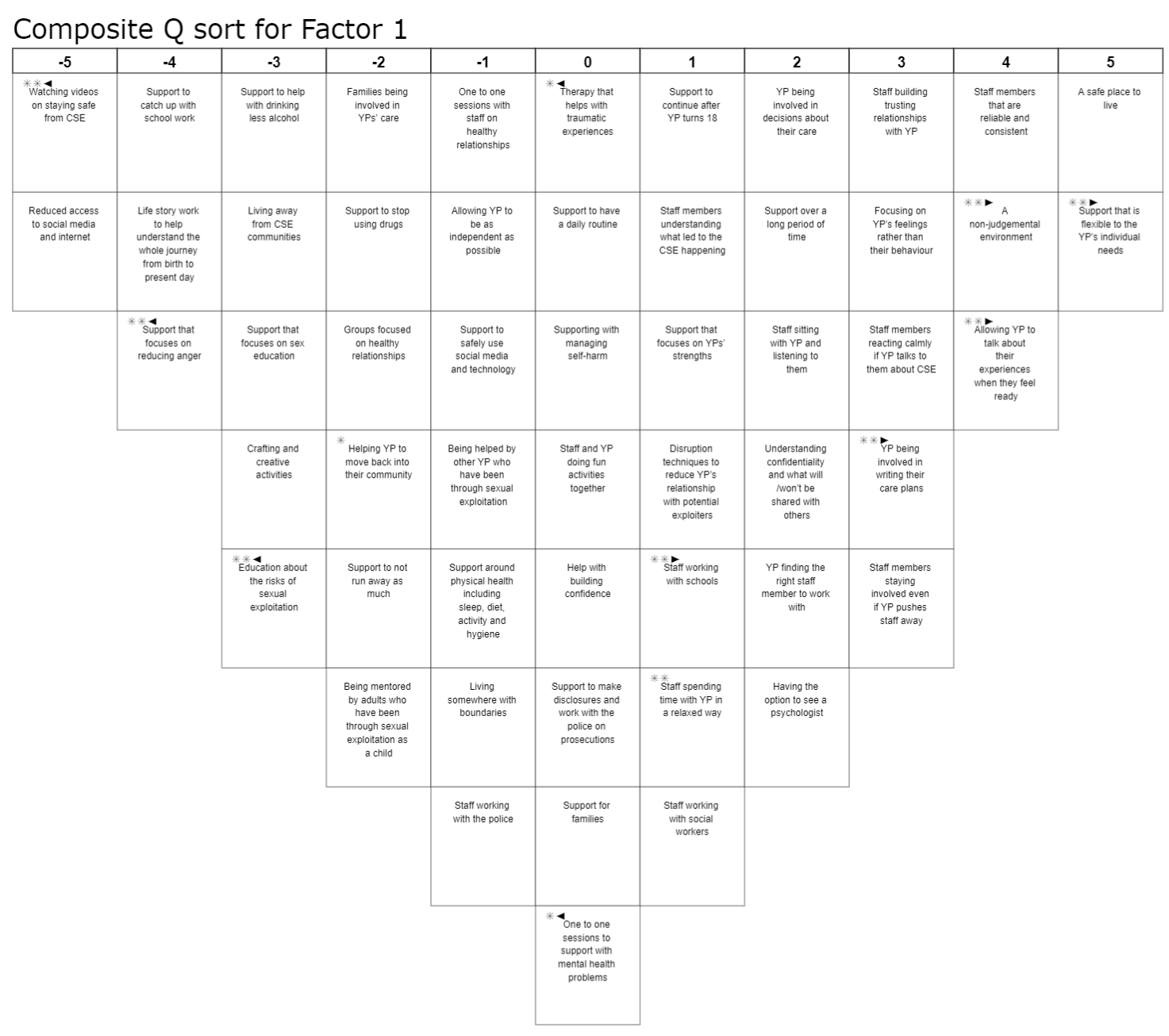

* Distrint at $P<0.05$

- $z$-Score for the statement is higher than in all other factors

- $z$-Score for the statement is lower than in all other factors 


\section{Appendix M - Idealised Q-Sort Factor 2}

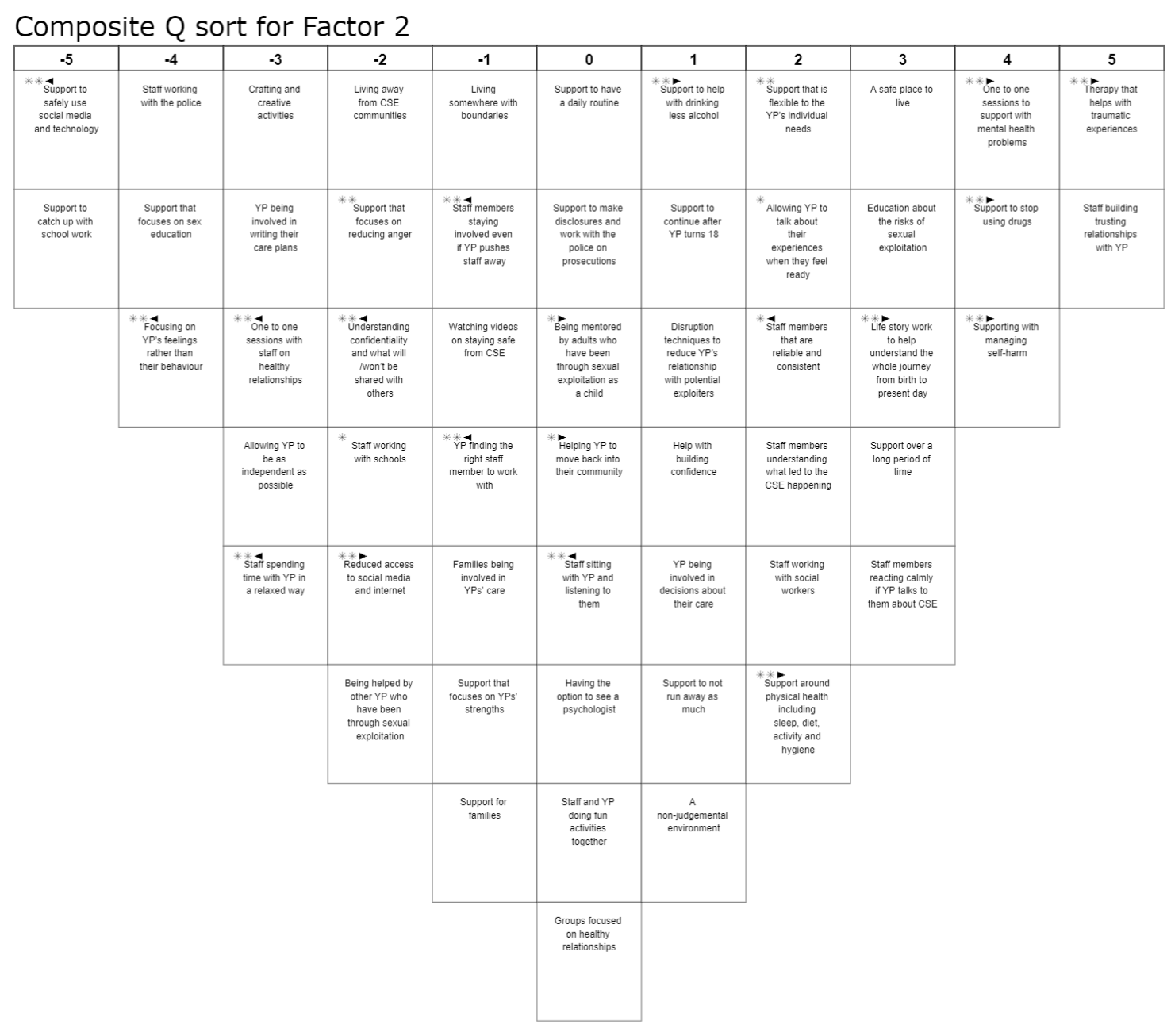

* * Distinguishing statement at $P<0.01$

- $z$-Score for the statement is higher than in all other factors

$z$-Score for the statement is lower than in all other factors 


\section{Appendix N - Idealised Q-Sort Factor 3}

Composite Q sort for Factor 3

\begin{tabular}{|c|c|c|c|c|c|c|c|c|c|c|}
\hline-5 & -4 & -3 & -2 & -1 & 0 & 1 & 2 & 3 & 4 & 5 \\
\hline 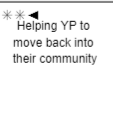 & 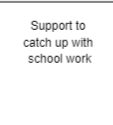 & $\begin{array}{l}\text { Life story work } \\
\text { to flp } \\
\text { understand he } \\
\text { whole journey } \\
\text { from mitht to } \\
\text { present day }\end{array}$ & $\begin{array}{c}\text { Allowing YP to } \\
\text { ob as } \\
\text { independent as } \\
\text { possiblete }\end{array}$ & 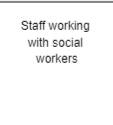 & 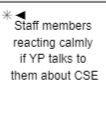 & 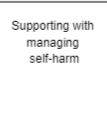 & 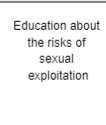 & 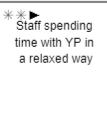 & 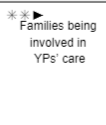 & $\begin{array}{c}\text { Statif bulling } \\
\text { trusting } \\
\text { relatanonships } \\
\text { vith } Y P\end{array}$ \\
\hline \multirow[t]{7}{*}{ 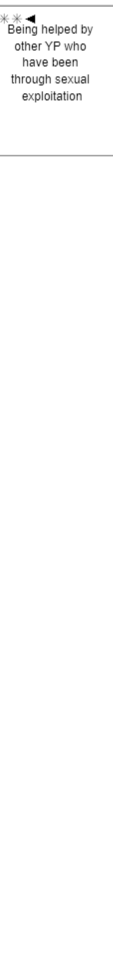 } & 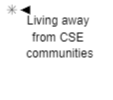 & $\begin{array}{l}\text { Crating and } \\
\text { crative } \\
\text { activities }\end{array}$ & $\begin{array}{l}\text { Watching videos } \\
\text { on stiayn saie } \\
\text { trom SSE }\end{array}$ & $\begin{array}{l}\text { Supportt to not } \\
\text { run away as } \\
\text { much }\end{array}$ & 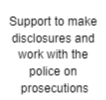 & 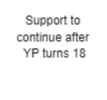 & $\begin{array}{c}\text { * *Supopot ior } \\
\text { familes }\end{array}$ & 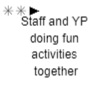 & 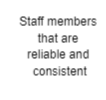 & $\begin{array}{c}\text { A saide place to } \\
\text { ive }\end{array}$ \\
\hline & 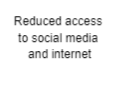 & 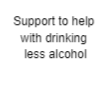 & 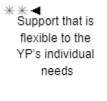 & $\begin{array}{c}\text { Support to stop } \\
\text { using drugas }\end{array}$ & 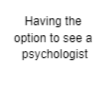 & 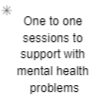 & 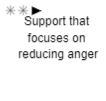 & 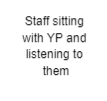 & 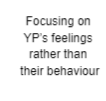 & \\
\hline & & 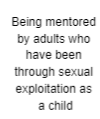 & 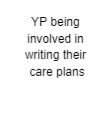 & 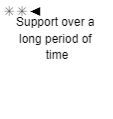 & 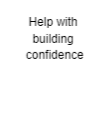 & $\begin{array}{c}\text { non-jidgemental } \\
\text { envivionment }\end{array}$ & 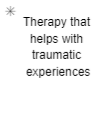 & 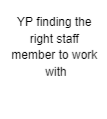 & & \\
\hline & & 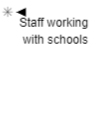 & 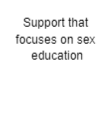 & 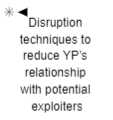 & 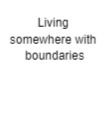 & 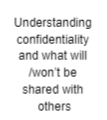 & $\begin{array}{c}\text { Support to have } \\
\text { udaliy voutine }\end{array}$ & 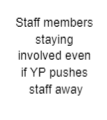 & & \\
\hline & & & $\begin{array}{l}\text { Stataf werking } \\
\text { with he police }\end{array}$ & 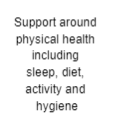 & $\begin{array}{l}\text { * Allowing Y Y to } \\
\text { talk about } \\
\text { expeir } \\
\text { expenences } \\
\text { when they feel } \\
\text { ready }\end{array}$ & $\begin{array}{l}\text { Groups focused } \\
\text { oul hearthy } \\
\text { reationships }\end{array}$ & $\begin{array}{l}\text { YP being } \\
\text { involved in } \\
\text { decisions about } \\
\text { their care }\end{array}$ & & & \\
\hline & & & & 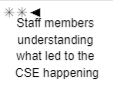 & $\begin{array}{c}\text { support to } \\
\text { salelys } \\
\text { socil medil } \\
\text { and technolology }\end{array}$ & $\begin{array}{l}\text { One to one } \\
\text { sessions with } \\
\text { stafif on } \\
\text { healthy } \\
\text { relatitionshipg }\end{array}$ & & & & \\
\hline & & & & & 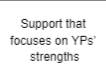 & & & & & \\
\hline
\end{tabular}

* Distinguishing statement at $P<0.05$

* D Distinguishing statement at $\mathrm{P}<0.01$

- $z$-Score for the statement is higher than in all other factors

- $z$-Score for the statement is lower than in all other factors 
Chapter Three: Executive Summary

'What do young people and staff members value from child sexual exploitation services?'

Jennifer Barrow

Professional Doctorate in Clinical Psychology

School of Life Sciences and Education, Staffordshire University

Word Count: 1231 
WHAT IS VALUED FROM CHILD SEXUAL EXPLOITATION SERVICES? 129

\section{What do young people and staff members value from child sexual exploitation services?}

"Everyone has a voice and it deserves to be heard no matter who you are, where you're from or whatever you've been through"

\section{Executive Summary}

\section{Jennifer Barrow}

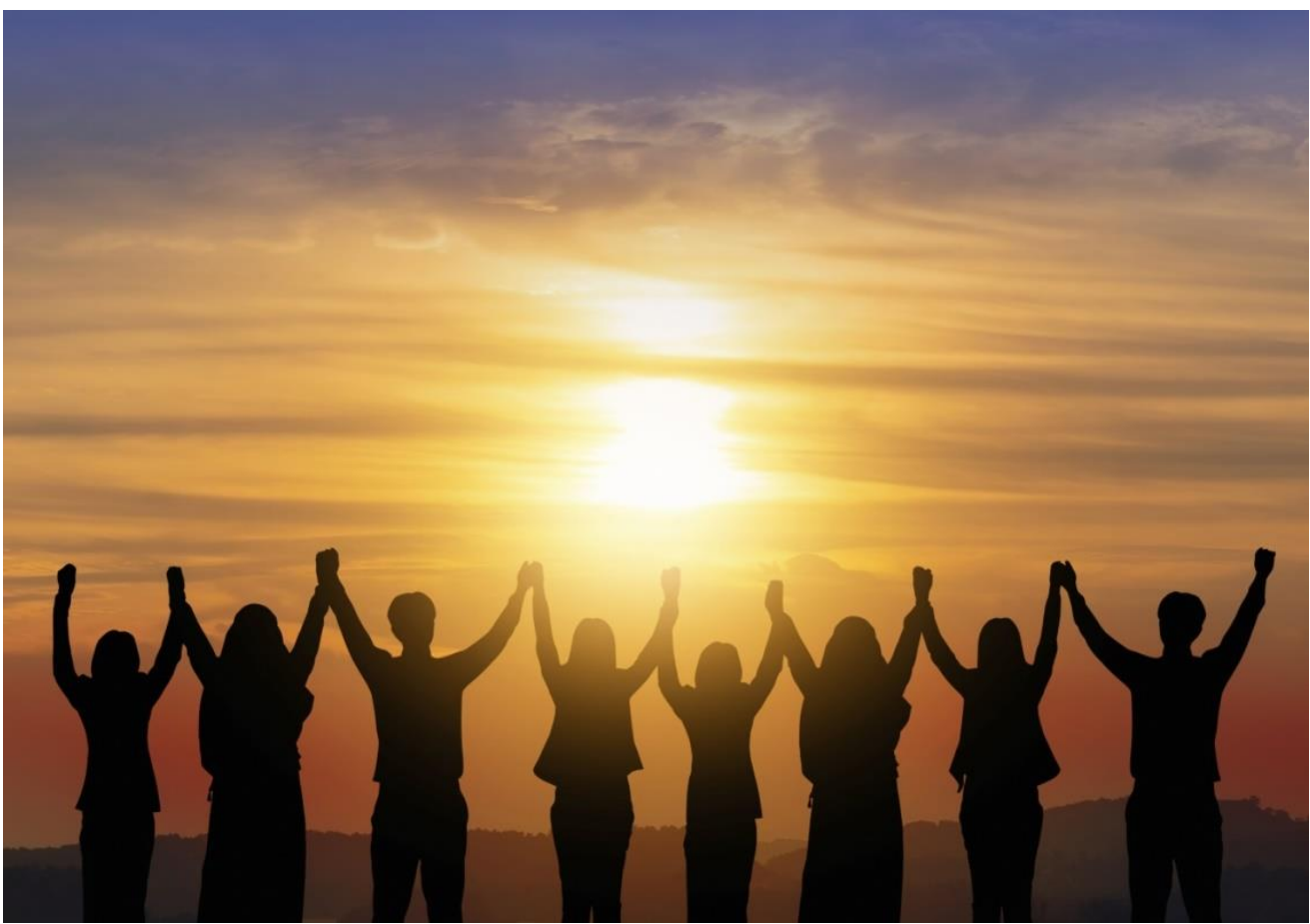

This executive summary has been prepared in a format that is accessible to the target audience; young people aged 13 and above and professionals they work with.

It has been developed collaboratively with a young person who is an expert by experience. 


\section{Who am I?}

My name is Jenni and I am training to be a Clinical Psychologist.

Before I started this training, I was working in a residential home with young people who had experienced exploitation and I became interested in learning more about this.

As part of my training I have completed a research project on Child Sexual Exploitation (CSE).

This document has been written to summarise what I did in the research and what I found out.

What is CSE?

CSE is when a young person is encouraged, forced or tricked into doing something sexual - this can be online or in person.

Sometimes the young person might get something in return, such as affection, money, presents, drugs, alcohol or somewhere to live.

Young people in this situation may feel guilty, scared or anxious about what has happened. This can be very distressing and may affect their mental health.

\section{Why was this research done?}

I am interested in services for young people who have experienced CSE, especially the different types of support that they offer to young people.

I wanted to know what young people's opinions were on CSE support from their own personal experience.

I wanted to know what parts of CSE services were most important to them.

I wondered whether staff members in CSE services had similar opinions to the young people or different ideas. 


\section{What was done?}

I searched the scientific evidence to find out all the things that services offer to young people who have experienced CSE.

I also looked at lots of books and articles, and I spoke to other psychologists and an adult who had experienced CSE when they were younger.

54 items were found that were all different features of support, for example:
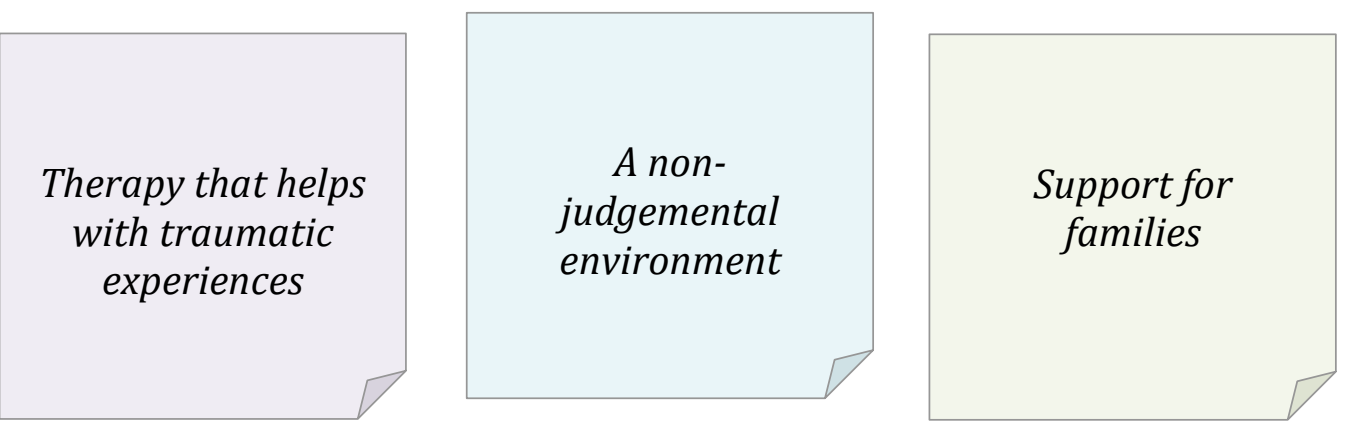

I wanted to know what features of support would be grouped together as most important and least important, and if young people and staff members have particular viewpoints about them.

Staffordshire University gave their approval for me to use QMethodology to find this out.

\section{Young people and staff members in CSE services were} asked if they wanted to take part in the research. Young people who were distressed were not asked to take part as they may have found it difficult and upsetting to talk about CSE support. 


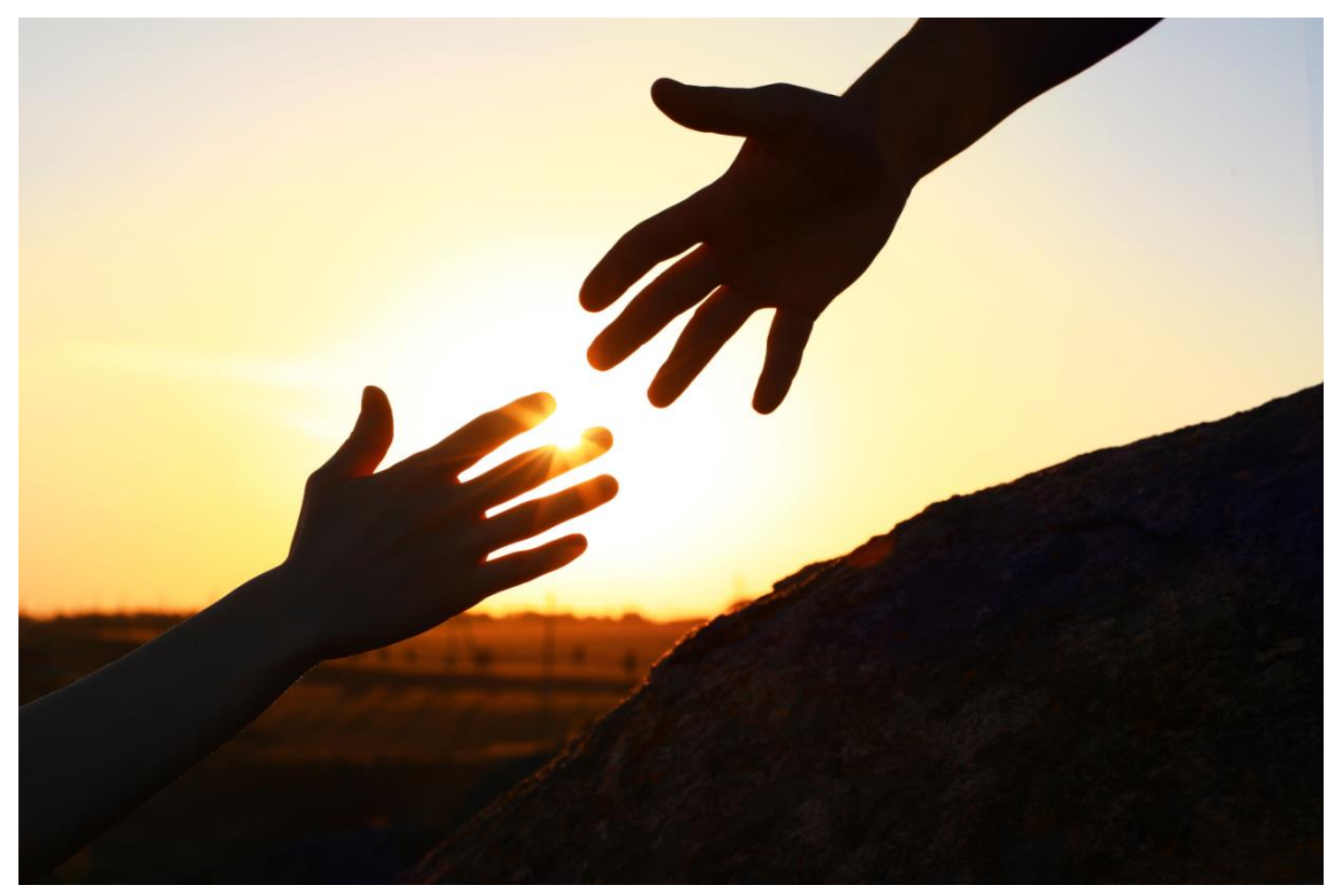

\section{What did people do for the research?}

The 54 items were printed onto plastic square cards.

Q-Methodology involves placing the 54 cards onto a grid, in order from least to most important.

18 people did the research project, 9 young people (aged 15 18) and 9 staff members.

Each person was asked some questions to tell me a bit more about them.

Each person then put the cards into three piles: most important, least important and neutral/not sure.

They put the cards onto a pyramid-shaped grid, and this showed each person's viewpoint.

People were then asked to talk through how they had sorted the cards and the reasons why they thought some cards were most and least important. 


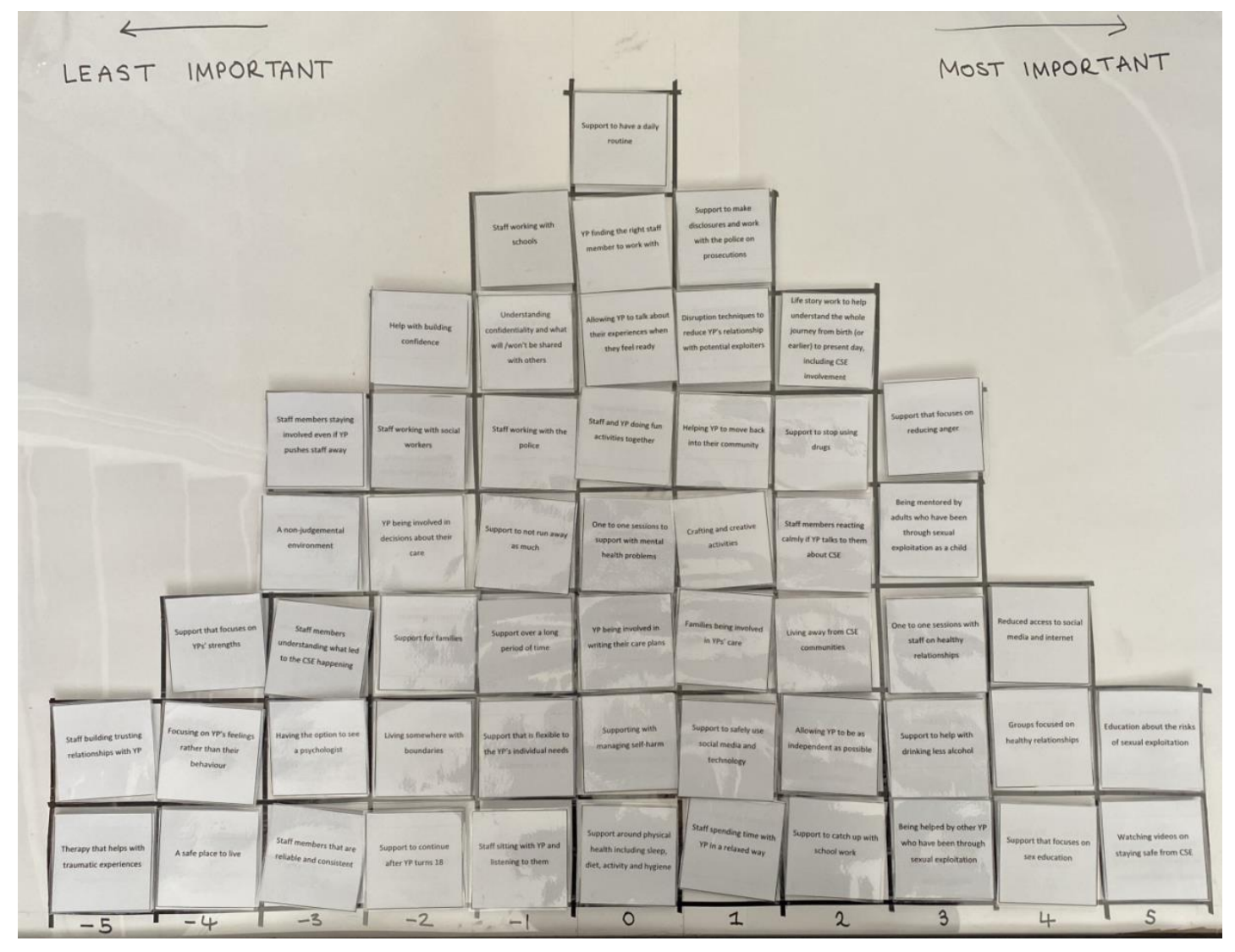

This is a made up example of what each person's grid looked like.

Each person's pyramid of cards showed their view on which features of support for CSE are important to them.

I used a computer program to see if there were any patterns and whether people had similar or different viewpoints.

\section{What was found?}

I found that there were three main viewpoints that people held - in Q-methodology these viewpoints are called factors.

All three factors agreed that trusting relationships and feeling safe are very important.

Two people (staff members) didn't share viewpoints with any of the three factors. 


\section{Factor 1: The importance of safety and attunement}

This factor focuses on relationships between young people and staff members in CSE services. Half of the participants (6 staff members and 3 young people) agreed most with this factor. These people thought that having a safe place to live is most important, and that comfort and safety is more important than practical or educational support. Attunement means understanding someone's individual needs. In this factor people thought it was very important for support to be flexible to each young person's needs.

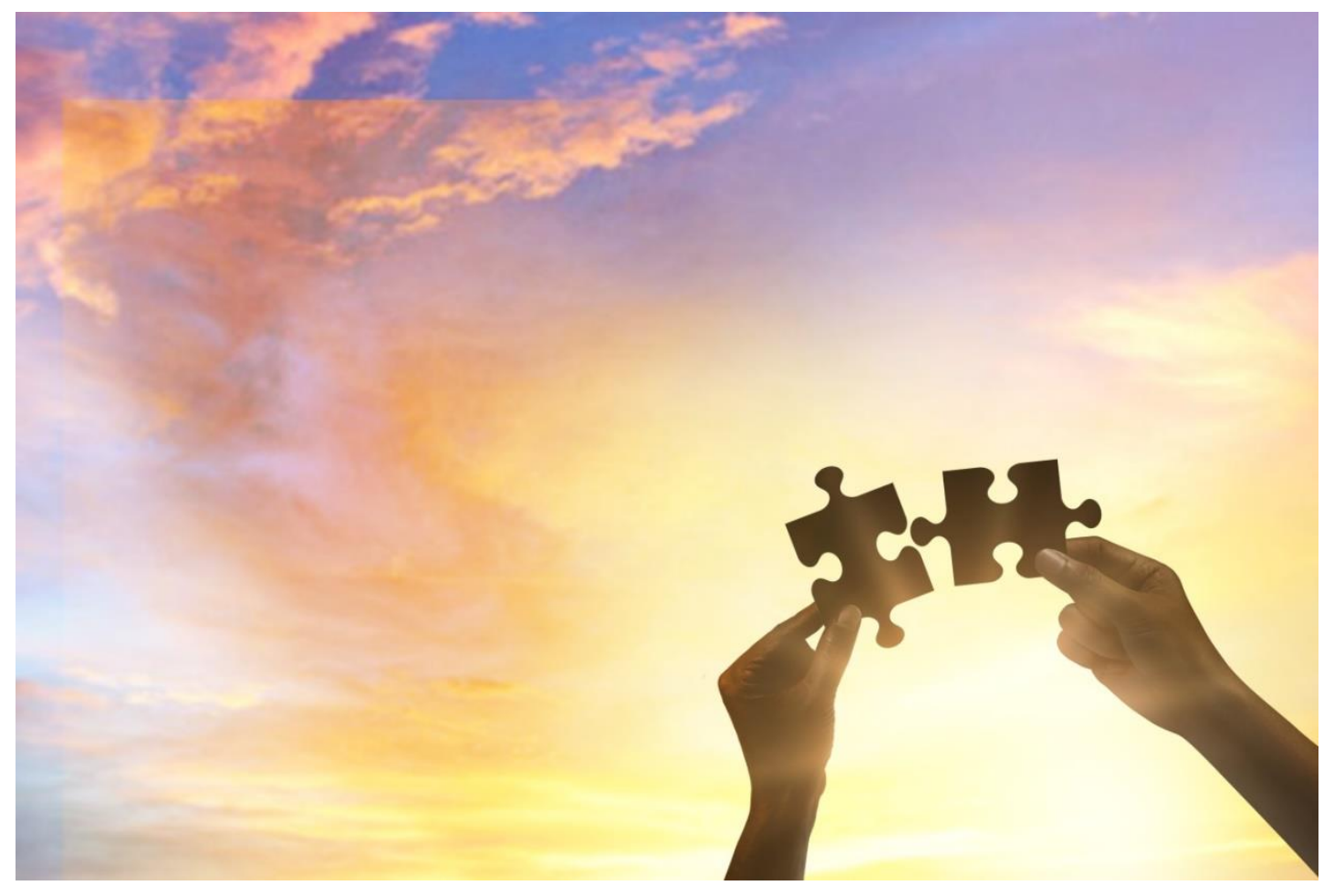

\section{Factor 2: Trust, trauma and mental health}

This factor focuses on the importance of building trust to help young people deal with traumatic experiences. 4 participants ( 3 young people and 1 staff member) agreed most with this factor. These people thought that consistent support that focuses on mental health problems, support with self-harm and support to reduce drug and alcohol use was most important. Viewpoints in this factor focused on supporting a young person to access therapy and life story work. 
Factor 3: Family, normality and a relaxed approach This factor focuses on the importance of informal support from staff members, such as simply listening to young people and doing fun activities with them. 3 participants (all young people) agreed most with this factor. These people also thought that families should be involved in young peoples' care, and that support should also be available for families. This viewpoint also valued support for using social media safely in order to help young people manage this when they leave services.

\section{What does this mean?}

The results tell us that there are some things that people agreed are important for CSE services, like staff members working hard to build trusting relationships with young people so that young people feel safe. Some young people agreed, but other young people had different ideas about what was most important.

Some young people thought it was most important that they have support to focus on their mental health, and other young people thought it was most important that there was support for families.

This information might be important to consider for people who plan and manage CSE services, so that they can think about what features of the service might be most important to the young people they work with. 


\section{What next?}

This research was part of my doctorate in clinical psychology.

There is a full report of the research and this may be published in a scientific journal.

If you would like further information on the research, please email my supervisor Dr Helen Combes at Staffordshire University: h.a.combes@staffs.ac.uk

If you would like further information on CSE you can find it here at:

http://faceup2it.org/ and

http://www.barnardosrealloverocks.org.uk/what-is-cseyoung-person/

You can also talk to someone if you need support by contacting ChildLine by telephone on 08001111 or on their website at: https://www.childline.org.uk

A big thank you to all of the young people and staff members who took part in my research, and thank you to the young person who helped with the development of this executive summary. 